\title{
Making Modern Self Through White Marriage: Living Together Without Marriage in Tehran, Iran
}

by

Mehrnaz Golestaneh

A thesis submitted to the Faculty of Graduate and Postdoctoral Affairs in partial fulfillment of the requirements for the degree of

Doctor of Philosophy

in

Sociology

Carleton University

Ottawa, Ontario

(C) 2018, Mehrnaz Golestaneh 


\section{Abstract}

This dissertation uses the phenomenon of "white marriage" among young heterosexual middle class Iranian women and men, who choose to live together without religious and legal documentation, as the focus to provide a window into the transformation of intimacy in contemporary Iran within a globalized world. In addition to explaining theoretical approach and methodology, throughout the first couple of chapters, I contextualize white marriage as in deeper socio-historical layers in relation to freedom of choice. Based on interviews with individuals in white marriages as well as analyses of textual data, this dissertation examines how Iranian middle class women and men in white marriages understand this mode of intimate relationship within the context of Iran's marriage norms and the global dominance of western culture. By investigating the categorization of white marriage, and conceptualizations of commitment, fertility and relationships with extended family, this dissertation offers an account of the different motivations and desires bound up in the making of the modern self through white marriage. I argue that white marriage signifies that sexuality, gender and class are emerging as fault lines in contemporary Iranian society, with notions of intimacy, love, body and self-being constructed by Iranian middle class women and men in reaction to western culture and to marital norms in Iran. Iranians in white marriages formulate their desires and construct their subculture in relation to global cultural forces on the one hand and articulate their understanding of cultural marital norms in Iran on the other. However, media discussions about white marriage, reflected in textual data, demonstrated different understandings of the phenomenon. I have identified three phases in media discussions related to white marriage: the first is silence and denial; the second is a prohibitive 
approach with religious and moralistic approach and the third is a management approach concerned with health and population. Thus, a diverse set of organized interests come into play to settle the phenomenon of white marriage in a variety of ways. 


\section{Acknowledgment}

This dissertation materialized because of the continuous guidance, support, and encouragement of a lot of people. The small space of this page is not enough to elaborate on their contributions, but I want to express my gratitude to each one of them who played a role in my academic accomplishments. First, I would like to thank my supervisor, Dr Xiaobei Chen. It has been an honor to be her Ph.D. student. She has taught me, both consciously and unconsciously, how a good research project is done. I appreciate all her contributions of time and ideas to make my Ph.D. experience productive. The joy, enthusiasm, and responsibility she has for the research was contagious and motivational for me, even during tough times in the Ph.D. pursuit. I am also thankful for the excellent example she has provided as a successful woman sociologist and professor.

Next, I want to thank the members of my committee, Dr. Alan Hunt and Dr. Amrita Hari, for providing their valuable comments and guidance to improve my dissertation. I also want to mention the role of administrative staff at the department of Sociology and Anthropology, especially, Paula Whissell, Darlene Moss, and Kimberley Seguin. They made the department environment warm and welcoming for me in last six years. I appreciate all their efforts.

My special appreciation goes to the members of my family. I would like to thank my mother, Mrs. Mahin Banou Rejali, and my late father, Mr. Taghi Golestaneh, whose love and guidance and prayer are with me in whatever I pursue. My mother, you are the ultimate role model and source of unending inspiration since early years of my life with your rich home library and your daily reading routines in the area of social science. I want to express my deepest appreciation for your loving support. Moreover, I would like 
to express appreciation to my beloved husband, Dr. Masoud Ebrahimi, who was always my support in the moments when there was no one to answer my queries. You read all single words of the dissertation and gave me courage to finish it. Thank you! I also appreciate my daughter, Mauna for being such a good girl and the source of joy. Thank you Azizam! They are the two noble ones stood by me with patience, tolerance and love. My words of thanks can not compensate their contribution, yet with all my love, I thank them for their splendid support. Thanks, are also due to my sisters (Golnaz, Farinaz and Nazanin) for listening to my ideas, helping me for translations and providing constructive criticisms. Finally, I would also like to extend my thanks to my dearest friend Narges Valibeigi, you were always there with a word of encouragement or listening ear or good ideas. I proudly dedicate the dissertation to my family. 


\section{Contents}

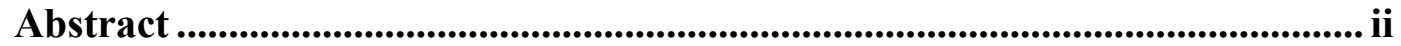

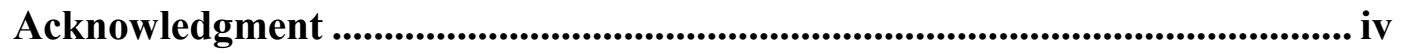

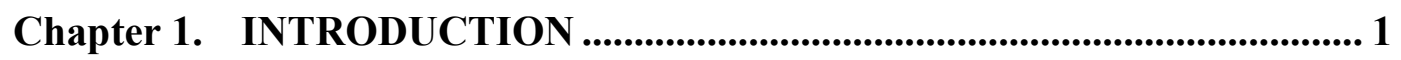

1.1. Heterogeneous White Marriage: Form of Being Single and Being

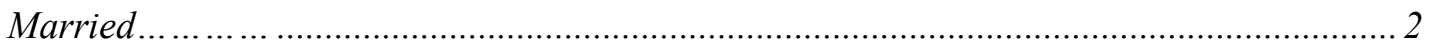

1.2. White Marriage in Contrast to Sex Work and Temporary Marriage ........... 6

1.3. Existing Scholarship on White Marriage …….......................................... 8

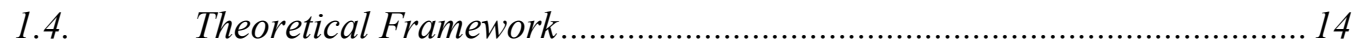

1.5. White Marriage and the Institution of Sexual Governance ........................220

Chapter 2. METHODOLOGY ............................................................................ 28

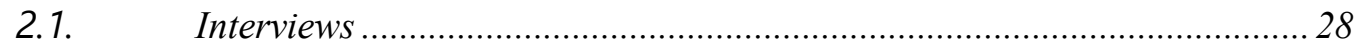



\section{Chapter 3. IRANIAN MARRIAGE AND THE FREEDOM TO CHOOSE43}

3.1. The Institution of Marriage in the Middle Class before the Revolution..... 44

3.2. The Institution of Marriage in the Middle Class during and after the

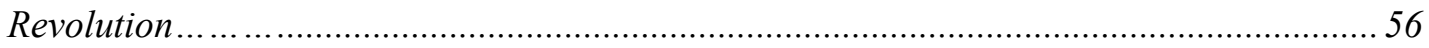

3.3. The Evolution of Marriage at a Time of War (1980-1988) ....................... 63

3.4. Rebuilding Society after the War and Subsequent Policies....................... 65

3.5. Information Technology, Partner Selection and Romantic Relationships . 68

Chapter 4. WHAT IS WHITE MARRIAGE? ................................................. 77

4.1. White Marriage and Demographics ................................................. 77 
4.2. Different Forms of White Marriage

4.3. White Marriage and the Extended Family ........................................... 106

Chapter 5. WHITE MARRIAGE AND CHILDBEARING ..................... 120

5.1. Population Control Strategies in Post-Revolutionary Iran ..................... 123

5.2. Attitudes Regarding Childbearing in White Marriage ............................. 126

5.3. Gender Difference in Attitudes Regarding Childbearing........................ 137

5.4. The Unequal Social and Physical Burden on Women in Untended

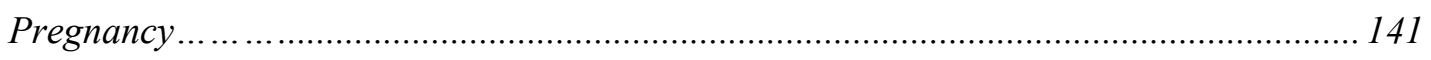

5.5. Media, White Marriage and the Issue of Childbearing.......................... 143

Chapter 6. COMMITMENT IN WHITE MARRIAGE .............................. 153

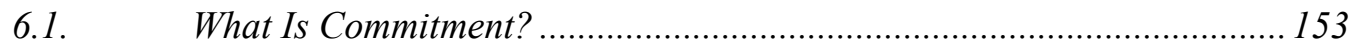

6.2. Contradicting Official Media Portrayal of Commitment in White

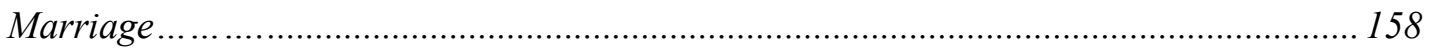

6.3. Commitment in White Marriage ............................................................. 160

6.4. Multiple Forms of Commitment ...................................................... 168

6.5. White Marriage and Commitment During Life Crises .......................... 174

6.6. Marital Commitment, Moralities and Cultural Power........................... 177

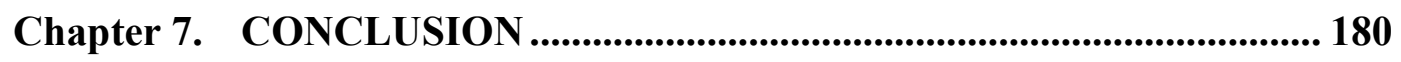

Bibliography .................................................................................... 191 


\section{Chapter 1. INTRODUCTION}

The purpose of my dissertation is to illuminate the little-known social phenomenon of "white marriage", or Ezdevaj Sefid (Ezdevaj literally means marriage; Sefid literary means white or blank), or Hambashi, (cohabitation), or Hamkhanegi (having a housemate), in Farsi in Iran. In the rest of the dissertation, I use the term white marriage and Hambashi alternately to discuss the broader context of the transformation of intimacy in post- revolutionary Iran (1978- 2016) and to suggest a framework for explaining desires that motivate the choice of white marriage among Tehrani middle class women and men. In particular, I examine how Iranian middle class women and men in white marriage understand this mode of intimate relationship in the context of Iran's marriage governance and the global dominance of western culture. I bring together Foucauldian and post-colonial approaches to sexuality to help explain the complexity of white marriage as a new mode of intimate life relationships in Iran. In specific, I use notions of hybridity (Gandhi, 1998) and third space (Bhabha \& Rutherford, 2006) in post-colonial theory as well as notions of governance (Hunt\&Wickham,1994), resistance (McNay,2009), power (McNay, 2009), and biopolitics (Foucault,1991) in Foucauldian theory. It is critical to examine white marriage as a counter-discourse to Iran's historic and contemporary marital norms, and as a practice that is shaped by Iranian young women and men's notions of the modern subject self, body, sexuality, and love.

White marriage has been chosen as the focus of this study for two reasons. First, white marriage is a new, de-institutionalised form of sexual relationship that rejects the legal, religious, and cultural authority over personal relationships in Iran. This rejection makes Hambashi a different category of relationship from documented marriage. As a 
new social practice, it is confronted with limited social acceptance and has caused much social controversy (Afary, 2009, Azad, et al. 2012). Second, since young women and men in this modality of intimate lifestyle are the first generation to practice white marriage, only a few studies have investigated the cultural meaning of white marriage (Azad, et al. 2012, Ghoddosi \& Bayat, 2014, Jalaeipour, 2015). For example, little is known about whether participating in Hambashi demonstrates a fundamental change in understandings of the self, body, sexuality and love. My dissertation seeks to fill this significant gap in critical scholarly understanding of this new form of intimacy in Iran.

\subsection{Heterogeneous White Marriage: Form of Being Single and Being Married}

As I explain in detail in chapter four, white marriage is heterogeneous: premarital, post-divorce, self-regulated relationships. Based on my investigation, pre-marital form of white marriage is a form of being married whereas post-divorce and self-regulated relationships are forms of being single. Pre-marital hambashi is usually characterized by childlessness, commitment based on pre-given normative definition and limited relationships with extended family. In this group, there is no rebellion and objection about marital norms, but it is a trial and test of the relationship, which makes it a form of marriage. Characteristics of post-divorce and self-regulated relationships, however, are

more complex. Post-divorce and self-regulated relationships are usually childless and involve mutually agreed-upon commitment. They have minimal relational ties with extended family as well as minimal expectations of relatives. These characteristics are often compatible with popular notions of being single. I briefly introduce each of these characteristics in this section and discuss them more extensively in chapters four, five and six. 
White marriage, as a form of non-marital romantic, intimate relationship, is potentially an alternative to a documented marriage. It has challenged normative traditional logics of family life and patterns of partner selection methods, as well as legal, religious and cultural authority over sexual relationships. The term white marriage was initially popularized by the mass media because couples partaking in a white marriage have blanked-out or white pages related to marriage in their Iranian identity documents (Shenasnameh). The existence or prevalence of white marriage is not reflected in formal statistics by Sabt e Ahval, the Office of Vital Registration System or national surveys. However, a member of the board of directors in Iranian Sociological Association, Ahmadnia, and colleagues estimate that $9 \%$ of young urban adults ${ }^{1}$ live in white marriage (Aghajanian, et.al, 2018). Regardless of statistics, it is evident in media (Ebrahimi, 2014; Tabnak, 2016; DW, 2014) that white marriage is a growing phenomenon in Iran, which requires systematic research and investigation.

Heterosexual white marriage is similar to heterosexual cohabitation in the west, which is defined as living with a person of the opposite sex in an intimate relationship without being married (Village, Williams, Francis, 2010). To theorize the transformation in intimacy in the form of cohabitation, Village et al. (2010) proposed a modernization stagism perspective in the context of Britain. Village et al. suggest that social acceptance of cohabitation involves four stages whereby: 1) cohabitation is a fringe phenomenon; 2) cohabitation is accepted as an introduction to marriage; 3) cohabitation is socially accepted as an alternative for marriage; and 4) there is no difference between marriage and cohabitation. Cherlin (2004) further predicts that the privileges and material

\footnotetext{
${ }^{1}$ Urban population of Iran is about 61000000, 2018 (Trading Economics, 2018)
} 
advantages of marriage, compared to cohabitation, have been declining and marriage will not prevail for long in European context.

It would be problematic to apply this modernist stagism approach to explain the situation in Iran. Assuming a single, rigid, and somewhat linear path for all societies to modernize, following the colonial or imperial logic of "first in the west, and then elsewhere" (Chakrabarty, 2000, P.6) is not evidently supported. Critics (Chakrabarty, 2000; Sachsenmaier, 2006; Torre, 2018; Sachsenmaier, 2009) of this perspective suggest that such a restrictive view is reductionist and is unable to capture the heterogeneity of peoples' experiences. Further, it attempts to fit all experiences into pre-set western categories and patterns regarded as universal. However, historical, cultural, religious, socio-economic, political, and other contextual factors make the universality of the phenomena inapplicable and inaccurate (Torre, 2018). Scholars who criticize the reductionist and deterministic nature of western-centric modernization theory argue that it provides little to no insight into the multi-layeredness and overlapping factors, which constitute different cultural contexts. For example, Mueller-Freienfels (1987) explored the diversity of relationships that were all called cohabitation in a variety of locales including countries in South America and Europe, Turkey, Japan, and the United States. The study concludes that dissimilarities in reasons for living together without marriage made them incomparable, supporting the idea of a complicated, nuanced, and heterogeneous pattern of cohabitation.

Hence, I begin with the premise that appropriate attention must be paid to geographical and historical specificities, rejecting an uncritical application of westerncentric theories and concepts and the tendency to equate white marriage with cohabitation 
in the west. This does not preclude attention to possible useful analytical insights gained from scholarship focused on western contexts. There are possible transnational connections inherent in the phenomenon of white marriage across different geographical and historical contexts. In this vein, there are three main perspectives regarding cohabitation in the west, which I found useful in considering the case of white marriage in Iran at the turn of the $21^{\text {st }}$ century. The first approach explains cohabitation as an alternative to marriage, the second approach stresses cohabitation as an alternative to being single, and finally, in the third approach, cohabitation is seen as an introduction to marriage.

The first view of cohabitation, as a variation of marriage, sheds light on the similarities between some cohabitation and marriage. They both share the same pillars of a committed sexual relationship: commitment, companionship, shared household duties, and childbearing (Rindfuss \& Vanden, 1990). The second view, which conceptualizes some cohabitation as a variation to being single, underlines the dissimilarities between cohabitation and marriage. For example, Rindfuss and Vanden (1990) showed that common-law partners more closely resemble single men and women than married couples in their attitudes and family activities. The conceptualization of cohabitation as a precursor to marriage in the third view, which considers cohabitation as a temporary state between singlehood and being married, note the qualitative differences between marriage and cohabitation, observing that common-law partnerships are typically short in duration and that a large proportion of cohabiting unions end up in marriage (Bumpass \& Lu, 2000). As mentioned before, in Iranian context pre-marital relationships can be considered as a variation of marriage. However, post-divorce and self-regulated white 
marriage differ qualitatively from documented marriage such that they are considered variations of being single. Considering all the complexities and also the heterogeneity of white marriage, defining the phenomenon in an inclusive manner is an uneasy task.

For my research project, I mobilize Baker's (2010) definition of cohabitation which highlights qualitative differences between marriage and cohabitation including: "difference in patterns of commitment, domestic work, childbearing and relationship stability" (Baker, 2010, p. 45). Drawing on the above, I define white marriage as a heterogeneous and fluid phenomenon which is living with a person of the opposite sex in an intimate romantic relationship with mutually agreed-upon commitment and shared household duties; the couples are usually childless. Moreover, in Iranian context there are significant distinctions between white marriage and documented marriage. White marriage is childless whereas documented marriage is usually not. Conceptualization of commitment in documented marriage is usually fixed and pre-given, but commitment in white marriage is usually agreed-upon. As white marriage is an individualistic decision, the relationship with extended family is minimal. However, decision making in a documented marriage is usually collective and extended family participates in all ceremonies, resulting in more frequent interactions between extended family and the couple in wedlock.

\subsection{White Marriage in Contrast to Sex Work and Temporary Marriage}

White marriage is not only distinct from marriage, but also differs from other forms

of intimate relationships in Iran, such as sex work and temporary marriage. As white marriage is a new concept in Iranian culture many discussions in media failed to draw proper line between white marriage, sex work and temporary marriage. The primary 
distinguishing factors are that there is no commodity exchange for intimacy and no significant class differentiation between couples in white marriage. In this section, I will discuss these two differences.

Scholars such as Azad et al. have observed that white marriage is distinct from two major non-romantic sexual practices in the context of Iranian culture: sex work and temporary marriage or Sigheh (Azad, et al. 2011). White marriage departs from the old practice of sex work because white marriage involves romantic relationships, shared households and duties, mutual commitment and the fact that there is no commodity exchange for intimacy. It also departs from Sigheh or temporary marriage. Ramazani (1993) explains, "temporary marriage allows a man or an unmarried woman to take a temporary sexual partner as his/her legal spouse for any length of time; at the end of the agreed time, the marriage ends automatically, without divorce, unless renewed. Any children from the union are legitimate heirs of the father" (P.419). Temporary marriage can be legally documented but religiously it is not necessary to document; moreover, temporary marriage involves a much simpler religious ritual in comparison to legal marriage. White marriage involves no religious ritual.

In addition, the socio-economic characteristics of those participating in temporary marriage and white marriage are different. Historically, women in temporary marriages tended to be socio-economically disadvantaged compared to men participating in the same relationship. However, in white marriage usually both partners are from the same or similar class backgrounds: upper or middle class. Another important difference between temporary marriage and white marriage is that temporary marriage is religiously approved, while white marriage is not, then people in white marriage are usually from 
secular middle class whereas people in temporary marriage who have religious affiliations. Although temporary marriage has had different functions in history, it primarily involves an agreement of commodity or capital exchange for intimacy, usually with wealth given to women who in turn provide intimacy (Azad, et al. 2011). Against these traditional practices, it is my view that white marriage signifies as a new and important form of familial relationship among non-religious or secular class in present day Iran.

\subsection{Existing Scholarship on White Marriage}

To my knowledge, the first time when the phenomenon of white marriage was explicitly addressed in academia is in Azad et al.'s categorizations of "pre-marital" sexual behaviors in Iran. In their research white marriage is defined as a premarital trial prior to documented marriage. Based on their analysis two main factors contribute to the emergence and evolution of white marriage: internal factors and external factors (Azad, et al., 2011). Equipped by interviews and employing a grounded theory approach, they argue that internal factors include a rise in the divorce rate, an increase in the age of a first marriage, generational gap, women's increased engagement in social spaces, and a decrease in parental control over children in a family. In addition, they identify three external factors related to the Iranian economy, culture, and modernization pursuits. These factors include neoliberal policies and job insecurity, rethinking traditions based on global western influences and resultant changes in personal value systems, change in the method of partner selection from collectivist to individualistic, a rapid growth of information technology, urbanization and an increased opportunity for anonymity in urban life, modern education, among other such factors. The authors emphasize the 
particular role of information technology in providing a private space for young people with minimum parental control. They conclude that modern patterns of sexual relationships such as white marriage are deeply rooted in discourses of modernity and post modernity. The authors argue that white marriage can be seen as a threat to the social order, capable of irreversible societal in the near future, even though they do not specify what these consequences are. The study is very valuable as it introduces the phenomenon of white marriage in academia. It also distinguishes white marriage from existing forms of intimacy. My work, however, criticizes modernist approach to white marriage and adds depth with a post-colonial perspective.

Relying on interviews, Ghoddosi and Bayat (2014) studied the diffusion of white marriage in Tehran. Although a popular rather than academic study, the results were published in the country's premier women's magazines, Zanan Emrooz (Women Today). The government shut down this magazine for encouraging white marriage. Interestingly, following the discussion in Zanan Emrooz, the discussion of white marriage in the popular media grew exponentially (Ebrahimi, 2014). The main finding from Ghoddosi and Bayat's study is that participants of white marriage intended to escape marital law. While conducting interviews with women participants of white marriage, the authors found that in their perspective, the defined legal relationship between a wife and husband in Iran is patriarchal and inherently unjust. In particular, marriage, divorce, and child custody follow a patriarchal pattern of power in relationships. The women discussed how this factor discourages them from entering legal marriage relationships and instead choose white marriage. The authors conclude that nonetheless, white marriage places women in a vulnerable situation because they do not have any legal 
support in the case of domestic violence and also in the case of unintended pregnancy and abortion, which is illegal in Iran. The study pays attention to vulnerability of women in white marriage in patriarchal setting. They mentioned that the vulnerability and inferior statues that women in white marriage try to avoid by rejecting marriage reproduces in different form in white marriage, as there is no established mechanism for financial share and for seeking help in the case of manipulation and domestic violence.

Responding to the emergence and persistence of white marriage in Iran, Jalaeipour (2015) identified three forms of family in contemporary Iran: traditional family, civil family, and white (marriage) family. Jalaeipour's (2015) study pioneered the idea of white marriage as a family union. He discussed the evolution of the Iranian family in face of social vulnerability in recent decades. In response, a white family not only reduces the vulnerability of a familial unit, but also increases it. The author however does not detail the exact nature and extent of these vulnerabilities, which are supposedly increased with the emergence of a white family. The acknowledgment of white marriage as a family is an important step to understand realities of white marriage without stigmatism.

Mahboobi's study (2016), one of rear published research about white marriage outside of Iran, contributed to these existing debates about white marriage and employed secondary analysis of interviews related to this phenomenon that are cited in popular media publications. She argues that white marriage emerged from a different historical context with different motives that distinguishes it from cohabitation in the west. She adds that while white marriage appears to be "modern", her analysis of published interviews reveals that people involved in white marriage practise and expect the same traditions they have tried to avoid, as they do not know any alternatives. For example, 
they gradually adopt old gender roles in house works and in financial share. The theoretical limitation of study is failure to acknowledge multycipity of modern and modernities in defining white marriage and the fact that making oppositional binary of traditional and modern does not reflect reality of white marriage. The study leads me to realize hybridity and ambivalence of white marriage.

A recent study by Aghajanian et al. (2018) examines this pattern identified by Mahboobi (2016), finding a decline in the rate of official marriages. In particular, the authors analyze the widely held popular and academic belief that the decline in permanent marriage is partly due to the increase in temporary marriage or sigheh. In their investigation, Aghajanian et al. (2018) categorize living together outside of marriage (white marriage) under the labels of "non-recorded temporary marriages" and "healthy sigheh cohabiting relationships." They explain that there are significant differences between people in non-recorded temporary marriages (white marriage) and other categories of sigheh in terms of education and career, especially for women. Moreover, they acknowledge different motivations for choosing this lifestyle as compared to sigheh, such as a belief in individualism, independence, and self-actualization; however, they still group white marriage under the same umbrella. The advantage of the study is examining white marriage within larger picture of intimacy in Iran with demographic lens.

All studies discussed above explained in diverse ways the complexity of this new phenomenon of white marriage in Iran. Azad et.al (2012) contribute to this ongoing debate by distinguishing white marriage from former intimate relationships and adding to Jalaeipour assessment of it as a new form of family union. Ghodosi and Bayat (2014) importantly highlight patriarchal foundations of marriage in terms of patriarchal family 
law and patriarchal marital relationships. They also discuss the marriage industry as a barrier for documented marriage, which then leads to the popularity of white marriage. The study of white marriage in relation to other demographic statistics such as divorce rate and marriage rate is the advantage of Aghajanian's et.al (2018) study. However, in my view the researchers failed to differentiate white marriage and Sigheh in terms of meaning and values in the perspective of people in white marriage.

Another limitation of these studies is the importance of socio-economic class in white marriage. White marriage is an urban middle class phenomenon, recognizing of course that the category of urban middle class is also heterogeneous. Moreover, a problem in the studies is that, except for Mahboobi (2016), white marriage is seen as the equivalent of cohabitation in the west (Azad, et al., 2011); (Aghajanian's et.al, 2018); Ghodosi and Bayat (2014). It is true that western scholarship's portrait of cohabitation after the sexual revolution in Europe offers valuable insights to examine new forms of sexuality, however, as Mahboobi (2016) mentions, to assume white marriage is the same as cohabitation as it exists in the west is not accurate and narrows peoples' experiences into pre-given western categories. Mahboobi's (2016) argument also sheds light on some aspects of white marriage as it relates to modernity, but it lacks empirical first-hand evidence and theoretical grounding.

Employing a post-colonial perspective (Chakrabarty, 2000; Bhabha, 2006), I add a layer of depth to understand intimacy in Iranian society and in turn understanding change in normative heterosexuality. I examine white marriage and its role in negotiating and reconstructing marital norms among the urban middle class, which has not received enough scholarly attention. My objective in this dissertation is to document how middle class 
Tehrani young people in a white marriage construct and understand their mode of intimate relationships and to suggest a framework for explaining their experiences and perspectives. The analysis of interviews is intended to illuminate new understandings of white marriage within a broader context of transformation in intimacy in Iran. In doing so, I investigate white marriage as a counter-discourse to Iran's marital norms and as a practice that is shaped by Iranian young people's notions of the modern subject of self, body, sexuality, and love.

Writing about the importance of socio-economic class, Foucault observed that one of the important designated factors in sexual change is class (Foucault, 1986). In the case of Iran as well, changes in sexuality vary in different socio-economic classes and rapid changes have been observed in the middle class (Afary, 2009; Mahdavi, 2009). Middle class women and men in white marriage are usually highly educated and are gainfully employed (Ghoddosi \& Bayat, 2014). Since white marriage in the middle class is an individualized decision where the emphasis is on personal choice, access to social and financial capital empowers the agency of young people and active decision-making in intimacy. However, living in white marriage out of financial necessity or to meet a housing need may play a more important role in the working class. For the purpose of my dissertation, I will focus on Tehrani middle class young women and men as the phenomenon is increasing among this class (Aghajanian's et.al, 2018). The dynamics of white marriage in the Iranian working class and how prevalent white marriage is among them (in comparison to the middle class) merit further study beyond the scope of the present analysis. 


\subsection{Theoretical Framework}

Postcolonial theory provides the conceptual tools for understanding white marriage beyond oppositional binaries of traditional/modern relationships. The notions of third space, hybridity, and ambivalence help explain how individuals negotiate the contradictory demands and polarities of understanding white marriage within Iranian dominant culture (Khan 1998). In this section, I revisit and reflect on the theoretical trajectory of the study, highlighting the specific theoretical insights that currently guide my dissertation project. Since white marriage in academic studies and the mass media is overwhelmingly viewed as exemplifying the contrast between the modern and the traditional as a modern form of relationship opposed to a traditional relationship. My view is that white marriage is neither traditional nor modern. And yet it is both traditional and modern. It occupies a third space. Next, I will criticize the binary approach of opposing modern and traditional marriages in the context of family.

Giddens (1992) is one of the most prominent theorists on modern forms of intimate relationships in family. He hypothesized a new form of sexuality by emphasizing the relationship between couples. In his view, intimate relationships can be categorized in two forms: a fixated relationship that is woven into traditions, and a liberal form of intimacy, which he called the pure relationship. Fixated relationships, as Giddens (1992) argues, are based on compulsive dependence rather than on codependence. Role separation according to gender is an important characteristic of fixated relationships, typically materializing as a relationship wherein women are responsible for domestic tasks and attending to the demands of children, while men are responsible for financial concerns and familial expenses. This structure provides the basis for an addictive 
relationship. Addictive attachments between couples do not allow for reflexive awareness of oneself and self-monitoring; consequently, these relationship patterns restrict selfdevelopment. The restriction of self-development would curtail improvement in developing talent, potential, identity and awareness. In addition, in such relationships, one's self-identity is inevitably subsumed both by the needs of other members of the family and by the demands of the daily routines of life.

The opposite of fixated relationship is pure relationship, which is characterized by its emotional component. The emotional component, being so central to the pure relationship, establishes a context that allows individuals to react to their circumstances in ways no longer governed by tradition (Holmes, 2010). The interactional framework in pure relationships is conducive to a more equitable consideration of emotions between partners, representing a more 'democratic' approach between partners. Giddens claims that such a relationship would represent the end of a visible hierarchy in the structure of the family and a move toward a more egalitarian approach to family.

When I started my research, I was initially drawn to Giddens's framing and saw white marriage as an example of pure relationship. This theory of intimate relationships could explain some aspects of transformation on intimacy in Iran. However, during my research, I realized that many other complexities remain uncovered. In the study, I demonstrate the ways in which white marriage cannot fall into either of the two fixed categories of "pure relationship" vs. "fixated relationship". Said (1985), in his seminal work Orientalism, has critiqued how Orientalist binaries, in the case here the binary between pure relations and fixated relations, homogenize cultural differences into unitary totalities of cultural practice. In my research, I gradually realize that Giddens' concepts 
are not helpful for understanding white marriage, which is neither and at the same time both, because people in white marriages actively select from traditional and what is called "pure" values and simultaneously make their own modality of relationship. This explains the plurality of understandings and definitions of this form of intimate relationship evident in my own observations and the experiences of my participants. The intellectual puzzle to be "solved" in my research is how Iranian middle class women and men in white marriage understand this mode of intimate relationship in the context of Iran's marriage governance and the global dominance of western culture? Specifically, in what ways is the emergence of white marriage associated with Iranian middle class men and women's desires for, and imaginaries of, being modern in Iran?

In what follows, I explain my postcolonial and Foucauldian approach. Postcolonial theory is pivotal to call into question modernization theory with emphasis on single path as a perspective to understand the reality of the global process. It illuminates one of the key criticisms of Giddens' concepts of pure relationship and fixated relationship: the implicit assumption about fixated relationship as being pre-modern (and non-western) and pure relationship as being modern (and western), and the anticipated linear progression from the former to the latter. Postcolonial scholars such as Chakrabarty (2009) and Mohanty (2003) reject the teleological position that there is a single path for all societies to modernize, following the temporal line of "first in the west, and then elsewhere" (Chakrabarty, 2009, p.6; see also Hall \& Gieben, 1992; Walby, 2009). Arising from a critical stance on the universalist notion of modernization, postcolonial theories rethink modernity. Based on postcolonial theories, I understand modernity as a 
"social transformation" (Bhambra, 2007, 9), a pathway from local to global (Bhambra, 2007). In postcolonial theory, there are plural understandings of modernity which are nonlinear, dynamic, non-universal or multidirectional (Delantey, 2004, 164). Eurocentric modernity in this view is a historical phenomenon not as an ideal, normative or authentic modality (Wagner, 2002).

Postcolonial frameworks emphasize that it is necessary to recognize plural histories and plural modernities. Chakrabarty (1992) argues that the understanding of history as a developmental process should be replaced by understandings of the plurality of the present. The plurality of the present also facilitates the anticipation of a plural future. At the same time, as Bhabha (1996) argues, wider interconnections among societies have formed the basis of "connected histories". Considering both arguments, social analysis would fall neither in false universalism nor in radical, relativist particularity.

At a time when the banning of western cultural products is no longer feasible, globalization is not external to Iran but internal to Iranian everyday life. In fact, middle class young people culture is tied up with consuming western cultural products (Mahdavi, 2009), which directly relates to identity, a conceptualization of self, and articulations of sexuality. In the age of globalization and the rapid development of information technology, no society can be affected solely by internal factors. I suggest that these factors, along with resistance to some traditional marital culture, contribute to changing the conceptualization of selfhood, love, body and changing the discourse of intimate sexual relationships, and thereby explain the emergence of white marriage among middle class young men and women in urban Iran. However, it is my view that such changes are best understood not as progress toward a western-centric universal state, but as a case of 
translating (Chakrabarty, 2009) existing categories and practices into the categories, practices, and self-understandings of modern gender and sexuality in Iran.

My intellectual engagement with these postcolonial criticisms led my investigation to the postcolonial concepts of third space, ambivalence and hybridity (Bahaba, 1994). One of the challenges of this study is that white marriage in the mass media ( $\mathrm{DW}^{2}, 2014$; Ebrahimi, 2014) and academic research (Jalaeipour, 2015); Azad, et. Al., 2012), is understood as the same as cohabitation in the west, with some exceptions. In this sense, as I mentioned before the specificity of white marriage is forgotten in the dominant discourse of intimate relationships in the west. To counter this tendency of homogenization and reductionism, Bhabha (1994) suggests conceptual tools to investigate the construction of cultural differences at a time of cultural dominance of the west. In what follows, I discuss some concepts from postcolonial literature that will help interpret white marriage as a practice of making the modern self in the context of the global dominance of west-originated ideas about sexuality, self, body, and love.

Bhabha's concepts of third space, ambivalence, and hybridity is particularly useful to understand the complexity of the construction of white marriage. His model offers a means to explain and articulate the presence of a hybrid understanding of self, body, love and sexuality within cultural differences rather than based on pre-given and fixated understandings of either traditional or modern. Challenging the fixity and unity of meaning that resides in the language of binary oppositions, he argues that cultural concepts are hybrid rather than pure, ambiguous and complicated rather than

${ }^{2}$ Deutsche Welle: s Germany's public international broadcaster (Wikipedia, 2018) that broadcast in Farsi. 
straightforward and simple, and inconsistent and ambivalent rather than direct (Nasirzadeh, 2014). In fact, individuals construct their culture from national as well as religious texts and often transform them into western symbols, signifiers of technology, language, or practices (Khan, 1998).

Bhabha demonstrates how both the understanding and performing of different concepts in everyday life are in a passage through a third space (Khan, 1998). Going beyond the binary opposition of either modern or traditional individuals' agency allows one to perform; as Bhabha asserts "once it [third space] opens up, we are in a different space, we are making different presumptions and mobilizing emergent, unanticipated forms of historical agency" (Bhabha, 1995, p.114). A third space also provides an opportunity to look at the ways in which tensions and contradictions in a white marriage challenge and disrupt representations of intimacy in the west and cultural assumptions in Iran. Bhabha's notion of hybridity in the third space helps to explain how individuals negotiate the contradictory demands and polarities of understanding white marriage within culture (Khan,1998). In sum, the concept of third space opens a possibility of an in-between within the mainstream rather than a one-dimensional portrayal of white marriage as emulating and identifying with western values.

These postcolonial understandings also point to another challenge in my project: interpreting the phenomenon whereby white marriage is informed by Iranian commonsensical and false imaginary about the "universality" of cohabitation in the west. It is clearly misleading to translate white marriage into terms such as cohabitation and common law partnership, using the languages, categories, and the conceptual world of a western audience. The phenomenon of white marriage should be assigned a term that is 
familiar and understandable in Iranian culture. Nevertheless, the term would be unfamiliar for English speaking cultures. These difficulties also arise when reinterpretation of local cultural practices, such as white marriage, need to be translated into a publicly acceptable academic language (Chakrabarty, 2009). For example, I was are what asked at conferences whether "white" marriage means marital style among Caucasians. Such challenges in translations and interpretations are what I need to reflect on throughout the research process.

\subsection{White Marriage and the Institution of Sexual Governance}

The third space of translating cultural practices is infused by power relations. What especially stand out in this case are the dominance of globalized western culture and the governance institution of marriage in Iran. In this dissertation, I prioritize the latter in my analysis. In my explorations of modalities of regulation and power, I found the institution of marriage in Iran to be an important regulatory power of intimate relationships. Foucault calls for attention to the relationship between sexuality and power. In particular, his conception of power also insists that power always involves and engenders 'resistance'. Resistance is formed right at the point where relations of power are exercised (Foucault, 1980, P. 142). Guided by this insight, I seek to understand white marriage as a form of resistance with the objective of expanding possibilities for different forms of intimate and family life. As Shahrokni (2014) notes Foucault (1991) only considered internal power dynamics, which enabled the emergence of governmentality in the sixteenth and seventeenth centuries and facilitated its mobilization in eighteenth century Europe. In my work however, I discuss both internal and external powers that consist resistance to marriage as an institution of governance. 
As noted earlier, my overall research question is how the emergence of white marriage, in a globalized world, is associated with Iranian middle class men and women's desires for and imaginaries of being modern in Iran. In this section, I explain my understanding of "the traditional," which is focused on marriage as an institution of social and moral regulation. Marriage can be seen as an institution of governance (Franke, 2006). The objective of marriage is to shape marital conducts and thereby regulate sexuality. One of the primary objectives of this governance activity is to ensure that parties in a marriage become capable of morally self-regulating their intimacy and to understand an acceptable way of having a sexual relationship and having children. The normative logic of marriage, based on the notion of the family, is concerned with sexuality, domesticity (Comacchio,1999), life schedule (Hareven,2013), and private property (Glendon, 1981). Operations of power over individuals supposedly protect society from "public order offences" relating to sexuality and contributions to future population growth.

Religion, culture, legislation and medical-based science are some of the key institutions that generate knowledge claims about sexuality and have an impact on the formation of marriage-based norms and further serve to embody these norms. Foucault explains that a system of social control not only functions by a legal-administrativesocial system of prohibition and censorship, but no less importantly by producing normative cultural meanings and self-identities associated with sexuality. A regime of sexuality is a product of a system of social control that determines normal/abnormal identities and its norm of a healthy, fulfilled sexual life. The regime of sexuality applies a kind of widespread, invisible power over people through cultural definitions, social 
norms, and self-images (Seidman \& Said, 1996). As such, legal, religious, traditional and medical institutions operate as prominent sites of governing sexuality. Legislation defines the boundary between the legal and the illegal, religion the sinful and the virtuous, traditions the moral and immoral, and medicine the healthy and the unhealthy. These give rise to regimes of truth in marital life and institute regimes of discipline, through which intimacy is governed and marriage, as an institution of governance, becomes an expression of power (Hunt, \& Wickham, 1994). Foucault sees social resistance against power as heterogeneous, local and specific to the logic of a particular social field (such as normative Iranian sexuality). Guided by this insight, I am interested in examining white marriage as possibly a local effort to push against, circumvent, or transform the local disciplines for the objective of expanding the possibilities for forms of life.

Departing from liberalism and Marxism, Foucault did not entertain dreams of a society free of power, seeing that "personal and social existence can never be free of constraint and regulation" (Seidman, 1994, p.190). The implication of this for my research is that the governance approach can be helpful for analyzing how power is exercised within white marriage relations and how participants in this mode of intimate relationship govern themselves once they have removed themselves from marital institutions. Taking cue from Lisa Rofel's on desires in China (2007), I examine how Iranians in white marriages formulate their desires and construct their sub-cultures and how such desires and cultures are produced in relation to global cultural forces on the one hand and articulated with national politics inside Iran on the other.

In the modern age in western societies, self- regulation is a new technique and individuals are expected to be self-regulated based on social hygiene (Hunt, 1999). As a 
result, in the west, the dominant discourse is neither religion-based nor legal-based, but it is medical-centered in the context of sexuality. For example, as I mentioned, Hunt (1999) argues that non-marital behavior and desire in the western societies, which was described as a "sin," translated into "badness" or "immorality." Now, this badness was explained rationally by medicine and became "un-healthy" or "abnormal" or "diseased". Therefore, modern sexual relationships in the west are regulated by medical discourse and they are not liberated or free.

In the less influence of religious, legal and traditional power over white marriage, it is important to investigate which discourses are central to the governance of the modern self in white marriage. For example, what are the extents to which public health and biopolitics discourse, Occidentalist imaginaries of the west ${ }^{3}$ (Chen, 1995), or other factors play a role in the emergence and evolution of white marriage practices? In my interviews, I pay careful attention to the discourse, mentalities, logics and techniques that women and men in a white marriage employ to explain and govern their relationships and address the gap in scholarship on white marriage.

In sum, daily negotiations and challenges of people in a white marriage within and outside of the relationship may suggest a notion of hybrid and ambivalent identity in the reality of a globalizing, postcolonial world. Conceptualization of hybrid and ambivalent white marriage also challenges scholars and journalists who perceive white marriage as a

\footnotetext{
${ }^{3}$ Chen (1995) study of Occidentalism in China relevant to the context of Iran. There is a relationship between totalitarian political regimes and the image of the West in the Oriental societies. According to Chen, in Occidental societies with totalitarian political regimes there are two types of images from the West including the official Occidentalism which is "the rejected West" and a counter discourse which is the unofficial Occidentalism which is "the idealized West". The idealised west is reflected in interviews in which people in white marriage found themselves in a disadvantageous position vis-àvis the West.
} 
monolithic and homogeneous phenomenon. These concepts also help to engage the local disciplines of Iranian cultures (for example in different categories of middle class) as a multiple, shifting, and contradictory site. I argue that white marriage shares many common characteristics with both pure and traditional relationships. For example, premarital group represents, to a large extent, the end of a visible hierarchy in the structure of the family and a movement toward a more egalitarian approach in terms of housework and financial share. However, conceptualization of commitment is pre-given and documented marriage is still highly valued symbolically. Post-divorce and self-regulated relationships are also conducive to a more equitable consideration of emotions between partners, representing a more egalitarian approach that also challenges marital norms and traditions. However, in some cases in theses settings still parental advice and approval are influential in keeping the relationship.

I believe my analysis opens a space for understanding the individuals in white marriage and their chosen sites of struggle, which are never singular but always plural, shifting, and dynamic. My study must also be differentiated from those that are more explicitly concerned with political power rather than cultural regulatory power and local disciplines, as I look beyond the state in understanding the governance of intimate relationships. Finally, a discussion of the connection between regulatory powers and resistance serves to underline the general importance of an individual's agency to push against, circumvent, or transform local disciplines for expanding the possibilities for forms of intimate life.

In my dissertation, I aim to suggest a framework for explaining desires that motivate the choice of white marriage among Tehrani middle class women and men. The central 
question of the dissertation is that how Iranian middle class women and men in white marriage understand this mode of intimate relationship in the context of Iran's marriage governance and the global dominance of western culture. As white marriage is a new practice in Iranian culture, the current academic attempts are not enough to explain different aspects of it. My research with Foucauldian and post-colonial approach investigates this phenomenon.

The rest of this dissertation consists of four chapters, followed by the conclusion chapter.

Chapter 2, "Methodology", reviews the broad philosophical underpinning to my qualitative research methods, interview and data analysis, which linked back to the literature and my research question. I choose interview because it is a flexible and lively interactive method for gaining qualitative information, such as people's experience, views and feelings. To add more room for interviewees' different responses, I followed a semi-structured format. Using textual data was necessary for answering my research question and revealing a great deal about the people, the related organizations and the social context in which white marriage emerged.

Chapter 3, "Iranian marriage and Free Choice of Partner", contextualizes white marriage as a classed phenomenon. After tracing the evolution of middle class in the last century, this chapter explains how increased accessibility of information technology shapes the understanding of modernity and western normative marital and romantic culture. In doing so, I use interview data to complement the discussion and strengthen the argument. 
Chapter 4, "What is White Marriage?", offers a thorough account of the formation of white marriage and its categorization, prevalence of the phenomenon, reasons and motivations, and also dynamics of the couple's relationship with extended family. Most of the above are informed by interview data and the rest is by media analysis.

Chapter 5, "White Marriage as a Childless Relationship", engages both set of data, media analysis and interviews, to investigate ideological reasons and/or documentation barriers that discourage child bearing in this relationship in each category. Unequal social and physical burden on women in the case of unintended pregnancy is the next covered topic. The section that gives a clue to understand the importance of the association between white marriage and population and health policies. Finally, the chapter explains three phases in official media for discussing white marriage: silence/denial; prohibitive approach; management approach.

Chapter 6, "Commitment", using interviews and textual data, demonstrates the complexity of both conceptualization of commitment and the commitment-making process in each groups of white marriage. More specifically, the chapter explains heterogeneity in understanding commitment and the process that couples adopt to reach an agreed-upon definition. The chapter also examines couples' commitment to the relationship in life difficulties with examples related to financial, medical or political issues.

Throughout this project, I demonstrate that current official and overseas media fail to account for the heterogeneity of white marriage and its differences with cohabitation in the west. Thus, instead I illustrate that it is more productive to look closely at white marriage and its categorizations as a very local yet a globalized phenomenon. Drawing on a Foucauldian 
approach to marriage as an institution of governance and post-colonial theories of modern reflexive identity, I explain white marriage, as a new, individualistic lifestyle, is a consequence of global cultural forces, articulated within the cultural politics of Iran. I argue white marriage is local efforts to push against, or circumvent, or transform the local disciplines for the objective of expanding possibilities for forms of normative intimacy. Moreover, white marriage challenges fixated, pregiven and standard understanding of intimate relationships as either traditional or modern. In fact, white marriage is hybrid, complicated and ambivalent. Then beyond binary opposition of either modern or traditional, a third space is needed to understand individual's agency in living differently. Third space also opens a room in-between mainstream rather than one-dimensional portrayal of white marriage as emulating and identifying with western values. Moreover, by third space I explain they ways each groups of white marriage negotiate the contradictory demands and polarities of understanding (Khan,1998) their intimate relationship within culture. I demonstrate polarities of understanding in different groups through several important aspects: reasons and motivations, commitment, childbearing. Finally, I explain, the theoretical and the empirical contributions, as well as the policy implication of the research and further suggestions for future research. 


\section{Chapter 2. METHODOLOGY}

Like others who have studied the complex relationships among subjects, intimacy (Sadeghi, 2008; Najmabadi, 2004), agency (Charrad, 2011; Hoodfar, et al. 2009), power (Mahdavi 2009; Farahani, 2007; Hoodfar, \& Sadr, 2010) and governmentality (Afary, 2009) in familial settings, my study employs two methods: interview and text analysis. In addition, I used notes provided by my sister from a public event: a seminar organized by the Iranian Sociological Association at the University of Tehran in November 2017 entitled "White Marriage." This multi-method approach allows me to investigate how people understand white marriage as a new form of undocumented romantic relationship in Iran. These methods in combination lets see above me collect two complementary sets of data. In this chapter, I will detail each of these methods.

\subsection{Interviews}

Creswell (2007) defines the interview as the creation of a co-constructed reality between a researcher and a researched, which is shaped by individual experiences. In line with Creswell (2007), Csordas (2002) explains the interview as an opportunity to move from a multiplicity of cultural meanings in a cultural world to a cultural pattern of meanings in each individual. This cultural pattern has "the intersubjective constitution of meaning through that experience" (Csordas, 2002:242). Interviews permit the exploration of the process of reproduction of social norms in each person. The way that informants shape the discourse of the interviews guides a researcher to learn about people's embodied values and the way that they understand subjects. During the interview, understanding is achieved by actual presence in a social situation as well as 
through a structured or semi-structured dialogue between the observer/interviewer and participants. Explanation therefore is the achievement of the observer/interviewer and concerns the dialogue between theory and data (Burawoy, 1991).

The majority of my findings emerge from interviews that I conducted in two months in Tehran from March to April 2016. I also draw on observations from previous visits during my Ph.D. program in 2014 and 2015. In the remainder of the chapter, I explain sampling and recruiting strategies, in addition to providing general reflections about the interview as an analytical process.

Considering the characteristics of the population under the study, I used a nonprobability sampling strategy, specifically snowball sampling. As Bernard (2011) explains, non-probability samples are appropriate for in-depth studies, involving sensitive topics, such as sex-related subjects, or difficult to reach people as a result of their illegal activities. White marriage engages both: it is a sex-related topic and it is an illegal activity; hence, probability sampling was impossible. Moreover, with the exception of the study by Ahmadnia mentioned in Aghajanian, et.al, article (2018), which estimated that 9\% people in middle class live in white marriage, there is no official statistics available related to white marriage (Ghoddosi \& Bayat, 2014; Azad, et.al, 2012). Ahamdnia's method was non-probability sampling among university students in Tehran. Nonprobability sampling methods help me select participants from a population who are interested in being a part of the study. In order to approach interested women and men from a diversity of backgrounds, I employed recruitment strategy with the assistance of several third parties. Three journalists and three hairstylists assisted to recruit interviewees. The main criterion in recruiting interviewees is participation or experiences 
with white marriage between 2006-2016. This is the time that white marriage gradually increased based on my observation. As white marriage is largely a middle-class phenomenon, which I explain further in Chapter Four, my sample consists of 16 middle class women and men between the ages of $25-40$, who experienced white marriage between 2006 to 2016 .

Interviews took approximately 90 minutes and were completed at either a university office or a coffee shop. Before starting, I read the oral consent document to them and obtained their initials. Oral consent provides a less formal environment between the researcher and the participant at the beginning of the interview. Informality eased the process of the interview and data collection. I asked participants a series of open-ended questions including: 1. age, work, education, and marital history, 2. childhood and family situation, and finally 3 . the experience of living together in white marriage.

Conducting these interviews in Tehran, bringing me, the researcher and the participants into the same space (Creswell, 2007), provided me an opportunity to not only observe interviewees but also see myself as a researcher with a particular positionality from interviewees' perspective. This dual perspective made me very conscious of the power of the researcher in shaping the interview about participants' life experiences and helped me understand these power relations in ways that are influenced by my theoretical, ontological, personal, and cultural frameworks. My positionality and personal experiences, as well as my use of language (Farsi) when asking, analysing, and interpreting the collected data, shape the knowledge produced through the research.

Power dynamics between the researcher and the researched is not only constructed by the researcher's position as knowledge producer on a small scale; but also is 
influenced by structural factors such as citizenship, gender, and discipline in a large context. Like in most research, I have control over the project agenda, interpretation of data and writing. I addressed power dynamics in terms of control over the project agenda by taking standard practices to obtain consent of participants and to include measures for them to have control over whether not to answer certain questions, tape recording, and their right to ask me questions. At the same time, this research is conducted by a female Iranian-Canadian researcher, partially insider/outsider, studying a social phenomenon involving marginalized people who are in white marriage.

In this project, I found gender to be an important factor that influences power dynamics between the researcher and researched. My gender influenced my access to participants, often when approaching women more so than men. Women participants often resisted when I asked to interview their partners. I would add that this is more of a general challenge based on gender expectations and norms, whereby usually women select to study only women and men only men in Iran. Such gendered practices were further evident when after one interview, when a male interviewee said, "I'll stay with you until the taxi you called arrives, after all I've never leave a "woman" in street at evening". Male interviewees would not let me to pay for tea or coffee when we were at a café. As an Iranian I know that this is a reflection of the usual Iranian courtesy, but it also signifies patriarchal norms that men should protect women. This incident also revealed the overdetermination of who I am as a woman, even among people who are critical of the kind of patriarchal and non-egalitarian logic and practice in normative familial settings. Nevertheless, I do not think that this necessarily shaped the research 
process in an irreversible way. Some participants were curious about my methodology but never questioned my research credibility.

Moreover, my national identity as a dual citizen - Iranian and Canadian - in a postcolonial context also adds complexity to the research. This in itself reflects the landscape of scholarship, the overlaps of social structure and knowledge making (Gusterson, 1997) and ideological construction of superiority of the west and its gender relations and living in the west as a privilege. Participants assumed that as an Iranian-Canadian, I too am "privileged". My experiences in the field reveal the influences of positionality, honor, and/or problematized intersectional notions of difference, which in my research context is my double citizenship. As an Iranian - Canadian I was categorized as an "outsider". To reduce possible influence on the data collected, I tried to consciously omit using any English words during my conversations and dress up as ordinarily ${ }^{1}$ as possible.

Despite these efforts, I continued to face challenges in the field as a partial insider/outsider. One of participants mentioned that I have not been in Iran for a while and I am not aware that the young generations has dramatically changed. They also indicated that as a result of my outsider status, I do not understand the normative pressure of the everyday in Iran as I am not living there. In another instance, an Iranian government official brought to my attention that I was no longer enough of an insider to access any governmental research related to white marriage because of my affiliation with western academic institutions. Moreover, I was given advice to study something else, just not a morally sensitive topic such as white marriage. In the worst case, I was advised not to transfer such cultural information to the west, which made me feel like an agent for the west! 
In a similar vein of curiosity, a few people wondered why a Canadian university should give me a scholarship to do research inside of Iran. These experiences with "placing" (Mizra, 1998; Egharevba, 2001) and "otherness" (Prasad, 2003) along with similar lived experiences, made aware of importance of the landscape of ambivalent, nonautonomous belongings that an immigrant in a general sense and a researcher more specifically has to deal with in post-colonial era. It also contextualized my understanding of Occidentalism (Carrier, 1995) and post-coloniality (Said, 1985) in everyday life. Such direct remarks like those discussed above although rare highlight how I was seen, "placed", and understood by third parties and interviewees, which in turn might have an impact on recruitment and interviews.

Regardless of these challenges, my affiliation with Canadian universities and ethics clearance, was regarded as a privilege. More importantly, it helped me establish credibility and engendered trust among my participants that I do not have any relationship with any political authority inside of Iran. However, it became clear to me early in recruitment phase that I still needed to assure interviewees that the study had nothing to do with the western Media. Some of interviewees wanted to make sure that they would not hear their voice or names in a report in the BBC or VOA that can turn into political hassles for them in Iran.

Overall, the recruitment process was time consuming. Often, it was difficult to explain my research topic to relatives and friends. On many occasions, especially among older generations, some asked why I was interested in speaking with people who "live in sin" and implied a personal offence. Some commented that not everyone could face "this kind of people". Some even raised their eyebrows and were skeptical that I would find 
any participant. Most of these curious people believed that "we do not have such people in our families!" and finally questioned if it is worth studying this group of rebels and sinners. I often felt frustrated when explaining my research topic to those critics. However, my status as a married woman helped "defend" myself against these challenges. If I were a younger, single woman, it probably would have been even more difficult and frustrating.

For a brief period, I opted to say instead that the study was about new forms of family in Iran. In the end, I managed to recruit a sufficient number of interviewees: nine women and seven men who were not partners.

During the interviews, the identity ascribed by interviewees and indicated in consent form - an Iranian researcher from Canada - often opened up conversations. Participants asked questions about my marital status, and the process of applying for Canadian universities, scholarships, among other similar personal topics. I found these conversations assisted in bridging the gap between the researched and the researcher and deepened the mutual trust produced during the interview.

I also noted that my discipline of study, sociology, can play role as a contextual factor. Research about family in a sociological context rather than psychological and demographical context, is unknown among most people involved in the project. They were not sure what I was looking for about intimate relationship in sociological context. Rather than narrating life stories, they usually focused on psychological aspects of their experience, psychological harms in their childhood or tried to give general opinions on society, documented marriage, and white marriage. At the end, after reminding what I want to know, they told "well, just talking and laughing (in farsi:begim o bekhandim) is 
that what you want"!? Their comment showed that they were not familiar with research in sociological context.

Upon reflection, it is possible that participants might have felt that I would be critical of white marriage because of my marital status. Paradoxically, assuming that I am coming from a western society, they might also have felt that I expected answers favouring western culture and white marriage as an accepted form of relationship in the west. For example, knowing that I am a Canadian resident, interviewees might have chosen to use English words and idioms more often and might feel that references to European or North American life styles make more sense. Despite such possible influences, data gathered from textual sources, participant observations, and existing studies suggest that western-centric attitudes among people in white marriage (Azad,etal, 2012; Jalaeipour, 2015) and being critical to normative marriage are indeed typical (Ghoddosi \& Bayat, 2014).

Among the different groups of interviewees, I found most affinity with men and women who discussed seeking equity in the relationship. I could identify the social (e.g. listening to stories of pushing back social limitations), emotional (e.g. listening to stories about fighting to serious illnesses) and intellectual (e.g. seeing strong women who stated feminist ideas in simple authentic words) ideas discussed by my informants. I also tried in earnest to find research errors that happen because of my blind spots. For example, as soon as the first interview with an informant was finished, I listened to it over and over and took notes on separate occasion to try and reduce possible tendencies of domination, over-detachment, submission, devaluation, idealization and overattachment (Luttrell, 2000) in subsequent interviews. Eventually, taking a reflexive 
approach, I accepted and documented my own involvement in the research process as much as possible.

I was inspired by Luttrell (2000) and designed three steps for documenting data at the end of each interview. First, I wrote about the material condition of informants' lives, their expressed emotions including all the non-verbal events (moments of silence and their duration, emphasis, meaningful gestures and expressions, etc.) and their cultural beliefs. Second, I noted the ways they applied their beliefs to their real life, and finally, I provided my interpretation on the basis of the selected theoretical framework for the study. I explained in detail how I came to each conclusion and interpretation. I also listened to the recorded interviews to identify missed opportunities to probe for information, understanding, and clarification. If necessary, I went back to the interviewees to fill any gaps in understanding. I sought permission from interviewees in advance.

While this research intersects with my personal journey of establishing my identity, subjectivity, and positionality in Iran, I realized that my voice and perspective cannot and should not be eliminated. I tried to employ a self-reflexive lens throughout the research process to explore and identify my position that was sometimes invisible and sometimes visible. It also made me reflect on many private moments in my life and of my family, in particular our interactions with the broad processes of the Revolution and resultant social divisions of middle class based on the level of religiosity, Pro-revolution government sponsored moralistic views on sexuality, informal Occidentalism, mass desires for migrations in the middle class, marital laws and patriarchy, and finally postcoloniality in everyday life. 
I needed to elicit life stories to learn about the impact of modernities and postcoloniality, governmentality, and resistance on making white marriage a new space for intimacy. To do so, I paid close attention to the terms, concepts, and discourses that the interviewee chose to rationalize their decisions within intimate relationships. For example, I used words that they use to describe their relationship, If they chose "Sharik zendegi in Farsi" or "partner"; "dostpesar/dostdokhtar in Farsi" or "boy/girlfriend," "hamsar in Farsi" or "wife/husband"; "Namzad" or "fiancée/fiancé," or/and only the name of their partner. I did not change their specific uses. The way that informants shape the discourse of the interviews helped me learn about their embodied values and selfunderstanding of body and love. For example, a person who uses "fiancée/fiancé" perhaps understands white marriage as a stage prior to marriage.

I also took extensive field notes at every opportunity. These notes were typed and saved as separate documents. For each interview, I also documented observations before, during, and after, In addition, I made note of the more informal day-to-day observations, conversations, and "small talk" I overheard during my travel to Tehran, at friendly or familial gatherings, or in the streets more generally. All formal and informal data are documented using pseudonyms, following the Tri-Council Ethical Guidelines and Carleton University's Ethics Protocol. In order to facilitate data organization and coding, I entered individual pieces of data into a series of spreadsheets and organized the material according to different types of data collected.

\subsection{Textual Data}

My primary interest in the study is in examining how meanings of cultural practices such as white marriage is constituted. As discussed in the introductory remarks in this 
chapter, to accomplish this task, I have used two main sources of data: interviews and textual data. Including textual data, specifically media narratives, extends the focus on people in white marriage to the context that they live in. Contextualizing the topic in media narratives can expose the role that various power discourses play in shaping white marriage and second it reveals how the phenomenon of white marriage is understood in the broader Iranian society. Textual analysis allowed me to ground the study in a particular set of social relations and to figure "out" meanings from the media depictions of such intimate relationships. Moreover, content analysis of textual data contributes to examining cultural meanings extrapolated from my interviews. This is especially important in the case of sensitive sex-related and illegal topics, such as white marriage that requires a high level of mutual trust, thereby making data collection an especially difficult and long process, and also often placing limits on the number of interviews and willing participants.

As content analysis broadly centers on textuality (Ruiz, 2009), I use the term content in a very specific sense - written and published news texts, whether on-line or printed in hard copy. Choosing a thematic approach to content analysis (Welch, et al, 1997; Ignatow, 2016), I focus on manifest meanings in texts (Mohr \& Bogdanov, 2013). To accomplish this task, as Ruiz (2009) asserts, I examine the selected data on three levels, which moves from textual to contextual analysis and finally aims to provide interpretation.

Similar to interviews, I am well aware that meanings of texts are also open to multiple interpretations and thereby influenced by positionality (the social location of the researcher). As a text analyst and subject who reads the texts, selects the relevant 
elements, and establishes the pertinent relations or significances (Ruiz, 2009), also who engages in producing knowledge, I have a unique standpoint. I sought to not only find the obvious meanings embedded in the text but also seek to understand how it is produced. That is why, I tried to formulate interpretations in as explicit a manner as possible.

For content analysis, I examined and coded the news coverage of white marriages in three sets: selected mainstreams Iranian daily newspapers, three Farsi news websites produced in Iran, and also three Farsi news websites maintained outside of Iran. In total, I coded 58 new articles, from the seven mainstreams Iranian daily newspapers, and six Farsi official news websites. The sample period is 27 months, between March $21^{4}, 2014$ to June 21, 2016 (or in Iranian calendar: Farvardin 93 to the year of Khordad 95 in Iranian calendar, which corresponds to March 21, 2014 to June 21, 2016 in western calendar. Sampled newspapers include Etemad ${ }^{5}$ (in English, Trust), Shargh ${ }^{6}$ (In English The East), Keyhan ${ }^{7}$ (In English the universe), Resalat ${ }^{8}$ (in English Prophecy), Jame jam ${ }^{9}$ (the glass in old literature that could show the future), Donyay Eghtesad ${ }^{10}$ (In English the World of Economy) and Iran. These newspapers were accessed on the internet. They

${ }^{4}$ The first day of year in Persian calendar

${ }^{5}$ Etemad is a morning newspaper that was established in 2002. It is owned by the Etemad Meli Party and is considered a reformist Iranian newspaper.

${ }^{6}$ Shargh is a morning newspaper that has been published since 2003. It is considered one of the reformist Iranian newspapers.

${ }^{7}$ Keyhan is one of the oldest newspapers in Iran, established in 1953. It is considered the most conservative Iranian newspaper after the revolution.

${ }^{8}$ Reslat was first published in 1987. It is considered a conservative Iranian newspaper.

${ }^{9}$ Jamejam has been published since 2000 and belongs to IRIB.

${ }^{10}$ Donyay Eghtesad is a morning newspaper that has been published since 2002 and is owned by the Donyay Eghtesad Taban Company. 
were selected on the basis of its accessibility in the Iranian Magazines Information Bank (Magiran.com) available in Canada. All the newspapers are published at the national level and in Iran's official language, Farsi. This selection includes both conservative and reformist (two main political parties in Iran) newspapers.

With the proliferation of information communication technologies and digital archives, there is a pressing need for the development of machine-assisted text analysis methods (Ignatow, 2016) that guarantees the collection of balanced representative samples in ways that reflect social reality. I used the keyword "Ezdevaj sefid" or white marriage to find 80 news items in the selected archives. After reviewing all of them, I selected 17 articles, which were more directly related to the topic. In some cases, white marriage was discussed as a brief example or a marginal discussion in relation to other central themes. I did not include these news items; instead selecting only those news articles that discussed white marriage as their central focus. My investigation indicates that there was a high concentration of coverage about white marriage after March 21, 2014 (Farvardin, 93).

The second source of textual data is the coverage of white marriage in three Farsilanguage western news websites. The three selected websites included: BBC Farsi ${ }^{11}$, $\mathrm{DW}^{12}$ and Radio Farad ${ }^{13}$, which broadcast from Britain, Germany, and the United States.

${ }^{11}$ BBC Farsi: The Persian Service of the BBC WS web page launched in1996 to Iran, to Afghanistan and to Tajikistan where most of population speak in the same language. This webpage is one of the most visited in Farsi language, especially popular among the Iranian Diaspora which covers different news related to politics, culture, sport and economy. It was blocked in Iran in January 2006 (Torfeh \&Sreberny, 2010).

${ }^{12}$ DW Farsi: This radio, based in Germany, broadcasts since 1962 in Farsi and the website has been launched in 2003 and covers different types of news from Iran and the world related to economy, politics, science, art, etc. (fa, Wikipedia, 2017). 
All three websites are among the most visited in Iran and the Iranian diaspora and available in the official language Farsi. While these websites are filtered in Iran; many people in Iran still access them to hear or to read news with a variety of perspectives. Within the 17 selected articles, I sampled and coded nine of the most informative texts related to white marriage. The third group of textual data included in three main news agencies $\operatorname{ANA}^{14}(8), \operatorname{IRNA}^{15}(11)$ and $\mathrm{YJC}^{16}(13) .32$ articles were selected from these sources. I used a combination of stratified selection (by year and month) and thematic selection to process collected data.

I employed codes which helped answer three questions: 1) how the authors expressed explicit and implicit messages about white marriage; 2) the voices that were included/excluded or dominant/silenced; 3) changes in attitudes and representation of white marriage over the time period selected. For the first question, I identified six thematic categories: moral, religious, medical, economy, demographic, and western oriented statements. For the second question, I found four main groups: local government, lawyers, academics, and representatives of religious institutions. In the

13 (Radio Farad: is the Iranian branch of the U.S. government-funded Radio Free Europe/Radio Liberty RFE/RL) external broadcast service. Radio Farda's new website was launched in 2006 and receives over 3 million-page views every month. It broadcasts political, cultural, social, and art news with an emphasis on Iran (en, Wikipedia, 2017)

14 ANA is The Islamic Azad universities- funded webpage. Beginning since 2004, this webpage covers cultural, political, social and economical news aiming to expand communication in academia (Ananews, 2017).

${ }^{15}$ The Islamic Republic News Agency, or IRNA, is the official news agency of the Islamic Republic of Iran. It is government-funded news agency from 1932. It broadcast in many different languages (En, Wikipedia, 2017).

${ }^{16}$ YJE is the official news agency of the Islamic Republic of Iran Broadcasting (IRIB), It broadcasts news in Farsi, Arabic and English in different areas (Fa, Wikipedeia, 2017) 
official media, white marriage is usually discussed by political/religious representatives, lawyers, academics and social activists (Ananews, 2014; IRNA, 2016; ISNA, 2015). However, couples involved in the white marriage could rarely have a voice for themselves in the media. Consequently, their perspectives about commitment are largely absent in public discourse. The overseas media (BBC, 2016; Boghraty, 2016; KarimiMajd, 2015), on the contrary, often refer to interviews and quotes. For the last question, I evaluated the positive and negative messages regarding white marriage and I outlined shifts (if any) that occurred over time.

In sum, the project draws on an interpretivist, qualitative study of white marriage in Iran. The primary data informing this study was mainly collected through interviews with 16 women and men who engaged in white marriage in between 2006 to 2016. Also, I analyzed and coded my personal fieldnotes as well as those from a public seminar about white marriage that was held by Iranian Sociological Association, November 2017 in Tehran. In addition, I employed media analysis of three set of sources of textual data: selected mainstreams Iranian daily newspapers, three Farsi news websites produced within Iran and also three Farsi news websites that are maintained outside of Iran. 


\section{Chapter 3. IRANIAN MARRIAGE AND THE FREEDOM TO \\ CHOOSE}

This chapter contextualizes the emergence and evolution of white marriage in Iran's prevailing marital culture, as well as Iranian understandings of western marital culture. Of the many continuing and contested changes that have contributed to the increasing phenomenon of white marriage among the middle class, I have chosen three factors to discuss in detail: first, the modernization project that was styled after the west before the Revolution of 1978. The 1978 Revolution changed the approach to modernity. Secondly, various governmental actions after the revolution demonstrated a new understanding of modernity. Thirdly, the accelerated global diffusion of western culture resulting from the exponential growth of information technology and its cultural and societal influences that created a new imaginary understanding of westernized modernity. I discuss how these factors in combination changed the everyday lives of the middle class in Iran. In particular, I argue that these factors contributed to profound changes in the lives of women by effectively reducing male dominance and the persistence of patriarchy in Iranian society.

Attributable to these changes, women gained further access to public spaces, education and professional opportunities, in turn establishing the context for white marriage. Consequently, while the lived experiences of women and men have changed over the last two hundred years, women's lived experiences have changed dramatically in the post-Revolutionary context. I discuss here the changing lifestyles of middle class women and their chosen methods of partner selection before and after the 1979 Revolution and its relation to the diffusion of information technology, which provided 
access to representations of western marital culture. I argue that these changes in Iranian society constitute the social context in which white marriage prevails. Young Iranian middle class men and women increasingly seek to experience the freedom of choosing their life partners in an egalitarian setting with minimal parental supervision, contributing to their construction of the modern self.

In the first section, I briefly trace the evolution of the Iranian middle class from the pre-modern era (1785 to 1925), modernization styled after the west (1925 to 1979), to the current post-evolutionary Iran. To avoid over-generalizing, I shed light on the internal differences of the middle class in pre-revolutionary Iran, including the old middle class, the secular and modern middle class, and the Islamic middle class (reformist and conservative) in post-revolutionary Iran (Afary, 2009). In particular, I discuss the shifting patterns and attitudes towards marriage and partner selection.

\subsection{The Institution of Marriage in the Middle Class before the Revolution}

This section begins with a discussion of marriage and partner-selection under the Qajar dynasty (1785-1925), which set the path towards modernity thereby gradually changing the makeup of the middle class. There is a long history of marriage and partner selection as it relates to socio-economic class (Afary, 2009; Mahdavi, 2009). To explain this history, I will also draw on Foucault's (1978) theorizations of sexuality and its relation to the historicity and construction of class. Perceptions and performances of sexuality in the Iranian middle class is dynamic (Afary, 2009). I focus here on changing women's lifestyles and strategies for partner selection among the middle class under the Qajar dynasty (1785-1925), followed by the influence of modernization that further divided the middle class into the old and secular. 


\section{The Qajar Dynasty}

Under the Qajar dynasty, the old middle class was associated with the bazaars (artisans and merchants), clerical families, and led by religious leaders. Gastil (1958) noted that many men of the old middle class were well-educated and that their loyalty was to religious and cultural values. Women in this category married based on previously made relationships and usually focused on procreation as opposed to emotional or sexual fulfilment (Afary, 2009). In this pre-1930 era, respect for one's husband was more important than intimacy and therefore the primary societal and familial expectation from women. In comparison, emotional relationship between middle class husbands and wives was marginalized (Azadarmaki \& Bahar, 2006). Furthermore, high fertility was normalized and privileged by the family and it was normative for women to be asked by extended family to change their priority from sexual desirability for their husband to motherhood and children soon after first childbearing (Afary, 2009).

Related to this point, Hamid, one of my interviewees shared and criticized his parents' relationship, demonstrating the persistence of such forms of marital relationships among the previous generation. ${ }^{17}$

I was born in a large home in a small city that my parents, other siblings, grandmother and young uncles lived together. I do not believe that my parents experienced an effective and meaningful relationship, they had no idea about love. Each one separately lived in their own world. They believed that anyone should eventually marry and have children. Marriage for them was a normative response to sexual needs and reproduction. (Hamid, male, 32)

${ }^{17}$ Nevertheless, there are no formal statistics available on silence or emotional divorce Salek (2006) estimates that people who live together without affection, is two times more common than formal divorce, which included 175,000 cases in 2017. This is the highest rate of divorce in Iran's recorded history. 
Intimate interactions between women and men in the middle class were mostly limited to relatives, who restricted partner selection to arranged settings under the careful eye of families. Men predominantly populated public spaces, while women were restricted to the home. Gendered division of space could be seen even at home's structures, including "a private part of home for women (andaruni) and a semi-public space for men" (birooni) (Shahrokni, 2013,2). Mobility across a public space for women was only possible if they fully covered all parts of their body except their eyes "representative of being inside a mobile andaruni "(Abu-Lughod, 2002, p. 785). Despite such barriers to mobility and visibility, according to Shahrokni (2013), women's daily errands in the bazaar, a clothier's, or public baths would inevitably lead to them crossing paths with men other than their relatives. These brief interactions however were insignificant and did not offer an alternative to partner selection outside of familial relationships.

Moreover, such brief encounters were associated with depraved women or with those from the lower classes, since only women of these classes were obligated to leave the alleged dignity of the private andaruni (Najmabadi, 2005, 153). Thus, a woman's presence in what is designated as male-dominated urban spaces, such as a bazaar, was a signifier of her belonging to a lower socio-economic class. In particular, domestic workers, as Shahrokni (2013) describes, usually ran errands for women of the higher classes. Often women of the higher classes brought their errands home, including inviting the bazaar merchants, the clothier, and the hairdresser to feminized and protected private spaces in the home. These higher-class women were seen as privileged and as a result frequently given "exclusive access to public baths and the streets" (Shahrokni, 2013, 
3)leading to the baths at specifically scheduled times (Shahrokni, 2013). In other words, public baths and even the streets to them are transformed to private spaces to facilitate women's access. This flexibility of public and private spaces to restrict women's movements demonstrates the societal value placed on protection from "Ekhtelat" or mixing among genders (Najmabadi, 2005, 153).

By the early twentieth century and towards the end of the Qajar dynasty, Iranians began travelling for education and business to mostly European countries. Simultaneously, the entry of foreigners and their correspondents into Iran increased (Azadarmaki \& Bahar, 2006). These changing patterns of mobility introduced discourses of modernity to Iran. It was also at this time that the first generation of Iranian feminists started to establish associations, write for newspapers, and claim their rights on a very small scale (Fathi, 2004). Despite the dissemination of the discourse of modernity and the emergence of Iran's urban society, urban spaces continued to be men-only. However, the gender division, restrictions placed on women mobility, and their depictions as "backwards," became sources of shame for Iran's modernizers (Shahrokni, 2013). In particular, male modernizers prioritized the desegregation of men and women. As Najmabadi, a female Iranian-American historian and gender theorist at Harvard University, says, the desegregation aimed to “overcome women's backwardness (to transform them into companionate wives, educated mothers, useful citizens)" (154). Moreover, Najmabadi explains, "[t]he modernist project of hetero-normalization of sexual morality and hetero-socialization of public life called for a re-envisioning of marriage from a procreative to a romantic contract" (2004, P: 367). Thus, the societal mixing and interactions of genders in public spaces became one of the important items in 
the modernization agenda. This however was not the primary concern of women's associations.

Women's groups in 1906 pursued four key aims: education for women, women's right to vote, a change in family law, and the dissolution of veiling (Yeganeh, 1984). They believed that this could best be achieved through the education for women (Hoseinkhah, 2017). These early women's movements were constituted of women from higher socio-economic backgrounds, including the extended royal family who had the distinct privilege of access to education (Yaukacheva, 1959). It was their efforts that resulted in a few schools for girls that gradually paved the way for future social changes brought about by the following generations of feminists.

Afary (1996), a female U.S.-based Iranian author, feminist activist, and researcher of Iranian history, religious studies, and women studies explains that in their long-lasting efforts and sacrifices, these first-generation feminists usually faced severe patriarchal resistance, forcing the shutting down of their newspapers and associations. In some cases, they were also physically attacked. This explains why most women writing during this period for newspapers and magazines used pseudonyms (Afary, 1996). An important theme that women activists wrote against was the unequal marital laws that permitted non-consensual polygamy, child marriage, mandatory marriage, and unequal and unjust divorce laws (Houseinkhah, 2018). The problem of unjust martial laws was indiscriminate, affecting women from all socio-economic classes in Iran. Even Tajalsaltaneh, the feminist daughter of Naser-aldin Shah, wrote about her painful experience of mandatory marriage when she was only eight years old (Etehadieh \& Sadvandian,1992). 
During the late Qajar dynasty, before the establishment of Reza Shah's monarchy, women's associations had similar aims and concerns, such as changes to marital laws, opportunities for education, and the recognition of women's choice with regard to veiling or unveiling (Sarnasarian, 1384). Veiling was mostly understood as a symbol of female subordination in a society that ignored women's agency. However, when Reza shah banned women associations, the dual policy of the dictatorship destabilized the unity and agreement among women's associations, which I discuss in the next section. Moreover, it is important to note that early women activists did not understand Islam as an anti-woman religion (Najmabadi, 2013), but rather they criticized men and clerics as the advocators of unequal laws. Despite this distinction, feminist activities began to be viewed as antiIslamic and attempting to change sacred laws, such as polygamy (Houseinkhah, 2018). The diverging views on the role and state of religion divided many women from the feminist associations and activities.

Moreover, modernity was viewed by many in either the traditionalist and reformist groups as an anti-Islamic activity, which was the view of early modernist intellectuals. For example, Mirza Fath 'ali Akhundzadah (1821-78), the most outspoken in his defense of secularism, makes an oppositional binary between religion (Islam) and modernity. He viewed religion as the main barrier to modernity and in turn social progress (Sanjabi, 1995). Mirza Fath 'ali Akhundzadah condemned the marital and sexual practices associated with arranged marriage, temporary marriage, and polygamy, which had been practiced for several centuries. Instead, he advocated for monogamous marriage based on the western notion of romantic love (Najmabadi, 2004). Influenced by the Eurocentric view of romantic love, his approach privileged romantic love, as it is exclusively defined 
in Euro-American culture (Jankowiak \& Fischer, 1992). Nevertheless, falling in love with someone outside of the family network and having this as a basis for marriage remains unacceptable in Iran (Najmabadi, 2004), especially because it was against social and classed order.

Iranian literature about love, sexuality, and marriage in the early twentieth century also indicates a rejection of new discourses of love-based marriages. Two genres became highly popular: firstly, the sexualized moral tales warning of urban corruption and of abusive men manipulating of naive young (often rural immigrant) women in the new cultural atmosphere of unrestricted socialization between men and women; secondly, influenced by old ideas related to chastity, "pure" romantic tales with no intimations of sexuality or love-based marriages (Najmabadi, 2004). These popular genres, according to Najmabadi, demonstrated the unpopularity of romantic love as a reliable basis for marriage. The main message of these tales was that love-based marriage should be abandoned in favor of arranged marriages and it should be based on the insights of the elders, and on kufv (social, class, and cultural matching), rather than on sexual desires that encourage transgressing class boundaries (Najmabadi, 2004). Thus, love-based marriages and the freedom to choose a partner outside of the family network was portrayed as a threat to the established way of life and representative of the collapse of familial and class order, which would ultimately damage the moral fabric of society.

In summary, the cultural and political debates in Iran since the middle of the nineteenth century privileged the notion that true love between a woman and a man would gradually develop after marriage in the many years of married life to follow. This form of true love and partnership could only be achieved through arranged marriages, 
which are blessed by parental guidance and approved among extended family. However, as I discussed at the start of the section and will elaborate on in the next, major westernstyled policies that aimed to modernize gender relations with gender desegregation in public and unveiling of women gradually laid the groundwork for alternative methods of partner selection and increased the possibility of the freedom to choose in the realms of love, marriage, sexuality, and the construction of the modern selfhood.

Pahlavi Dynasty (1925-1979)

In the late 1930s, inspired by the Ottoman Empire, the former Soviet Union, and western Europe, Reza Shah ${ }^{18}$ attempted to introduce sweeping modernization policies in Iran to reconstruct Iranian nationalism (Ze'evi, 2006). In doing so, he invested in the modern legal system and the modern education system, as well as a new army and health institutions. Moreover, in creating and reproducing nationalist ideologies, he also seriously considered a "reconstruction of boundaries between genders" (Bahbah, 1990) in order to change gender relations. He believed that the nation could not be modernized without bringing about change for women. As Najmabadi (2005) also mentions, the Pahlavis' modernizing discourse focused on the importance of gender desegregation and unveiling as a transformative way toward communal assimilation (Yuval-Davis, 2004) with the west. Women therefore were seen as "modernization signifiers" (Shahrokni, 2003, 4).

Eleven years after Reza Pahlavi was appointed as the legal monarch, desegregation and unveiling of women became official state policy in 1936 (Shahrokni, 2013). The rule

\footnotetext{
${ }^{18}$ The first legal monarch after the Qajar Dynasty.
} 
banned women from wearing the chador ${ }^{19}$, scarf, or bourka. His preferred mechanisms for reconstructing gender relations towards increased gender equity were desegregation and unveiling policies, which would in turn modernize (that is, westernize) Iranian women and encourage them to become full and contributing citizens in society. He applied sovereign power to permit police officers to hit women wearing a hijab on the street or in a public space and prevent them from entering schools. Surprisingly, he also adopted a policy, banning all women's associations and their activities (Houseinkhah, 2018). This aggressive policy, as Housinkhah (2018) explains, resulted in a dual reaction among women activists: including objection and support. Afzal Vaziri, activist, objected this policy and wrote an article on this discrepancy and paternalism in the Shafagh newspaper in 1932 before unveiling became formal policy. She argued, "government should stop the unveiling policy and should leave women free to make their personal choices, to neither rule the wearing of the chador, nor to prevent taking it off' (Ahmadi khorasani, 2012).

Ahmadi Khorasani (2012), a female Iranian author, translator, essayist, journalist, and women's rights activist based in Iran, argued that hitting women on the street and dissolving their associations further demonstrate that the unveiling policy was in effect Reza Shah's patriarchal decision to control women's bodies rather than liberate or empower them. She adds that the decision was not in recognition of their right to be free, nor did it respect a woman's agency or right to make her own choices; rather, it was dictated by the sensibilities of men who travelled to the west. Male travellers saw that

${ }^{19} \mathrm{~A}$ form of hijab, the most used at the time, that completely covers women's body and was mostly used in urban areas. 
changing a woman's way of dressing was a way to transform society from traditional to modern. That is why some women activists opposed the unveiling policy altogether. Nevertheless, the majority of women activists preferred to stay silent or to accept it. Moreover, Ahmadi Khorasani (2018) believes that women activists had been previously faced harsh resistance or denial of traditional society including traditional women, that is why they did not object to the mandatory unveiling in support of traditional women those who were mostly willing to keep wearing the hijab.

After the dissolution of independent women's associations, a governmental association named "Kanon Banovan" Ladies Center was formed under the supervision of Shams Pahlavi, the daughter of Reza Shah (Ahmadi Khorasani \& Ardalan, 2003). Many women activists and intellectuals joined and supported it. In this governmental association, they could participate in national projects and social engagements. A few female activists who resisted joining this government-sponsored women's association remained isolated and as a result unwillingly stopped their activities. Sansarian (1982), an Iranian feminist and professor in the United States, argues that the reasons why almost all women activists became absorbed into the new governmental organization was: firstly, the government was actively shutting down all possible movements and organizations that were not within its control; and secondly, women's movements were often based on weak ties and lacking a clear mission or vision. These organizations were highly intellectual in a way that limited communication with women from other classes, thus compromising their support. Moreover, the consistency between what women wanted and what governmental programs provided, such as public education for women, encouraged them to join and to accept governmental policies, thereby instigating change from within 
existing structures rather than resisting it. All policies of Reza Shah in combination created a socio-political climate in which women and men found more opportunities to meet in newly established social environments such as universities, social institutions, bars and cafés, shopping malls, and supermarkets (Mirmiry, 2011). This policy remained intact with the change in power from Reza Shah to his son Mohamad Reza Shah.

Some of my interviewees' parents first met in public environments that demonstrate the result of this change in subsequent decades:

My mom was a nurse and my dad was a soldier, they met when my dad injured in the war and got married and immigrated to Tehran. (Fazi, female, 30)

My parents were non-religious, identified themselves as supporters of left-wing parties, especially the Socialist People's Party. All my childhood I was a little observer of political debates about left points of view. My parents met in one of these meetings. (Pouria, male, 40)

During Mohammad Reza Shah's reign (1941-1979), besides continuing modernization policies, the Family Protection Act (1967 and 1973) reformed laws for women. These reforms legislated restrictions on polygamy, raised the legal age for marriage for girls, and gave women some divorce rights (Moghadam, 2016). Following these legislative changes, women of upper and secular middle class could pursue education at universities and many women from different classes entered the workforce that formed a new urban middle-class lifestyle. As a result, supported by state-sponsored policies advocating modernity, the secular upper middle class and middle class gradually emerged, comprising of landowners, merchants, and manufacturers, as well as a larger group of army officers (Gastil, 1958). These changes pushed women (of the middle and upper classes) out of the privacy of their homes and into the public urban areas, challenging old middle class assumptions that mixing with men was a signifier of 
backwardness, and suggesting it was instead a marker of modernity (Shahrokni, 2013). I believe this is an important shift for middle class to understand gender relations.

As I mentioned, mandatory unveiling was also an attempt to modernize Iranian women to appear like western women, or rather an attempt to exhibit them as signifiers of Iran's progress. Grounded in modern Eurocentric gender conceptualization, communication between young women and men gradually increased in public spaces such as cafés and clubs, and also was promoted in mass media such as radio and television (Mirmiry, 2011). Taking its cue from western modernity, following western fashion and consumerism became an important part of the secular middle class lifestyle. As the middle class found opportunities for public education and for going to the university, and as they sought employment, they also expected more romantic and sexual intimacy in their marriages (Afary, 2009). Despite the state's efforts to modernize Iranian society and to eliminate factors that differentiated and subordinated Iran in relation to the west, Iranian society remained quite conservative regarding men and women's intimate interactions.

Although men and women were officially encouraged to interact freely at work and in the public domain, women were still socially restricted by cultural codes of feminine behavior, feminine dress, and speech (Shahrokni, 2013). In addition, secular public spaces such as cinemas, universities, and parks continued to be seen as immoral, unethical, and anti-Islamic environments for women by the old middle class. Alienated from public life, women of the old middle class mostly continued their existing lifestyles, such as marrying and giving first birth at a very young age, not attending postsecondary schooling, giving multiple births, and housewifery. 
By 1970, the gender gap in the job market increased. The rapidly rising revenues from oil were ploughed into capital-intensive industries, created more jobs in oil industry that had been dominated by male workers. Consequently, capital-intensive industries enforced the gender gap in the job market (Moghadam, 1995: 176). Meanwhile, women's opportunities increased in the service sector. Women in the secular middle class mostly benefited from the new job market, but women in traditional middle class and unprivileged classes were alienated and had minimum participation in the growing service economy in Iran (Bahramitash \& Esfahani, 2011). Less than a decade later, in 1979, the massive involvement of old middle class women and women from the unprivileged class in the revolution, demonstrated their alienation from the prerevolutionary regime and their demand for change. The revolution facilitated the emergence of a third group of people between secular and old middle class that hybridized a "Shia-style of religiosity" (Afary, 2009) with westernized modernity. During the $\operatorname{war}^{20}$, also massive participation of old middle class women and women from the unprivileged class repeated that I will unpack further in the next section.

\subsection{The Institution of Marriage in the Middle Class during and after the}

\section{Revolution}

As discussed at the start of the chapter, the transformation of the middle class and its internal differences is associated with socio-historical events: first the revolution, then the

20 The Iran-Iraq war was an armed conflict between Iran and Iraq, beginning on 22 September 1980, when Iraq invaded Iran, and ending on 20 August 1988, when Iran accepted the UN-brokered ceasefire. (Wikipedia, 2018) 
war, and finally post-war rebuilding policies. After the Islamic Revolution ${ }^{21}$ ended the Pahlavi dynasty in 1979, many changes occurred in Iran and in the world that brought about further gradual changes to family structure, the institution of marriage, and partnerselection patterns. These changes set the stage for the conceptualization, emergence, and evolution of living in white marriage.

\section{The Islamic Revolution}

This section focuses on the transformation of middle class women's identities, attitudes towards marriage, and strategies fort partner-selection, following the revolution. The political shift in political post-revolution Iran goes beyond a simplistic resistance to western modernity. It was also a way to cultivate a "Shia Muslim style of modernity" (Afary, 2009) that changed some of middle class women's understanding of religion and social life. Bahramitash (2006), an Iranian sociologist and researcher in Canada, argues that the change in the idea and understanding of the middle class facilitated a move away from the historical binary between Eurocentric modernity and Islam. It shed light on the third space that modern Shia Islam made for women (Bahramitash, 2006). This section concludes with a discussion of the shifting familial context that led to white marriage.

${ }^{21}$ The revolution in 1979 was named Islamic in many literatures (Arjomand, 1988; Dadashi, 2017; Milani, 2018; Algar, 2015; Taheri, 1985), because of its sprit in last days of victory and after and because of its leadership by a Marja Taghlid cleric, even though there were many different social groups and parties involved in the process, the Islamic faction of revolutionary forces and the religion played an important role for mass unity, support or tolerance (Behnia, 1993). The revolution is also termed Iranian revolution in many other academic works to acknowledge all many different social parties, different class and simply different people who contributed in (Afary \& Anderson, 2010); (Stempel, 1981); (Rasler, 1996); (Kurzman, 1996). This question is not the concentration of my project. With respect to all parties that contributed in the process, I choose to use Islamic revolution, because of Islamic faction of revolutionary forces. 
During the revolution, leftists, nationalists, Islamists, and a variety of social groups including women and men of the middle class and the working class participated and fought to overthrow the Pahlavi dynasty (Moghadam, 2002). However, the dominant revolutionary discourse that united them was based on Islamic spirituality or what Foucault calls "political spiritualty" (1978: 49). Ayatollah Khomeini, a well-known Marja Taghlid cleric, who was acknowledged and accepted as the revolutionary leader by the majority of Iranians, initiated a new form of nationalism based on Shia ideology. This explains why many women from different social classes who participated in the protests gradually began to wear the hijab and exhibit their collective solidarity (Afary, 2009). In addition, women from the old middle class who traditionally wore the hijab and who were alienated from public spaces joined the revolutionary forces. Thus, wearing the hijab and not wearing a tie (as was the western dress code) became the basis for constructing larger "collectivities" (Lutz et al,1995,12) and the symbol for creating a social solidarity among revolutionaries from different social classes. Nevertheless, there are scholarly debates on the meaning of head scarf for women.

Shirazi (2001), an Iranian professor and a researcher of Islamic studies in the United States, believes that for protesters, the hijab became a symbol of being modern, as socially active women resisted to be seen as western "dolls". Apparently accepting the hijab transformed the revolution as an inclusive space, accepting women from all social classes. Nevertheless, the popularity of the hijab as a symbol of the revolution led to compulsory veiling for women based on Sharia law soon after the revolution. Gradually, leftists and liberals who could pluralize revolutionary acts and decisions, such as making the hijab mandatory, were also marginalized or eradicated (Moghadam, 2002). A protest 
by thousands of women against the mandatory hijab took place on March 8, 1979 in Tehran (Shirazi, 2001), but it was ignored in the turbulent days and environment of the newly established government. Following the revolution, many radical decisions were made that directly affected women, such as negating family protection law, banning contraceptives (Moghadam, 2002) and putting in place segregation policies for some public spaces and for some organizations (Shahrokni, 2013). Eventually, a regressive political process again constructed boundaries for and influenced gender relations in an authoritarian manner. Moreover, the revolution also deeply influenced and eventually entrenched class divisions and restricted class mobility on a large scale. This is what I discuss in the next section on the transformation of the internal differences of the middle class.

\section{The Revolution and Transformation of the Middle Class}

After the revolution two different groups within the middle class, associated with a Shia-style of modernity, emerged: a new "Islamic reformist middle class" (Afary, 2009) and an "Islamic conservative middle class". These internal categories usually departed from the old middle class and the secular middle class. The revolution, the broader political climate of the time, and the profound and unexpected Islamic-spiritual environment, also known as the "political spirituality" (Foucault, 1978, 49), caused many Iranians to rethink their religious or secular identities. This is one of the reasons that new group within the middle class emerged. Some from the secular middle class redefined themselves as the Islamic reformist middle class; and others from the old middle class affiliated themselves with either conservative or reformist middle class categories. The revolution also provided a wide range of services and new opportunities for mobility for 
the working class (Bahramitash, 2013) and for the Islamic middle class, either reformist or conservative. For example, the revolution promised public housing, public schooling, and public transportation (Shahrokni, 2013) and prioritized providing them in disadvantaged areas. Shortly after the revolution, the voluntary organization, Construction Jihad, was initiated to serve the 1979 harvest, but gradually took on a wider, more official role in rural areas (Keddie \& Richard, 2006). Road building, piped water, electrification, clinics, schools, and irrigation canals were some of the services (Keddie \& Richard, 2006) as well as providing "extension services, seeds, loans," etc. (Bakhash, 1984) to small farmers. Meanwhile, previously established opportunities for the secular middle class were lost (Moghadam,2002) and people from the Islamic middle class replaced them in the education system, the army, the ministry of foreign affairs etc. The uneven distribution of wealth, opportunity and advantage, which did not favor the secular middle class in many cases, led to many from this group to immigrate to the west (Moghadam, 2002) or motivated them to redefine themselves as the Islamic middle class or at least to recast their lifestyle.

Women in the Islamic reformist middle class, like women of the old middle class, are religious, but similar to secular middle-class women, they are educated, and they are usually employed. In the early years after revolution there were no significant differences between the lifestyle of women belonging to the Islamic reformist middle class and Islamic conservative middle class except their political affiliation. The differences however became significant over time as the Islamic conservative middle class began advocating for traditional gender values for women. 
As already discussed, ideal womanhood became a central yet controversial theme and point of contention in modernist discourses before the revolution (Sanasarian, 1982). These discussions continued in a different way after the establishment of the Islamic Republic (Shahrokni, 2003). New definitions of womanhood assumed and claimed that women lost their dignity, humanity, and respect of the pre-revolutionary era in western and Eurocentric modern discourse. The argument was that the western woman was characterized as "a Barbie doll” and a sexual object (Osanloo, 2006, 196). The Shia-style of modernity, on the contrary, claimed the re-establishment of a new identity that combined active public life (including education, employment and political contribution) with religiosity for women. In this respect, the new regime ended the secular domination of the Pahlavi legacy, but not its modernization process in terms of urbanization (Shahrokni, 2013), or the rise in public education ${ }^{22}$, public health ${ }^{23}$, and transportation

${ }^{22}$ Literacy campaigns, which were Khomeini's call for women and men to jihad (a religious term for a fight) against poverty (Jihad Sazabdegi) and against illiteracy (Nehzat savad amozi), attracted an overwhelming volunteer-based participation of women in the 1980s. In addition, volunteer women (Basij khaharan) were trained in basic first aid and went into battle during the wars between Iran and Iraq in 1980 (Bahramitash, 2013). Mosques all over the country became schools for adult men and women, increasing female education rates and eventually female employment rates. More importantly, this led to the mobilization of female volunteers, especially religious women, which challenged the taboo of women in public spaces in Iran. There is a similarity between this period in Iran and the first-wave feminists of the late nineteenth century in the west, during which time women began to raise their voices and to express themselves collectively in search of social and moral reform, as well as the period of the two World Wars, after which women challenged gender norms and cultural inequalities, particularly in the 1960 s to 1980s (Prentice, 1996).

${ }^{23}$ By the late 1980s, active family planning began with a social/political program that employed volunteer women working from mosque-based organizations. The family planning policy was supported by religious authorities and led to a cultural atmosphere of acceptance of the use of birth control. The policy covered different classes of women, including low-income women, traditional and wealthy women, rural families, highly educated women and so on. The national family planning policy successfully operated after 1986 due to investments and female volunteers, who worked door to door. This program not only provided education about the necessity of using contraceptives, but also made contraceptives easily accessible and free (Bahramitash \& Kazemipour, 2006). 
(Bahramitash, 2013). Thus, Shia-style of modernity did not simply halt or erase Eurocentric modernization style in the previous regime. However, as mandatory unveiling and women's westernized dress code in a pre-revolutionary era signified modernity and progress, after the revolution women dress code centred around wearing the hijab began to signify Shia-style of modernity and ultimately resulted in the mandatory veiling policy (Shahrokni, 2013). The previously discarded modest Islamic dress code had now been transformed into a symbol of a new era, which was markedly distinct from the Pahlavi era. In this way, once again women's bodies became a battleground for political ideologies.

The revolution and the war also dramatically transformed the labor market for women from different socio-economic classes, including the middle class, decreasing many opportunities for women from the secular middle class and opening up room for women from the religious middle and lower-income classes. These latter groups were given a unique opportunity to have an education, which could be mobilized towards employment and participation in public life (Paidar, 1997; Kian, 1995; Mehran, 2003). For example, because of the gender segregation policy in the education system, a huge need for teachers, produced job opportunities for women and in the war time demand for nursing and other sectors increased (Moghadam, 2002). I explain these changes and transformations in the next section. Altogether, women, depending on their class background, experienced a revolution in their lifestyles that also in their family and married lives. 


\subsection{The Evolution of Marriage at a Time of War (1980-1988)}

The eight-year Iran-Iraq war that began only seven months after the revolution dramatically influenced the concept of marriage. Based a study by Mirmiry (2011), a woman researcher and blogger based in Iran, the conceptualization of marriage and romantic love during the war became an ideological notion and nostalgia to return to the pre-revolutionary society. Within this highly politicized and ideological post-revolution social environment, which was further intensified by the Iraq attack on Iran, people understood and described love in the context of ideology and religion. Many people married for religious reasons to avoid being "sinful." Meanwhile, as Mahdavi (2009) discusses, love-based marriage, which was understood as a western concept, was discouraged, and the government set strict regulations against dating in public.

Thousands of young men were killed or seriously injured in the war, a situation that left countless families in crisis. Consequently, the political system strategically attempted to encourage simple and inexpensive arranged marriages at young ages. Similar to the policies introduced after the revolution, the government adopted a pronatalist policy during a time of war and contraception was strongly discouraged (Bahramitash, 2002). Instead child-bearing was likened to religious obligation, to ensure reproduction of the population that had been decimated by the war. These changes were reflected in the 1986 national census of population and housing that indicated a dramatic rise in fertility rate (Moghadam, 2002). The resulting baby boom between 1979 and 1988 and the high population growth rate alarmed policy makers and led to a reversal of Iran's wartime population policies (Abbasi-Shavazi, et al. 2009), which I discuss in the next section. 
These circumstances had another impact on women's lives, which has so far received little academic attention (Bahramitash, 2002).

As many young men left the cities to fight in the war, many women who were previously responsible for duties in the home, entered previously exclusively male public spaces to fulfil the needs of households. Women also volunteered in various national projects such as the literacy campaign and participated in war work such as nursing (Bahramitash, 2002). Women's contributions during the war expanded their horizons of opportunity and their confidence. Scholars such as Bahramitash sees these contributions as emerging from modernity in Shia context, further extending the skill base women could acquire to either volunteer or get paid for ${ }^{24}$ (Bahramitash, 2013).

Mandatory post-revolutionary dress code policies, which included wearing the hijab for women, changed the pre-revolutionary belief that secular public spaces, such as cinemas, universities, and parks were immoral and unethical environments for women as long as they were the hijab (Afary, 2009). Consequently, women who were originally from the old middle class could enjoy these public spaces (Shahrokhi, 2013) and, more importantly, could attend school and pursue a university education in their hometown or in another city (Bahramitash, 2013). Hundreds of thousands of university students went to free, state-provided, co-ed educational institutions with same-sex dormitories, which

${ }^{24}$ Census data demonstrates a steady growth in the female labour force, more specifically, in the urban setting from 1956- 2006. The employment rate for women reached 33 percent in 2006 which is above the average in the Middle East and North Africa (Bahramitash, 2013). The greatest increase was from $4.4 \%$ to $5.8 \%$ in 1996 to 2006 (Bahramitash, 2013). In addition, women's participation in the informal economy, volunteer work and unpaid production in families such as work on the famous Persian carpets a that does not is not necessarily captured in statistics. 
nonetheless provided more opportunities for dating and intimate relationships outside of familial and kinship networks and arrangements (Afary, 2009). Using public transportation and personal automobiles as well as the emergence of home-based telephones further widened social opportunities for communication between men and women and the freedom for mixed gender interactions. This changed young people's perspectives on romantic love, psychological and social compatibility, and mutual intimacy, to the extent that they could now insist on choosing their own partners. Yet, a lack of employment opportunities was the main barrier for women, making them financially dependent on their fathers. Furthermore, marital laws also extended a father's authority over his daughters in terms of partner-selection and marriage (Afary, 2009).

\subsection{Rebuilding Society after the War and Subsequent Policies}

Generations who were born during and after the war faced dramatic social changes, such as urban development, neo-liberal policies, and fast-growing consumerism that led to significant shifts in ideologies and attitudes concerning selfhood, love, and marriage. Neo-liberal policies were implemented just after the war in 1990s. Some of the consequences of neo-liberal policies were the increase in the size of the private sector, rising inflation rates, and a decrease in social care and related welfare policies (Bahramitash, 2011). On the other hand, the growing private sector opened considerable administrative jobs for women. In addition, Bahramitash (2013) explains that increasing inflation forced many women to seek jobs to help and support their families. Unlike the case in the past previous eras, women tended to continue to work even after marriage. This is related to the high inflation and heavy costs of household in the post-war society. 
The increased employment opportunities for women coincide with greater social acceptance of women's employment and a gradual fading of parental authority over marriage in the middle class, in Tehran, and other large cities. The continued support of mixed gender public places such as cafes, universities and workplaces (Shahrokni, 2013) facilitated further opportunities for the younger generation to intimately connect with men and women outside of family and friends' networks. As a result, education, employment and more generally urban spaces increased the probability of choosing a partner in engaging in alternative marital relationships.

The political environment also changed after war. Moghadam (2016) and Najmabadi (1997) discuss these policy shifts and reforms in their writings on women and gender in 1990s. The authors almost uniformly critiqued the gender segregation during the 1980s. Shahrokni (2013) also discusses that there was a discursive shift in understandings of gender issues that transformed from prohibition of social activity to encouragement of gender integration .

In the aftermath of the war, young people's understanding of romantic relationships also changed. Mirmiry (2011) notes that the younger generation in urban areas soon learned that the link between divine or religious love and romantic love is not the only way to define a relationship that they can choose. All these changes taken together gradually transformed the dominant pattern of parents finding a partner for their children to prospective partner and children requesting parental approval as more of a courtesy and out of respect (Afary, 2009). Consequently, it became increasingly socially acceptable for young women to have one or two boyfriends before marriage, and for the first time, being involved in pre-marital sexual relationships (Mahdavi, 2009). As a result 
of the increase in dating and socializing between men and women, marriage within the familial network gradually became less unpopular in some of urban areas. If a young couple faces unwavering familial disapproval, they usually date discreetly. It is interesting to note that while some families welcome their sons' girlfriends into their homes (Mahdavi, 2009) for visiting but staying overnight, it is much less tolerated in the case of daughters, creating a gendered double standard. Many families consider the boyfriend or girlfriend of their children as potential marriage candidates. Therefore, it is not only modes of partner selection that has changed but there is also a shift in the understanding of a romantic relationship and marriage.

Mirmiry (2011), in her research on familial relationships and romance in Iran, argues that romantic relationships among young Iranians are mediated and shaped by information technology, and characterized by temporality and plurality. Leaving aside the idea of "Eshgh elahi" (divine love) and "Ta akhar omr be khobi o khoshi ba ham zendegi kardan" (living happily ever after), the young generation understands romantic love as an experience that happens several times during one's life, and for short periods. This idea is also reflected in the higher rates of divorce (Aghajanian \& Tompson, 2013), remarriage, and extramarital relationships. As already explained, the change in understandings of love and partner selection must be contextualized within socio-historical events and policy changes. This is not to deny the profound influence of the global diffusion of western culture ${ }^{25}$ and the unexpected growth in the use of information technologies, which have undoubtedly accelerated and facilitated the shifts in attitudes towards

${ }^{25}$ In the period that I was in Iran for data collection, many western TV series such as "Sex and the City", "Lost" and "Game of Thrones" were widely watched by young people in middle class. Young women and men frequently referred to those TV series in their daily conversations. 
marriage, relationships, and intimacy among the urban middle class, which I discuss in the next section.

\subsection{Information Technology, Partner Selection and Romantic Relationships}

In this section, I discuss the evolution of two important communication technologies - satellite and internet technologies, which played a significant role in facilitating Iranians' access to media and cultural products of the West, which in turn influence attitudes towards partner selection and romantic relationships. I argue here that the influx of western cultural products via satellite and the internet accelerated the propagation of western ideology among the urban middle class.

Pragmatically, internet usage among the middle class has changed previous temporal and spatial restrictions on romantic relationships. Couples can maintain a relationship no matter where they are and with no time limits. Moreover, internet has extended the radius of search for a partner beyond family and personal networks (Ahmadi, 2013). Derakhshan (2017), Iranian researcher and media analyst based in the US, explains how internet content (in the Iranian environment) with emerging popular websites such as Facebook, YouTube and Instagram shifted its usage from educational, text-based, and non-linear platforms to entertainment, video-based, and personalized media. This shift has contributed to observing and in time emulating represented western romantic relationships. More specifically, the shift in utilizations of cyberspace has influenced an idealization of love-based marriage and western familial lifestyle, including a preoccupation with cohabitation.

Most of my interviewees, Ebrahim, Pouria, Maryam, Poya, Naz, Toranj, Fazi, Elaheh, Samar, Sepideh, mentioned their use of satellite TV and the internet technologies 
on a regular basis. Naz (age 30) explained that she did not watch national TV and only watched satellite TV in her free time and mentioned some of her favorite TV series such as "Suits" and "Game of Thrones" and many western movies. Navid (age 33) also recalled a memory from one of his followers on Facebook and told the story about his relationship with her to clarify his point about gender relations and fidelity. He met his partner on Instagram and then began to date. Pouria (age 40) also mentioned his photography project on Iranian Facebook celebrities. Still another example, Fazi (female, 33) was the administrator on a topic-centered group on Facebook.

The mass consumption of western cultural products and the popularity of social media are not surprizing as the end of the eight-year war with Iraq was also the beginning of a mass diffusion of information technologies. The impact of information technology has been well-documented in a political context (Sreberny \& Khiabany, 2010; Golkar, 2013; Aryan, H., \& Halderman, J. A. 2013), but it has been rarely studied in a cultural framework with a subject-specific focus such as partner selection and romantic relationships (Shakory \& Shafiy, 2015; Ahmadi, 2013). This is what I seek to contribute with my study.

\section{The Role of Satellite Technologies in a Postwar Iran}

Similar to what happens during war in general, unique situational socio-cultural contexts were created during the eight-year battle in Iran. Social and cultural constraints were implemented, including a restriction of cultural exchange, access to information on neighbouring societies, and communication with other countries through mass media (Alikhah, 2007). By the end of the 1980s, as the country entered the post-war reconstruction era, the Iranian government was initiating various modernization and 
development projects to participate in the global economy. One of the main ways of doing this was by providing access to information technologies. Nevertheless, the policies gradually reoriented their focus towards more preventive and restrictive approaches (Shahrokni, 2013).

Iranian citizens began using satellite dishes in the early 1990s, when those who lived in the rich northern part of Tehran installed dishes to access global television networks (Alikhah, 2007). Satellite television networks mostly offered two categories of programming: political and non-political. As I am investigating the impact of the satellite programs on the conceptualization of romantic love and partner selection, I restricted my focus on non-political programming, which includes reality and fiction-based TV shows, advertising, and movies. These networks generally played music produced in America (Hemmasi, 2010) and recently in the Persian Gulf countries. In this way, satellite dishes opened new horizons for a middle class whose cultural life had been localized in the war time and related the discourses. Over time, satellite networks have reached other socioeconomic classes. Frustrated with a war environment, young people in middle class Tehran and other large cities turned to satellite television to watch western young people culture, what Mahdavi calls a "global" young people culture and luxury lifestyle (2009). Some gradually developed a desire to be part of this global culture and began imitating the lifestyle and practising commercial and popular holidays, such as Valentine's Day (Mahdavi, 2009), an observance that has since become very popular in Tehran and other large cities (Alavi, 2005). 


\section{The Growing Influence of Internet Technologies on Iranian Young People}

The connection to the internet in 1991, made Iran the first Muslim nation in the Middle East to be online and the second country in the area after Israel (Rahimi, 2007). Considering the high cost of purchasing a personal computer and of using the internet, as well as the necessity for basic computer knowledge and language skills in English, most internet users were middle class young people (Rahimi, 2007). In 2014, the Iranian population was about 75 million. About 40 million people were internet users, which is about 54 percent of population, $34.8 \%$ were men and $27.6 \%$ women. It is also notable that 58 percent of all users were between 15 and 24 years old (Esmaili \& Sepehrnia, 2016).

One of the more popular applications of the internet is partner election (Skopek \& Blossfeld, 2010), and this specific use is most evident among the middle class. A cameraequipped portable device captures visual information (Robinson, etal. 2012) and such functionality is integral to facilitating virtual dating and long-distance relationships. Some of my interviewees, such as Toranj (female) and Fazi (female), engaged in longdistance relationships for a while with their respective partners, which would been challenging if not impossible without the internet.

Despite its short history in Iran, the internet has served as a medium for increasing ease and speed of communication. More specifically, electronic mail (email) has paved its way as an alternative to traditional mail; internet "chat rooms" and dating websites have facilitated young people's freedom to find, choose, converse with and date potential partners for relationships and marriage. This has profoundly changed possibilities and avenues for partner selection and dating outside of family and personal networks to 
virtual and digital networks of people from diverse backgrounds and across long distances. Middle class young people use the internet to form interpersonal relationships facilitated by a computer rather than exclusively relying on face to face interactions facilitated by family. These relationships are characterized by more flexibility in terms of time and space and has contributed to an increased sense of choice when it comes to finding a romantic partner while keeping their identity anonymous (Cooper, 1998).

In my interviews, some participants described meeting in cyber space. Toranj (female, 28) and her partner, for example, first met in Yahoo chat rooms ${ }^{26}$ and discovered that they both were interested in classical Persian music, and in particular the famous classical Iranian singer Shajarian, and also playing the setar, a Persian musical instrument. They maintained this relationship with daily chats. Fazi (female, 32) also met one of her ex-partners via a Facebook group. The relationship did not last long, but through that Facebook group Fazi and her partner learned of and discussed concepts such as liquid love (Bauman, 2003) and open relationships.

As Derakhshan (2017) argues, the internet initially was a "decentralized, textcentered, and abundant source of material, with many hyperlinks" and an extension of the world of written culture. The internet led web browsers to a variety of opinions, including reformist voices in the blogosphere. By the late 1990s, however, the vast informative environment of cyber space raised suspicion within Iran's government. Political hardliners were pushing back against the more open policies of then-president Mohammad Khatami by introducing preventive and restrictive policies on the use of

${ }^{26}$ Chat rooms are electronic venues on the Internet where people can communicate with other Internet users" (Cornwell \& Lundgren, 2001). 
technologies. The subsequent closing of dozens of reformist newspapers however had an unintended effect: an explosion of the Iranian blogosphere (Sreberny \& Khiabany, 2010; Derakhshan, 2017). As Rhoads, etal. (2011) argue not long after anti- Ahmadinezhad and the post- 2009 election demonstrations, which was arguably the largest legitimacy crisis for the Islamic Republic since its establishment, the state articulated a strategy calling for a "soft war" and "soft war soldiers" by Iran's Supreme Leader. This meant the explicit coming together of parallel approaches to both new media and new cultural products in cyberspace (Rhoads, etal., 2011). This approach of the soft war encouraged young people to create cyberspace content that spoke against political and cultural opposition. However, young people approach added more restrictive policies regarding the internet. The government not only interfered with but also participated in social media (Agustino \& Mohamed, 2015). During this time, some of Islamic conservative middle class young people used cyberspace to vocalize their advocacy of the political goals of the Islamic Republic of Iran. Unlike Islamic reformists, who are critical of the government, these young people affirmed and advertised the dominant political ideology to exhibit their loyalty to Iran's Supreme Leader and his ideas.

Gradually, according to Derakhshan (2017) Iranian cyber space shifted to more passive communication mediums, like television, and became part of the entertainment industry. In fact, the user experience was more influenced by visual displays, especially pictures, videos and shows, rather than printed material and opinion. Moreover, based on new algorithms in social networks, internet users were exposed to posts selected based on popularity and user habits; as a result, diversity, decentralization, and nonlinearity diminished and people watched only ideas that were consistent with their 
mentality. These changes and strategies presented less of a threat to political system than the time that Iranian cyber space was a platform for critical thinking, then political system did not totally prohibit the accessibility. Meanwhile, the vast usage of the internet has made the banning of western products no longer feasible (Shahrokni, 2013), which remained accessible and influential for the middle class young women and men savvy with information technology. The change in Iranian cyber space to visual content had unexpected influence on understanding of the west in the context of family.

This predominance of visual displays of western liberal progressiveness and superiority reinforces postcolonial stereotypes of romance, intimacy, relationships, and marriage, documented in several empirical western and non-western studies (Penn, (2011); Dosekun, (2015); Aguir, 2013). This dominance of the West facilitated the gradual shift in normative perceptions of romantic love, partner selection, and marriage in non-western countries, including Iran. The binary of arranged marriage and love-based marriage depicted in Hollywood movies, for example, ensures that romantic love and love-based marriages are attributed the highest possible cultural and aesthetic value (Wexman, \& Wexman, (1993). Built into the cultural construct of capitalism, not only films but also graphic advertisements represent a romantic utopia (lllouz, 1997) connected to a romantic consumer brand relationship (Sarkar, 2011). This western ideology is more appealing to Iranian young people because of their age and consequent access to technologies that circulate such ideals.

In this section, I have traced the evolution and influence of information technologies that led to profound changes in strategies for partner selection method and popular understandings of romance, love, relationships, intimacy, sexuality, and marriage among 
the middle class young people in Iran. Pragmatically, the internet mediates establishing lively and widespread social networks by linking users to each other who are simultaneously engaged in the same or similar interests. It also largely reduces the time and space barriers that previously affected relationships. Despite all governmental efforts to control the use of these technologies, the internet continues to serve various functions and facilitates access to more choices for romantic partners, for dating, and maintaining long distance relationships. Both satellite TV and the internet contribute to portraying the romantic love ideology of the West as superior, and in particular love marriage and sometimes cohabitation, as a modern, enlightened, and easier path for middle class young people to choose. Moreover, internet content aligns with satellite content and has overtaken the influence of printed material. These rapid changes to the socio-economic and cultural contexts of Iran have impacted attitudes towards the country's marital norms and understandings of partner selection and romantic love that are aligned with western ideals. Middle class young people liken the west to modernity; they transferred their desires for and imageries of being modern to their intimate lives, in other words, they seek to make their modern selves through romantic desires.

In this chapter, I highlighted, reviewed, and discussed the various socio-historical process that led to the construction, division, and transformation of the middle class in Iran, in time creating the social, cultural, and economic context for white marriage. White marriage emerges as a classed phenomenon, a change associated with the middle class and in particular a reflection of women's changing attitudes and desires to become a modern self in present day Iran. These desires were emboldened by the recent emergence of information technologies, in particular satellite TV and internet technologies, which in 
time significantly influenced strategies of partner selection method, perceptions of relationships (romantic, familial and kin), and marriage to align with young people's understandings of modernity and western normative marital and romantic culture. In the next chapter; I turn to the new phenomenon of white marriage and seek to demonstrate the connection between perceptions of relationships and young people understanding of modernity. 


\section{Chapter 4. WHAT IS WHITE MARRIAGE?}

Despite frequent discussion about white marriage in Iran's official media, the concrete data is very limited. That is why further attention must be paid to exploring information that mirrors the heterogeneous realities of life of people in white marriages. Mapping white marriage to life course events, such as documented marriage and divorce, is one way to understand the heterogeneity of the phenomenon. This categorization also explains different conceptualizations of white marriage, as well as reasons and motivations. Moreover, the grouping is related to conceptualization of commitment and attitudes regarding childbearing. I have developed three groups for better understanding white marriage, including: premarital, post-divorce, and self-regulated relationship.

In the following, after addressing general demographic remarks, first, I discuss the conceptualization of white marriage in premarital relationships as a trial, in post-divorce as an objection to marital regulations, such as divorce law, and in self-regulated relationship as a anarchises and rebellious act against marriage as an institution of governance. Second, I locate white marriage in relation to extended family systems. Finally, I examine their relationship with extended family.

\subsection{White Marriage and Demographics}

This section gives an overview of the socio-demographic characteristics of people practicing white marriage, including age, education, socio-economic class, religious background, and childbearing. As I mentioned in the introductory chapter, the prevalence of white marriage is not reflected in formal statistics by sabt-e ahval (the national registration bureau) or in any national survey. The best possible estimate is derived from 
the efforts of the Iranian Sociological Association board member Shirin Ahmadnia and her colleagues, who estimated that nine per cent of young urban adults live in white marriage and 25 percent accept the concept of white marriage unions (Aghajanian, et.al, 2018). The research is based on random sampling among university students. During my visit to Iran in 2016, I had the opportunity to talk to Ahmadnia about the subject. She said that some couples during the last census (2016) said that they live together without marital documentation, but as there is not a recognized category for white marriage, statistics are not available. Thus, the quantitative expression of white marriage is simply hypothetical, and any estimates are based on sampling. A more accurate picture would require more systematic data collection (Aghajanian, et.al, 2018). What is certain is that, based on many media reports (See: Ghodosi \& Bayat, 2014); Mohamadi, 2018; KhezrHeydary, 2018), the phenomenon of white marriage in urban areas is increasing.

People usually begins their white marriage relationships in university, when young people move away from their family networks and social constraints to metropolitan areas to study. They also find the same opportunity for white marriage when they move to large cities to find a job, thereby providing chances for socializing, romance, and in turn for white marriage. The population is generally between the ages of 25 and 40 and includes young men and women, especially who have gained the social, educational, and economic skills they need to be independent. Some of them begin living together to share housing costs during their university studies, for example. Among my interviewees, only Sepideh and Farid began their respective white marriage before the age of 25. Sepideh came to Tehran to study when she was 20 years old and her boyfriend joined her. Farid also started living with his partner when he was 21 , while both were in university. 
People in white marriage have generally attained a higher level of education and employment (Amirmazaheri, et al. 2016)). Socio-economic class and gross domestic product (GDP) are among the controversial factors associated with cohabitation in literature. In fact, because of the heterogeneity of cohabitation in different cultures, there is no consensus as to whether GDP increases or decreases the incidence of cohabitation. Some studies indicate that as GDP increases, marriage also increases, because countries with high GDP have more social security, higher standards of living, and less couple dependency in terms of financial matter. Therefore, the only reasons for wedlock would be symbolic values and psychological advantages. As a result, people in richer countries have a higher tendency toward marriage as opposed to cohabitation (Inglehart, 1997). This explanation might apply to societies such as the United States, where the pattern of cohabitation is mostly concentrated in the working class.

Opponents of this idea argue that cohabitation is partly related to achieving financial benefits and avoiding housing challenges, considering that there is a significant direct relationship between GDP and the rate of marriage (Fagan, 2010). In support of this opinion, Scandinavian countries have both a high GDP and a high rate of cohabitation. In these countries, the rate of cohabitation is high in the middle and upper classes of society, where members can certainly access material and intellectual capital (Perelli-Harris, et.al., 2012).

The average educational level of my interviewees was a master's degree. They all had a bachelor's degree and above, and one was a university instructor with doctoral degree. They were educated in fields such as graphic design, sociology, engineering, law, English literature, and photography. They worked in a variety of careers, including 
journalism, filmmaking, teaching, engineering, and accounting. I want to highlight that although the employment rate for women in Iran is not high, all the women I interviewed, consistent with Amirmazaheri study (2016), were employed and economically independent. They also identified themselves as non-religious (Amirmazaheri, et.al, 2016).

The absence of religious devotion is one of the factors that influences the choice of white marriage. A decline in religious affiliation is predictive of an increase in cohabitation in some countries, including Britain (Village, Williams, Francis, 2010), Italy (Nazio, \& Blossfeld, 2003), and Canada (Laplante, 2004; Pollard \& Wu, 1998). Thus, in some countries the rise of cohabitation is more readily explained by referring to the decline in religious beliefs. People in white marriage usually describe themselves as nonreligious. In two cases, they state "non-religious but spiritual." However, many of them come from religious families. Some came from families with parents who prayed in mosques on a regular basis. This might demonstrate a generational decline in religious affiliation among these families. In two cases, when I asked about familial background in terms of religiosity, they referred to the word "Marxist" to describe their critical approach to religion.

As evidenced in my interviews and other studies (Amirmazaheri, et al, 2016), most people in white marriage obtain a high level of education and usually have employment. It is also therefore more likely to be associated with a diffusion of secular ideas among the middle class: a set of ideas that place religion in the private domain of individual believers and oppose its "public" display. Moreover, it promotes an ideological perspective that removes the individual from religious and communal constraints and 
promotes integration into the society as individual citizens (Wimmer, 2007) with equal rights. The combination of three factors- secularity, employment, and university education- demonstrates that people in white marriage are from the secular middle class. This is one of the sub-groups of the middle class that I traced and described in chapter 3.

Childbearing is also an important socio-demographic factor in white marriage. I have devoted a subsequent chapter to the topic of fertility, however here I shall briefly introduce the relationship between white marriage and childbearing. A very small proportion of my sample report living with children in the household: only one of my interviewees lives with her partner's child. In almost all cases, the initial agreement between couples was to avoid childbearing (for ideological reasons that I extensively discuss in Chapter 5); however, some, mostly women, change their minds about childbearing as they get older. As the current legislation does not allow documentation for children born into a white marriage, the relationship remains childless. It means that although the documentation barrier did not stop the growing incidence of white marriage, it is enough of a disincentive that couples to keep their initial agreement and remain childless. Finally, it is important to mention that with one exception all my interviewees had an active immigration file or a plan to leave the country for the West. I explain this more in Chapter 5.

My analysis underlines important socio-economic factors related to white marriage, including age, education, socio-economic class, religious background, and childbearing. Altogether, these factors provide a general picture of the people coupled in white marriages. As white marriage is heterogeneous in the sense that it happens at different 
stages of people's lives, in the next section, I analyze various forms of white marriage and their characteristics.

\subsection{Different Forms of White Marriage}

In studying white marriage, I found Xu et al. (2006) categorization of cohabitation in relation to divorce and marriage in the United States useful: they categorized population "into 4 subpopulations, namely, noncohabitors, premarital cohabitors, postdivorce cohabitors, and sequential cohabitor (2006, p. 262). In the instances of white marriage, I have observed these three groups of relationship: post-divorce experience, premarital, and self-regulated ${ }^{27}$ relationship. Moreover, $\mathrm{Xu}$ et al. (2006) categorization helps us to identify the after-dissolution pattern of white marriage. It seems that repartnering is more common after dissolution in white marriage.

\section{White Marriage as a Post-Divorce Experience Choice}

Post-divorce white marriage is one relationship category. There are two aspects to the relationship between white marriage and divorce: firstly, some people avoid remarriage after divorce, thus preferring white marriage; and secondly, many people in white marriages come from a divorced family.

In countries such as the United Kingdom and Australia, there is a significant relationship between the increasing rates of cohabitation and divorce (Skew, Evans, \& Gray, 2009). It means when the divorce rate increases, cohabitation rates also rise. In Iran, although there are no statistics available about white marriage, the divorce rate has increased unprecedentedly, and the marriage rate has decreased. It seems reasonable to

27 - The term self-regulated marriage or Ezdevaj khod-khandeh is taken from one of my interviewwith Ebrahim. 
hypothesize that there is a connection between the rising divorce rate and the emergence of white marriage, which indicates that some divorced people prefer white union over remarriage. Furthermore, post-divorce white marriage apparently, partially contributes to the declining rate of marriage while the rate of divorce increases. In what follows, I discuss the interviewees' attitudes towards divorce. That is, after a divorce, white marriage is an attractive alternative to remarriage. This does not indicate that all white marriages happen after a divorce, but these are plausible explanations for the many cases of white marriages that occur after divorce. I also explain the various aspects of white marriage in relation to divorce. For some interviewees, the experience of white marriage is a post-divorce experience. Among my interviewees three unions have one party, and two unions have both parties who are in post-divorce relationship. Elaheh talked about her ex-husband:

He could not see that whereas he was afraid of water, I was the lifeguard. He could not see me drilling and installing stuff and setting up electronics. He was admittedly unhappy when I opened the car hood to fix the engine and knew where the problem was. He used to tell me to do it all to humiliate me and mock his masculinity. We finally divorced, although I really did not want to. I supported him while he continued his education, and grew up, and made progress. Now I am thinking I was wrong. It would have been better not to encourage him. I needed to accept him as he was. I have learned in white marriage that people do not promise themselves to each other forever. (Elaheh, female, 35)

Maryam who did not talk about her divorce experience, as her marriage lasted only a couple of months, left her hometown and went to Tehran to work. Her father, who is religious and attends a mosque, accepted her white marriage. In his opinion, white marriage is similar to a temporary marriage and, consequently, a divorcee does not need her father's approval on legal and religious grounds. However, her father was concerned about her possible persecution by the police, and asked Maryam to secure temporary 
marriage documentation that would be acceptable to the police. Maryam does not believe in temporary marriage, but for the sake of her father, she provided a fake document for temporary marriage.

After all, I should be prepared to answer to the police, just in case! (Maryam, female, 31)

Maryam's experience of divorce highlights an important aspect of white marriage. As a divorcee, a woman has more freedom to make decisions. Under Iranian law, she does not need her father's approval to remarry, and women gain more autonomy to make decisions. Moreover, even though Maryam's father is a religious person, he does not strongly object to white marriage. This is because of the similarities between temporary marriage and white marriage, which in Maryam's case allowed her to maintain a relationship with her parents as well as her partner ${ }^{28}$.

Poya's experience of divorce indicates the unequal gender roles between husband and wife that prevail in Iran. He says in white marriage, he experienced an equal, respectful, and loving relationship. Divorce had heavy costs for Poya, such as Mahrieh or the spousal support that he must pay, and the long legal process of divorce. Moreover, post-divorce depression engendered in him a negative attitude regarding marriage, which eventually resulted in his willingness to choose white marriage.

The issue between me and my ex-wife was our relationship, a domineering relationship. For example, she was very traditional, including in our sexual relationship. She thought she was doing me a service! After a year, we just lived together as house mates and it took two years to get a divorce and I am still paying the marriage portion (spousal support) in instalments. My parents told me that she was not a

28 - As I mentioned in introduction chapter having the concept of temporary marriage back in Iranian culture facilities accepting white marriage. 
good match for us, but I did not listen. I was thinking of this choice in my life as a challenge that would make me stronger. (Poya, male, 32)

Pouria also experienced divorce involving a child who lives abroad with her mother.

He explains that it happened quickly.

My ex-wife without ever convincing me decided to divorce. I could not and should not force her to live with me, and the divorce process did not take long, because we were in mutual agreement. Later my friend told me that she was in a romantic relationship with someone else, but I don't know if that is true. (Pouria, male, 40)

His next partner was a divorcee too and had two children who lived with their father.

For a smooth transition after divorcing her partner, she took an apartment where she went for a few days a week, and eventually she just visited her children a few days a month. Meanwhile, she was in white marriage with Pouria.

Fazi's partner is the father of an eight-year-old son. He is divorced and has full child custody. After having lived with him for a few years, Fazi is happy that her partner's son is their main "common project" to raise. She explains that it is very important for her and her partner to provide a quality life, so that their son can be a happy and well-behaved child.

As I explained, many people in white marriage have experienced divorce in the past, not only in their own lives but also that of their parents. The experience of divorce among parents and immediate family members is frequently mentioned during my interviews. Seven interviewees, that is, almost half, reported that either their parents or their partner's parents are divorced. In one case both partners' parents are divorced. Their experiences in this regard has contributed to their negative attitudes towards marriage. Some of the interviews reflect that divorce is still considered taboo and the preference is for an easy separation after a white marriage rather than being a divorcee. Samar for example has a 
negative attitude towards divorce. Her parents' divorce affected her relationship with her ex-fiancé's family. Her mother-in-law told her, "We do not have such a thing in our family." Afterwards, Samar felt very unwelcome in her ex-fiancé's family and eventually decided to end the relationship.

Ebrahim for example says, "My partner's father, who tried to convince me to marry, later got divorced! It is so ridiculous!" He believes that a good relationship cannot last forever. After five to seven years, the relationship becomes "parasitic" with one partner becoming attached to the other. He believes that after a certain amount of time, most married couples "have to" continue the relationship, or they tolerate it to avoid the hassles of divorce or to stay for their children's sake.

Sepideh also said that her partner's parents are divorced. Although her partner's mother is divorced and lives alone, she continuously asks Sepideh about her marriage plans. Sepideh suggests that if marriage did not work for her partner's mother, then it is difficult to see why she would think that marriage is better for her son than white marriage.

Hamid is not from a divorced family, but he believes that his parents do not understand the meaning of a relationship. "They are living in their own separate worlds."

Neda describes the familial situation in her partner side as such:

His (her partner's) brother got divorced and his parents weren't romantically bonded, they were living separated. He has always faced these marital hassles. My brother also got divorced while he was seriously ill. At my other brother's wedding night, a quarrel happened and resulted in a bitter evening for us. Therefore, I hate wedding ceremonies. (Neda, female, 31 ) 
Regardless of family dynamics in the parents' life or in their previous relationships, couples in post-divorce white marriage have a specific set of motivations: it may or may not end up as a documented marriage.

In post-divorce white marriage, participants highlight their opposition to marital law and divorce regulations ${ }^{29}$ as well as the culturally normative system of marriage. Women and men in this form of white marriage are looking for a more egalitarian way to live together and for an easy and respectful separation if that becomes necessary. They repeatedly point to the dysfunction of institutionalized patriarchy in the documented marriage system, including marital law and marital cultural practices. In fact, they resist the non-egalitarian approach in current marital and divorce legislation as well as the nonegalitarian marital practices of the culture, which they perceive as overly complicated and costly. The legal and normative barriers and negative consequences of divorce, as discussed above, seems to have contributed notably to the rise in white marriage. In Samar's case, frustrating cultural norms led her to think about white marriage after a failed engagement.

We were engaged for a year, but his family did not initiate any contact with my family regarding a marital ceremony (traditionally expected from the groom's family). It was a frustrating situation. When I saw him again, I returned my engagement ring. I hated wearing a scarf, which I

29 -In Islam, family dissolution is permitted as a last resort for a man and a woman who cannot maintain a socially healthy marriage and family (Aghajanian, 1986). Under current Iranian law, divorce is only allowed through legal procedures (Aghajanian, 1986). "The court has to be convinced of the ratification for divorce - that is, the court required evidence that the wife and husband could not reconcile" (Aghajanian, 1986). This law leads to legal proceedings which require excessive time, are tedious, and provoke public embarrassment. Furthermore, the requirement to produce evidence to justify a divorce tends to enforce divorce-related difficulties both psychologically and socially. In other words, women in this new legal setting have only a small amount of social and legal support. The logic behind it is that Islamic law permits a woman to place in a marriage contract any condition that is mutually agreeable to them as long as it is not against the nature of marriage. 
had to do for them (to respect their traditions). I was not myself anymore. My next relationship was a white marriage . . . However, society does not approve. I told (my neighbours) that he is my uncle, my relative. But still people talk. (Samar, female,31)

When I contacted Samar to make an appointment, she gave me her workplace number and asked me not to say anything about the nature of the interview. She did not reveal her relationship to anyone. Poya also shared his story of divorce, and the long process that resulted in his depression and financial hardship, as he had to pay his ex-wife Mehrieh in instalments.

At a seminar by an Iranian sociological association at the University of Tehran in November 2017 entitled "White Marriage," an audience member commented about reasons for white marriage. She said, “Under current family legislation, a woman's right as a citizen decreases as soon as she marries." She said that she believed that is why white marriage is considered a valid option. She pointed to family laws that legally give men the authority as a husband to grant or deny permission to his wife to pursue higher education, to get a job, to leave the country or even to leave the house. In practice, young middle class men do not use this power to limit their wives in normal situations, but in situations of conflict, there is not only no legal protection for women but also legislation that works against women's basic rights. My interviewee Maryam, who identifies herself as a social activist, also says that marriage and divorce legislation is among the reasons for white marriage. She added:

Whenever a divorced woman goes for a job interview or tries to rent a place, she has to show her ID (Shenasmane). The ID shows she is a divorcee. Why is it anyone's business whether I am married or divorced? People judge, and it has consequences. In white marriage though, there is no such hassle in the case of dissolution. (Maryam, female, 35) 
Surprisingly, even my male interviewees objected to patriarchal marital laws. Ebrahim was one:

Ebrahim: A woman who accepts that stupid marital law would not be my woman.

Me: What is the problem with the marital law?

Ebrahim: It does not consider a woman to be a person. She is under the control of the man. It's ridiculous that I have the right to divorce while she does not. (Ebrahim, male, 32)

Even though Farid did not experience divorce himself before white marriage, he still considers divorce regulations as a reason for avoiding documented marriage.

My parents insist that we marry. But our choice is to be together outside of documented marriage. White marriage for many is not a choice. They have to, and when they find the opportunity, they marry. However, for us, it was a choice. I do not believe in family and marriage. Have I lost my mind (to marry)? Do I want hassles? We would say goodbye, if we no longer wanted the relationship ... In the West, marital rules and regulation are much better. Property should be divided. But here in Iran or in Islam, divorce rules show no rationality. Why should I accept such rules? ... Accepting marriage is accepting something that is offensive to your wisdom ... marriage is a traditional structure, to me. (An intimate relationship) is a personal decision though. (Farid, male,32)

Regardless of legislation, resistance to marital norms is another motivation for white marriage. However, there is a gender difference that indicates women are more likely to follow cultural marital norms.

Pouria explains the cultural pressures for costly wedding traditions that are extremely important for women. In the case of a marriage plan, there is an expectation to follow wedding norms to avoid trouble.

Culturally, we are expected to hold a marriage ceremony, and a good one (if we want to marry). My ex-wife, a day after the wedding, returned to her work abroad. She could not even stay one more day. But in the divorce court, she said, 'You are the person who did not arrange a honeymoon.' Accept it or not, you are expected to follow marital 
traditions step by step. My friend's wife insisted they not have a marriage celebration. But once she told me, while tearing up, 'My son told me today that all my classmates have seen their parents' wedding photos. Where are yours?' I told her if she would like, I could make them on Photoshop. She said, 'You are making fun of me. (Pouria, male, 40)

Poya's experience of post-divorce white marriage also points to the same trend. His white marriage failed, because his partner asked him for a documented marriage based on cultural norms.

White marriage is a rebellion against tradition. But I question that a person (his ex-partner) who is so modern (as to chose white marriage) still faces the issue (a marriage plan) in such a traditional way. She asked me to go to her parents' home for a khastegary proposal ceremony. I told her I would invite them to a restaurant and ask them to marry her, but my answer disappointed her, as it is not the traditional form of proposing. She asked me for a wedding celebration that she knew I hated. I was shocked! (Poya, male, 32)

There appears to be an early agreement among people in white marriage that marital traditions are secondary, but there is a gender difference in the perception of those traditions: women believe in a marital plan that follows traditions, while men reject that. While there are a few exceptions, such as Elaheh, mostly women tend to pursue marital traditions (in the case of a marriage plan). couples eventually agree on breaking form and traditions. For example, after moving in together, Shirin threw a party and invited her extended family, in the customary way a newlywed couple would. As they would for a documented marriage, her relatives brought gifts and congratulated the couple. Shirin did not accept a dowry from her family and the couple bought furniture with their common savings.

Neda also rejected Mehrieh and any form of wedding ceremony after deciding to have a documented marriage, but she insists that she and her partner wear rings and be recognized as husband and wife. 
The prior experience of divorce for people in white marriage taught them that it is better to form a relationship that exists as long as enough satisfaction is delivered within it for each individual to stay. People in white marriages believe this structure can free them from legal and normative power, compulsion and institutionalized violence.

Altogether, negative attitudes regarding marriage are partially rooted (I discuss other contributing factors in the following chapters) in the fact that many people in white marriages have personally experienced divorce or come from divorced families or from a family where parents have a contentious relationship.

In this section, I introduced post-divorce as being one trajectory ending in white marriage and mapped the experience of white marriage in relation to divorce. In summary, an important group of white marriages reflects the evolution of relationships post-divorce, which is gradually changing remarriage patterns. In the absence of official data about white marriage, the change is apparent in the declining marriage rate and the dramatically increasing divorce rate (Aghajanian, et.al, 2018). Increasing numbers of white marriages could explain the rising divorce rate, although some of the divorced population does not enter legal and traditional martial relationships, instead choosing white marriage. Negative attitudes regarding marriage increase after a failed marriage among friends and family, thus discouraging people to remarry. The time-consuming, complex, and costly process of divorce are further deterrents to remarriage, making white marriage an attractive option for some. Divorce also gives women more freedom to make independent decisions. For example, as I mentioned in Maryam's case, Iranian legislation permits a divorced woman to make her own decision about remarriage, which paves the road for white marriage. Lastly, women are readier and more willing to live 
independently after divorce. This is usually the result of maturity and economic independence. Ultimately, negative attitudes regarding marriage are also associated to the fact that many people in a white union experienced divorce or contentious relationships in their parents' life. The most important reasons and motivations associated with postdivorce white marriage are the rejection of divorce laws which are, in their perspective, patriarchal, time-consuming, and unnecessary; as well as rejecting the normative culture regarding marriage, which limits individual decision making.

\section{White Marriage as Premarital Experience}

In many cases, white marriage is a precursor to documented marriage. As I mentioned in the introductory chapter, many people whom I approached who declined an interview were people who had experienced white marriage for a couple of years and then married the same partner. Some of them had children after marriage and did not want to talk about their white marriage. There were also some cases where they had married a different partner after the dissolution of the white marriage and did not want to recall the unsuccessful experience. Among my interviewees, Hamid and Nastoh had a serious short-term plan for marriage and Shirin and Neda each married their white marriage partners.

The aim of our relationship is ultimately marriage. We'll get married within a year, when we are economically ready. In this society, marriage means you are committed, and official, and others will accept you. Others' acceptance and having an official marriage is important to us. To apply for a visa, we also need to be married, and it's more beautiful. It's like we are saying we want to be together forever and to have children. In marriage, other doors are not open and getting out of it is harder". (Hamid, male, 28) 
For Hamid marriage has significant symbolic value. It expresses commitment to a long life lived together. In addition, it suits everyday official functions.

Shirin relates:

I was afraid of marriage. I thought it would be like a chain suffocating me. He suggested, "Come and live with me, then stay if you like it, otherwise go." We were happy with white marriage at the beginning. However, there was a turning point. Once my partner had to be hospitalized and I was asked about my relationship to him and I had to say wife. If I didn't say that, the next question would have been, "Who are you then?" And I couldn't have stayed in his room. After this experience, I realized that I don't have any legal status in my practical life. I had a negative attitude about signing a marital contract. I didn't like that. If I weren't in Iran I definitely would have continued (living with him without marrying him). But eventually I decided to make it official. We were going on a trip with our friends. Before we left, I asked my partner to stop in front of one of the marriage offices. We went in and signed a marriage document. The clerk took our ID and did the processing, then we went on the trip. The clerk in the office wondered why we were in a hurry! He also did not expect to see a bride and groom in sports outfits. (Shirin, female, 40)

It seems for Shirin marriage did not hold any symbolical value but rather a necessary step to navigate societal obstacles in everyday life. She also mentions other societal barriers for white marriage:

We travel across Iran a lot. During our travels to foreign countries, we faced no problems, but here in Iran we couldn't go to hotels, so we camped, but sometimes you really want to go to a hotel. We were under pressure most of the time. For example, once we wanted to go to Kish Island and we thought we should go with our families so that we could get hotel rooms. Or at work how should we introduce each other? We couldn't introduce each other as a friend or a partner. There were many other kinds of pressure also, which made us decide (to marry). Unlike me, my husband loved the idea of marriage and I think maybe after two years or so he would have proposed anyway. (Shirin, female, 40)

The reason for marriage in the case of Farid's sister was childbearing. He said:

I hate to use the term "our groom," but I must. Despite my disagreement, "our groom" and my sister were married after a year in white marriage. They wanted a child. (Farid, male, 32) 
Pouria, after an unsuccessful marriage and then unsuccessful white marriage, believes that he needs to marry his third partner, if he wants to keep the relationship. The reason seems to be the symbolic value of marriage for his partner in Iranian society. But he did not believe in documented marriage and mentioned in other parts of the interview that this relationship would fail because of the disagreement.

If I want to keep the relationship, I must marry her. How can I not to do that with a young woman, who every night dreams about her wedding dress and has already decided about the best brands of fridge and microwave she wants to purchase for our home after marriage with the dowry! (Pouria, male, 40)

He thinks women's normative expectations for marriage are unavoidable. His partner at the time of the interview was 19 years younger than him. It seems that his partner understands white marriage as a premarital stage whereas he sees it as a self-regulated relationship.

Samar's experience also demonstrates the difference between her perspective and her partner's regarding the meaning and value of white marriage. For her it is a premarital stage, while for her partner it has nothing to do with marriage:

I was fearful of losing him. I used to tell him didn't you tell me there is only death that has no solution? Why don't you find a way for us to get married?

In another part of interview, she said:

Once we went to register for a language school; the staff asked about our relationship (there was a promotion for married couples). I said he is my fiancé, but he said she is my girl-friend. I realized in that moment, I needed to take signs more seriously. (that he does not have a plan to marry) (Samar, female,31)

Moreover, in a premarital relationship, the participants generally are not rejecting marital norms and regulations and do not have a fundamental objection to the institution 
of marriage; rather, they stress the significance of independent mate selection based on the idealistic notion of love. They eventually proceed through the legal and religious norms of documented marriage. White marriage gives them the opportunity to spend time together, to complete their education, to establish their careers or simply to get to know each other better prior to documented marriage.

Hamid's marriage plan is based on financial matters. He also wants his partner to finish her education. They did not totally reject the traditions of marriage, but they are selective in how to practice them. The method of selecting a partner in this form of white marriage is an individual decision that does not involve asking advice of the extended family. Meanwhile, they develop a marital plan to adopt after white marriage.

Ever since I came to Tehran at 17 to continue my education, I have defined my own values. But others' recognition of our relationship is important for us. If we want to immigrate, documentation will be important, too, as well as for childbearing. We plan to marry in one year or so when I am ready economically and when she is done with her education. (Hamid, male, 28)

Under pressures, some people such as Sepideh think about a plan for marriage. She first mentions the social pressures that make her think about a marriage plan and then she discusses the barriers to having a documented marriage. As I mentioned, white marriage gives her the time to stabilize their economic situation.

I never thought about (documented) marriage as long as I could easily visit my extended family with him, or I could book a hotel on a trip. But there is a pressure, for example, when I pass the lobby man everyday, his dirty look hurts. I moved into this apartment first, then Maziar joined me. I don't know what the lobby man thinks. Marriage is so costly, and parents usually want to see job security and a stable situation, which is hard to achieve. Instead, people can start living together easily, and women are not afraid to move in to their boyfriend's place anymore. Nothing bad will happen. (Sepideh, female, 25) 
Nastoh also has a marriage plan, but since he and his partner launched a startup company together, they are busy establishing their careers. Moreover, their families are not aware of their white marriage, and he believes his partner's father would not accept white marriage if he knew. They eventually plan to marry.

As I discuss extensively in the chapter on commitment, and in line with research by Amirmazaheri et al. (2017), women are more likely to understand white marriage as a trial for or precursor to documented marriage, whereas men usually understand it as a self-regulated relationship. Social and legal barriers to white marriage, childbearing, and cultural expectations as well as the symbolic value attached to the institution of marriage contribute to the pressure to convert white marriage into marriage. In the above quotations, premarital white marriage is a step in the courtship process especially for women. Importantly, interviewees in premarital relationships did not reflect on any objections to the religious, cultural, and legal aspects of marriage, instead they valued independent partnerships selection based on love.

As is evident in the interviews, however, white marriage for some people is an independent and distinct kind of intimate relationship bearing no connection to marriage. In other words, some in white marriages seriously critique the institution of marriage and perceive white marriage as a viable alternative.

\section{White Marriage as a self-regulated Relationship}

White marriage is sometimes independent from divorce and marriage, meaning that people ideologically believe in the value of white marriage when compared to documented marriage. In these instances, white marriage does not happen before or after a documented marriage, which makes it a self-regulated relationship. Among my sample, 
five individuals, three men and two women, were in this group. There are different logics for choosing white marriage. One is the opposition to the normative culture supporting documented marriage, as described by Toranj:

I have no positive feelings toward this (i.e. marriage), because I feel like it's a bargain between two families, like we give our daughter to you, especially the Iranian version, which has a trousseau (marriage portion), dowry and so on ... What I have seen in most marriages is that most problems are caused by family conflicts. A positive point here (in white marriage) is that families are not involved. It's just the two of us and whenever we decide to break up, then we'll do it. Everything is OK and we have peace of mind, but if one day we want to get married, I don't like marriage ceremonies and parties; however, these just come with the package of marriage because our parents have always wished to see their daughter in the wedding gown and it's really hard for them to accept their marriage without the ceremony. In my opinion, spending money on this is ridiculous, when (in white marriage) you don't have these burdens on your shoulders. You feel free. I also don't want to have a child; therefore, why is marriage necessary? I haven't got into the necessity of getting married when we can stay together like this. And there is a belief, especially among mothers: They say if you get married, he can't just leave you easily. Well, who is willing to go will go anyway. When I know someone wants to leave, I'll just let him leave. Why should I stay in such a relationship? I won't try to make him stay and it's on him whether to stay or leave. I prefer it this way because generally a person should be satisfied with his or her life, and I am. We should get the approval of two others (parents) and well we will. (Toranj, female, 28)

For Ebrahim, white marriage is also a relationship distinct from marriage; an alternative with many advantages. White marriage in his words reflects a practice of selfcreation and self-realization:

White marriage is a self-oriented marriage, the most humanistic type of relationship, because everyone who gets involved in such relationships does it by choice and they accept all the responsibilities themselves, and not because of norms, religion or law. The aim is to be free and comfortable. Nobody minds my business and I won't mind anyone else's business. We live our own life. Social norms can destroy a family. The most significant destruction is that both families force traditions on couples. Now, if the father of my partner wants to say anything to me, I'll say, “Am I your groom?” (Ebrahim, male, 35) 
Moreover, for Ebrahim white marriage is an anti-authoritarian struggle and a practice against the marital institution and its associated norms, laws, and religious practices. In other words, white marriage is a counter-discourse to documented marriage. In what follows, Ebrahim also explicitly mentions what he resists and how:

It's a pleasant feeling, the free choice of having a family and defining it on our own terms. The pleasant feeling of having a democratic union! It is so cool to create parameters for our family, parameters that we create for the first time. It was a kind of resistance for us to not accept old outdated norms, to express our opposition, to write our own holy book, not to live based on the Bible, the Old Testament or the Qur'an. (Ebrahim, male, 32)

From Navid's point of view, the institution of marriage, as defined in religious and legal frameworks are meaningless. He mentions during the interview that he would marry his partner only in the case of an unintended pregnancy and may then celebrate it with close family and friends without the pointless costs of a large celebration. In other words, in devaluing the marriage system, he challenges religious, legal, and cultural authority over sexual relationships. Similar to others in this group, Navid has his own interpretation of the criterion that makes a relationship legitimate, which is to say love. He also explains his opposition to religion, law and culture.

My father says it's forbidden in Islam to sleep with someone without getting married. They should read a verse of the holy Qur'an. Between you and I, I say it's ridiculous. Verse is actually my feeling when I love someone and I want to live with her, this is verse. The father of my partner says make it official. His problem is the identity certificate. I want my partner to write with her own handwriting that she is Navid's wife and I will engrave it. We want to live with no limitations. (Navid, male, 32)

White marriage, like many anti-authoritarian struggles in Europe such as the struggles of homosexuals for recognition and the de-medicalization trend, does not aim to contest a particular political or economic form of government; rather, these current 
oppositions revolve around the question of self (Hunt \& Wickham, 1994) and lifestyle.

At the end of interview, I directly asked a question whether interviewees understand white marriage as a political activity against the government. None of the participants affirmed and understood white marriage as a political act against the regime but almost all agreed that white marriage is a struggle against cultural power.

Fazi, who was twice in white marriages both inside and outside of Iran, explains:

No, I don't see it as a political problem. It's mostly cultural. Our problem was our families' culture. (Fazi, female,30)

Ebrahim explains why he does not consider white marriage as a political activity:

Nowadays, boys and girls hang out easily. In general, most of them have sex. It's no big deal. It's not political. Government and politics will do their job whether or not I get married. Government can hurt me but I can't hurt it. It's like a kid who tells her mom, 'If you don't buy this for me, I won't eat lunch.' 'Well don't eat! You'll get hungry and you'll eat in the end.' This way, nobody gets hurt. It is not political. (Ebrahim, male, 32)

Political?! Uh, young generations are not into politics! (Samar, female, 31)

Maryam was the only person who affirmed a weak association between white marriage and political activity, but she still emphasized the cultural aspect:

I see myself as a political activist. From this point of view and in general, white marriage is a political action, but it's more the personal aspects of it. (Maryam, female, 35)

In fact, cultural power dictates a whole series of norms regarding the proper way to live. As I have explained, white marriage couples also complain about the cultural norms that control them in the name of commitment ethics. White marriage is a union of rejection and resistance, that is, a rejection of legal/religious interference and cultural violence which ignores individuality. It is also a rejection of normative knowledge or 
administrative investigation, which determines who one is (Foucault, 1982), who one should be and how a relationship should work. Redefining a relationship in white marriage is an example of generating mutual knowledge about how a relationship should work. White marriage, to follow Foucault, demonstrates resistance by expressing new forms of subjectivity, which is vital for the creation of the self: "Maybe the target nowadays is not to discover what we are, but to refuse what we are" (Foucault, 1993,78). The practice of resistance, in Hunt and Wickham's words, is directly linked to the practice of self-creation and self-realization. Rejecting what a person is is an important element of group action of the sort which Foucault applauds (1994). In this sense, white marriage for people who have been silenced, stigmatized and excluded by mainstream society is an anti-authoritarian struggle in many aspects.

For people in this sub-group of self-regulated relationships, re-partnering is commonplace. After the dissolution of their relationships, Navid, Ebrahim, and Fazi, repartnered. They believe that love does not last long. Consequently, a decline in feelings is the destiny of all relationships. Thus, believing in the temporality of a relationship, their perspective is that white marriage is a relationship with open doors, giving a relationship flexibility in both its form and dissolution, without legal and familial hassles.

In Ebrahim's words:

(Here is the process of a relationship): People meet each other, hold hands, kiss, go to the cinema, sleep together, live together, they may have a baby or not, they get tired of each other gradually and finally they want to split up.

Biology tells humans that a relationship can't last more than five to six years. If you talk to boys and girls who have limited themselves to a long-term relationship, you'll see that they're suppressing themselves. Suppression exists in this relationship. Our relationship won't last either. In marriage, family pressure exists, but in white marriage it 
doesn't, and it's really important, especially when partners want to break up. The pain is less. It's a surgery with less bleeding.

Fazi also says, after re-partnering twice:

My parents always say fly together but do not make a nest together. I'll be with my partner as much as my profession allows. To pursue my career, if I need to leave the city, I will. If he can accompany me, that would be great. Otherwise I will go alone. (Fazi, female, 30)

Pouria is also in his third relationship but does not have any hope that the relationship would last if he would not marry. His logic, like that of Fazi, is related to his professional life and its demands.

Marriage is not compatible with any professional level of working. I'm a photojournalist and I'm always on trips. Once my girlfriend sent me a text angrily asking me where I was when I did not answer her call right away. I took a selfie picture while I was in black mud to my waist and I said I'm doing photography here. She said, "Oo ok! Don't get sick." This professional life is not suitable for long-term commitments, but white marriage gives me the flexibility to pursue my profession while being in a relationship. Everyone who has a professional job has a fake marital life. These are mutually exclusive. Expectations in marriage are too much, but white marriage is much better. Loneliness is epidemic nowadays. We should accept it. (I guess) my current relationship will end too and it will be my third unsuccessful trial. My family will see it as a third failure. I feel disappointed when my family gets sad. (Pouria, male, 40)

Pouria's and Fazi's experiences epitomize individualism and the pursuit of individual goals. Studying cohabitation in the West, Rindfuss, Vanden and Heuvel (1990) have argued that the rising trend of cohabitation is a response to the historical and the gradual growth of individualism. There is also evidence that widespread non-marital sex and flexible approaches to commitment, in opposition to traditional family values, are associated with the rise of individualism in Europe (Lesthaeghe \& Surkyn, 1988). North American studies also confirm the association (e.g., Axinn \& Thornton, 1992, 1993; Wu \& Balakrishnan, 1992). Studies of white marriage by Azad, et al. (2012), Ghoddosi \& 
Bayat, (2014) and Jalaeipour (2015) also associate white marriage with individualism.

Within the broader context of transformations in intimacy, my analysis also points to the same trend, that individualistic values in partner selection patterns and life goals can play an important role in selecting white marriage as a distinct form of intimate relationship.

White marriage as a self-regulated relationship combines all the rationals of postdivorce and pre-marital relationships with greater emphasis on resisting cultural norms in order to pursue self-creation and self-fulfillment. This is a form of rebellion or anarchy in opposition to the institution of marriage. People in this form of relationship, as the first Iranian generation to do so, are proud to create a new lifestyle for young women and men. As mirrored in Ebrahim's account, various motivations are associated with forming white marriage as a self-regulated relationship.

White marriage allows you to feel good about having a family by your own choice, of having our own lifestyle, of creating new parameters in a common life for the first time in Iran's history. This is a self-regulated life. This is me who decides. That is why I am a winner. Because we and people like us swim against the tide. We deny the conditions that we are forced to accept. It is a form of anarchism against 2,500 years of human relationship, which I believe is a mature stance and so pleasant ... Talk to people who marry. None of them can close their doors against society, traditions and the hurtfulness of others. We have made our home with a new mechanism. Our mothers and fathers are not determining or commenting on our outlying lifestyle. We bought many second-hand things and started our common life. Furniture and the rest. This is much easier and beautiful ... We object to hurtful traditions and unpleasant rules . . Religion should not rule our life. It should not enter into the decisions we make in our life ... This is the step that our generation has taken to insist on this different lifestyle. Whoever asks me for a marital document (to rent an apartment, for example) violates my rights and my freedom. It is institutionalized abuse! (Ebrahim, male, 32)

Similar to Ebrahim and many others, Neda is proud of her courage to create a new lifestyle. 
It was a nice feeling that we wanted to live in a new way, in such a way that others can understand that people can live differently. Nevertheless, I paid a heavy cost. (Neda, female, 31)

Their normative reference for believing in white marriage as a lifestyle was the practice of cohabitation and common law partnership in the West as a successful model. Believing in the prestigious western lifestyle, couples in white marriage usually reflect upon the higher value of their relationships.

Well, I have not seen this lifestyle around me, but everyone in Europe lives like this. (Shirin, female, 40)

I'm not against law. Marriage can be registered. For example, religious marriage has been abolished in Scandinavian countries, but civil marriage exists. (Navid, male, 32)

In the West, even for immigration purposes, two persons who have lived together can apply to immigrate. This lifestyle is extensively recognized. (Toranj, female, 28)

The understanding of white marriage as a highly prestigious form of relationship is a very important aspect of this relationship. The personalization of intimate relationships is bound up with an analysis of globalization and the diffusion of ideas (Gross \& Simmons, 2002). Personal relationships in globalized times can best be understood by paying attention to the role of mass media in spreading western values relating to the family. Moreover, young people's understanding of modernity and what it means to be modern, and their evaluation of the role of the west in the process of globalization merit attentions. I expound on this important point in Chapter 5.

Beyond the reference to a western lifestyle, the resistance to cultural marital norms in Iran is another important aspect of white marriage as a self-regulated relationship. People in white marriage as a self-regulated relationship find themselves in conflict with 
marital norms, which results in the relationship becoming less oriented to local kinship

groups and communities. The following quotes associate marital norms and patriarchy.

Marital traditions poison a relationship and change the approach of couples to the union at early stages. For example, a woman may believe that marriage requires having a sexual relationship with her husband, because he is the husband or because of a document that indicates Mehrieh (marriage portion). It (the documented marriage) is based on a relationship of ownership, rather than one of love. In white marriage, we want to keep our parents' noses out of our relationship. They think that we need to live by their beliefs, because they are the parents. We also want to escape the old gender roles of documented marriage. We want to break that cycle. When a woman marries, she is expected to do dishes, clean the house and cook, and a man should be home no later than a certain time and provide money. They repeat what they have seen in their parents' home. Then, after a while, when a man comes home, he says, "Bring me a tea" or "Set the dinner table!" It happens gradually in any marriage. In white marriage, though, it is different, because it has started differently. We do not accept these gendered roles. (Navid, male, 32)

I was afraid of marriage. I thought it would be like a chain suffocating me. (Shirin, female, 40)

Women mostly want independence in a white marriage and it's their right. They are 20 years old but they have to obey their stupid father and be home by 8 p.m. Or on the way home, they have to worry about being harassed. My friend (female partner) suggested that we live together (Ebrahim, male, 32)

My friends in white marriage believe that documented marriage (under the current marital law for women, such as Mehrieh) is selling one's body in a legal way. If a woman depends on her husband for daily living costs, it has the same meaning (as selling the body). This is the way my friends in white marriage criticize marital laws and norms. I do not go that far though. (Neda, female, 31)

Based on the above quotations, the advantage of white marriage for women in the patriarchal context is greater because, as Gross \& Simmons (2002) argue about cohabitation in the US, it frees them from the fear associated with gender roles and gender discrimination in the relationship. Thus, people in white marriage believe this 
relationship allows couples to determine their life goals and their lifestyles themselves, rather than have them determined by other individuals and old institutions.

Due to the heterogeneity of white marriage, different motivations lead to the forming of relationships. The premarital experiment approach usually involves reasons related to time and economy. People in this relationship perceive white marriage as a trial that gives them time to test the relationship and the time to develop their careers, it also gives them room for independent partner selection. People in post-divorce white marriage are opposed to marital norms and regulations governing marriage dissolution. They also mention their desire for a more egalitarian approach to the relationship and the rejection of patriarchy. In the case of a marriage plan, they generally break from tradition and establish it in terms of their self-identification. The last group, who consider white marriage as a self-regulated relationship, takes a resistance and anti-authority stance, and seeks recognition of their chosen lifestyle, self-creation, and self-identification in a manner that is guided by individualism. People in this category understand white marriage as part of their proud identity of being modern, which takes its normative reference from how they imagine intimate relationships are in the West. This lifestyle is also believed by adoptees to be a rejection of Iranian marital norms, legislation, and religious understandings of intimate relationships, which are all perceived to be in the shadow of patriarchy.

I have also explained that white marriage is not a long-term relationship. Break ups and re-partnering are a common pattern. That is why maintaining relationships with parents and siblings as a more stable source of support over the course of a life is very 
important. In the next section, I explain the relationship of people in white marriage with extended family.

\subsection{White Marriage and the Extended Family}

"Do the parents know?" This is one of the most frequently asked questions about white marriage that I encountered in conferences and from people who learned about my research: did parents know about the relationship their children were in? People in white marriage have different relationships with their families, which is usually very contentious at the beginning. I argue that generational differences in values are significant between people in white marriage and their parents. Although there are no clear links between different groups of white marriage and patterns of relation with extended families, I found gender dynamics. To avoid challenges, women usually hide the relationship for a while, however men stay distant from their families. After the relationship is relatively established, men revile it and women usually try to convince their families, while maintaining functional solidarity. In this section, I explain the different forms of solidarity between people in white marriage and their parents, following what Bengston (2001) has suggested as structural, functional, or consensual.

Like other aspects of white marriage, relationship to family is complex and diverse. In this section, rather than presenting a simplistic binary of nuclear and extended familial relationships, I explain intergenerational family relationships in a white marriage setting. In the North American context, intergenerational support generally flows from the older to the younger generation in the family, explains American sociologist Bengtson (2001), and it is greater and more frequent than that offered from the younger members to the older. Younger members' help to older family members is usually offered only in times 
of crisis. Within this general framework, however, married couples receive more emotional support from family than do cohabiters in United States (Kurdek, \& Schmitt, 1987). In other words, compared to married or single young adults, cohabiters experience significantly less support from their parents (Eggebeen, 2005). They also are significantly less likely to rely on or name their parents as an emergency contact (Eggebeen, 2005). In Portugal, the extent of family support in cohabitation implies slightly lower levels than marriage (Wall, et.al 2001). In the Netherlands, cohabiting couples have less contact with family members, (Hogerbrugge \& Dykstra, 2009) resulting in less support. Moreover, Baranowska-Rataj (2014) found that in Poland, where cohabitation is not institutionalized or fully socially accepted, the role of this form of family in intergenerational relations is not neutral and cohabiters have fewer intergenerational relations (Baranowska-Rataj, 2014).

In contrast, Nazio \& Saraceno's study (2012) in the United Kingdom and Italy suggest that cohabitation does not weaken intergenerational relationships. They found no differences between cohabiting and married individuals with regards to intergenerational contact in the United Kingdom and only to a very limited extent in Italy (Nazio \& Saraceno, (2012).

However, the intergenerational family ties in some countries are more important, as it functions as social safety net. Intergenerational exchanges of time and money within families in South Asia, more specifically in Indonesia and Malaysia, for example, serve as insurance for family members, both for parents and for young couples, but it is more likely downwards from old to young (Schröder-Butterfill, 2004). There is no data 
available to know if cohabitation weakens the intergenerational contact and support in this context.

In Iran, familial interaction and support are very important (Jalali, 2005). One of the most central characteristics of Iranian culture is its family orientation, specifically the strong preference for maintaining a relatively high degree of loyalty toward family (Javidan \& Dastmalchian, 2003). The absence of strong social communities and social networks further emphasizes family solidarity as a salient and powerful source of social support. As Nassehi-Behnam (1985) mentions, kinship networks in a new formation still function as support exchanges. Although Nassehi-Behnam's (1985) study is dated, new studies still highlight the importance of family as a social safety net (Amirmazaheri,et.al., 2016). Amirmazaheri,et.al (2016) their study about white marriage emphasizes the importance of familial support and that couples in white marriages lose this familial interaction, according to her research. Amirmazaheri, et. al (2016) add that "normative disapproval" (Mayer, 2004) of white marriage has led to a decline in well-being for people who engage in it. Nonetheless, my research demonstrates that normative disapproval is not always the case. This is a gendered phenomenon and women are more frequently subjected to normative disapproval, while men are more easily able to reveal the relationship to their families who then welcome the partner as part of the extended family.

For example, Farid explained that even though he was in white marriage with his partner, his parents did not accept this form of relationship for his sister. His father beat his sister when he realized that she was in such a relationship. With Farid's support though, they gradually accepted their daughter's white marriage. In another example, 
Neda explained how she was under such pressure from her extended family to explain her relationship that she preferred to cut all contact with them. However, she did visit her partner's family occasionally. Naz was always invited to her partner's family parties, yet she was not comfortable enough to reveal her relationship explicitly to her own family. This is also the case for Toranj, Sepideh, and Elaheh, all female interviewees. As I mentioned, however, disapproval is not always the case and people in white marriage have different forms of familial relationships and these relationships can vary over time.

Assuming a classical binary of nuclear/modern and extended/traditional family is not sufficient to capture the diversity of familial support within white marriage. To explain it, I applied three concepts "structural", "functional" and "consensual" relationship (Bengtson, 2001). Drawing on the above-mentioned family research of American sociologist Bengtson (2001), who categorizes generational interactions, I divided my interviewees' reflections on their relationships into three groups. The three dimensions of or approaches to generational support in white marriage relationships are: "structural" relationship (Bengtson, 2001, p.1), that is the opportunity for cross-generational interaction based on geographic closeness among family members - theis concept focuses on whether the partners in a white marriage live close to their parents. "Functional" relationships (Bengtson, 2001, p.1) designates the giving and receiving of support across generations, including the exchange of instrumental assistance and services as well as emotional support. Finally, the term "consensual" relationships (Bengtson, 2001, p.1) designates agreement in terms of ideas, values, and life orientations between members, and whether the agreement or disagreement facilitates or prevents support exchange. In what follows, I use these three concepts as heuristic devices to discuss approaches to 
relationships with extended families on the part of people who have chosen white marriage. As will become clear, structural solidarity among people in white marriages and their parents is low, for they are usually living in two different cities. Functional solidarity exists at a medium level, as some people in white marriages exchange support with their families, but mostly women receive and give services. Finally, consensual solidarity is very low, as a result of disagreement in values and ideas, and relationships frequently become extremely contentious.

\section{Structural Relationship}

Most of my interviewees were not geographically close to their family members. Given that their structural solidarity was relatively low as a result of geographical distance, this factor does not allow many interactions with family members. In fact, such distance may often be considered a condition for white marriage, for the distance provides the option to the couple to not reveal the nature of their relationship to their parents. Hamid met his partner in university after coming to Tehran to study and work. Sepideh is also a student in Tehran, whose partner came to Tehran for work. Neda also left her city after her brothers to study and met her partner in Tehran and stayed there. Nastoh's partner came to Tehran to study and stayed for work. Ebrahim, too, moved to Tehran to study and to work. In Maryam's case, she left her hometown to study in Tehran, then stayed there to work by choice. When Torang and her partner left Tehran to study in Kish, a city on the southern coast of Iran, they started to live together, then returned to Tehran. Generally, people in white marriages were not able to have interactions with their parents frequently or easily, because of their geographic distance. Among my interviewees there are some exceptions including, Samar, Navid, Elaheh, and 
Shirin. They were from Tehran and lived in the same city as their parents, but still did not have many interactions with their parents for different reasons that I explain in one of the sections below.

\section{Functional Solidarity}

Functional solidarity refers to the giving and receiving of support across generations, including exchanges of instrumental assistance and services, as well as emotional support (Bengtson, 2001). I observed functional solidarity among my interviewees and their parents in the process of interviewing. For example, when I wanted to set up an appointment to interview Fazi, she told me about her plan to visit her native town to visit her family. Another time, she cancelled our appointment and sent a picture of her sister in hospital to show that there was an emergency. Another example is Toranj: before we began the interview, she made a phone call to a currency exchange agency to check the rates as she wanted to send money to her brother abroad. Farid also bought an apartment for her sister as an investment for her future. Similarly, Elaheh's extended family is very important for her; she co-signed loans for her sister in support of her small business. During the interview, Neda also mentioned the time that she took care of her sick brother.

Among my interviewees, five people mentioned this form of relationship, not only with their parents but also with their siblings. I should also mention the gender dynamic of the relationship, which was significantly more observed among women rather than men.

These examples demonstrate that functional solidarity exists among people in white marriage and their extended families, although it is mostly women who offer such support to their families rather than men. I also observed gender differences in the 
receiving of financial assistance. In some cases, women's parents helped their daughters financially, whereas men usually did not receive any money. Naz for example received financial support from her father for accommodation. Sepideh's mother also provided a place for her and her partner to live, and she named her mother as an emergency contact. The same held true for Samar and Shirin. However, none of the men reported that they received financial aid from their parents, and in some cases, they helped their parents. Navid, for example, complained that his father did not support him in his career, and Farid said he gives financial support to his family, his sister, and her sister's partner. Thus, the gender difference in receiving support from family favours women.

Emotional support in most of cases was not easily accessible, because of the geographic distance between the couples and their parents. In addition, the wide gap between generational values and life orientations, which is related to the broader changes in Iran that have contributed to the emergence of white marriage, prevents them from receiving emotional support. Hamid says that he has no emotional relationship with his parents and does not care. Samar's parents are divorced and having various challenges within her family means she prefers to keep her distance from them.

Emotional support is apparent in Neda's case. Her partner bought Neda's mother medicine that was not easy to come by and stayed with her mother at the hospital when Neda could not be there. Neda also sometimes cooked for her partner's father, who provided accommodation for them, as she said his diet was very unhealthy. Navid speaks of a strong emotional bond with his grandmother as a first grandchild, and of their long conversations about everything. He says if he wanted to have a simple marriage ceremony, he could not imagine it without the family elders. 
My research demonstrates that functional solidarity in white marriage is moderate. In other words, couples in white marriage enjoy some support, but there is also a gender difference in functional solidarity, with women receiving and offering more support to their extended families than men do. Based on my observations, the support they that they receive is significantly less than the normative support received by married couples in the Iranian context. This seems to mirror the situation in the United States (Eggebeen, 2005; Kurdek, \& Schmitt, 1987) and Poland (Mynarska, et al, 2014) and the Netherlands (Hogerbrugge, et al., 2009).

\section{Consensual Solidarity}

People in white marriage usually have low consensual solidarity and different value systems than their parents, especially in terms of marital norms and values. An important component in familial relationships is consensual solidarity, or agreement in ideas, values and lifestyles. Many studies in Iran have analyzed the generation gap, shekaf nasli (Moidfar, 2004; Sarokhani \& Sedaghati, 2009; Panahi, 2008), rather than familial relationships. This idea can be extended to white marriage, for most people in these partnerships disagree with their parents' values, norms, and sometimes life goals and orientations. Although the disagreement does not prevent moderate functional solidarity between people in white marriage and their parents, the conflict limits intergenerational transparency. As a result, sometimes people in white marriages, most often women, hide their relationships at the beginning. There are two reasons for this: to avoid conflict or to solidify their decision. Over time, they do inform their parents and gradually try to convert them. Men mostly do not hide the relationship but, to avoid conflict, they do try to limit their relationship with their parents as much as possible. In many cases, men are 
indifferent to their parents' opinions. In what follows, I review some examples that demonstrate a lack of consensual solidarity that leads to hiding the relationship.

Toranj's story is an example of hiding the relationship.

My mom doesn't accept Nima and says his financial situation is not good. She doesn't insist we get married now. She knows him and knows about our relationship, but she can't accept that we've lived together for a year, and that I did not tell her. My father does not know about the relationship at all, he would not accept it. But Nima's family knows everything. Ultimately, we are not worried about our families finding out, since I know we are very close from a cultural standpoint. For example, my dad before the revolution had Marxist-Islamic views and Nima's dad is also a Marxist. My dad is not religious any more, but he is still sensitive about me. I believe our family share many commonalities. I need to convince my family if I am to continue in this way. Then I will (convince them). (Toranj, female, 28)

Similar to Toranj, Naz explains that she never explicitly told her parents that she is living with her partner, because she does not want to damage her respectful relationship, hormat, with her family. In other words, her bond with them would be damaged if she revealed the nature of the relationship. Although her partner's family invited her to their parties and bought her souvenirs after going on a trip, they never visited Naz and her partner in their home. They did however invite them for New Year parties and to dinner.

Ebrahim reduced his relationship with his family in order to avoid conflicts, but his partner's family knows about their white marriage. They tried to convince him to marry, but he did not consent. Before their white marriage, Ebrahim's partner left home and lived on a pension, as she could not tolerate her father's interference in her personal life. The couple usually hangs out with their friends rather than family members. Thus, they keep a certain distance from their family.

In the case of Hamid, female members of both his and his partner's families know that they are in a romantic relationship but are not aware that they live together. As they 
are both studying and working far away from their families, it is not difficult to hide their relationship. Hamid believes that his parents do not understand what a good relationship is. Like Hamid, Nastoh and his partner's family do not know about their white marriage, but they do know about the relationship. Nastoh believes that his partner's father would never accept white marriage if he knew they were living together. Thus, they plan to hide that fact until they marry. He does not care about his parents' opinion and believes that there is no reason to inform them as it is personal life.

Navid and his partner's relationship is not secret. Navid's family, including his grandmother, actively assert their opinions about his girlfriends and give him advice about whether he should marry them. For example, Navid mentioned her grandmother likes his ex-girlfriend and advised him to marry. His parents are religious and could not accept white marriage, then he prefers to keep distance with them. His partner's family also knows the relationship. She visited her father's home (her parents are divorced) to talk about Navid out of courtesy.

Shirin had an interesting strategy for being transparent with her extended family members.

When we began living together under the same roof, since we bought a new house, we decorated it for ourselves and threw a big party. Relatives came -- my family -- but his family is too religious to accept our white marriage. They knew of our relationship but never asked if we had officially documented it. Once his sister joked that they didn't know when I had become their bride. We announced our identities (that they are living together) without getting married officially and everyone accepted that. They came, congratulated us and brought gifts that I hadn't expected from some of them. We were friends for almost two years and then he came to our home for six months. Then we renovated our own house and moved in. It happened gradually. At first we were together as once a week, but then got more and more frequent. Because I hated the idea of marriage, he suggested, "Come and live with me, then stay if you 
like it, otherwise go." At this time, my mom gave me a message from someone and asked me to get married officially, but I didn't consent. (Shirin, female, 40)

During the interview, she mentioned that her husband's family did not know any details of their relationship. They did not know whether they were in white marriage relationship or already married.

In Fazi's case, her family knew about her partner Mohammad and their common life together which was a challenging stage, because both Mohamad and Fazi's parents disagreed: "My father knew that I was going to Mohamad's home. Once he called me angrily and asked where I was. I said I was at Mohammad's home. He said, 'Stay there then forever!" However, her partner's family never accepted the relationship and even avoided her. She explained that his mom sometimes brought homemade pickles and jam for him, but only she would only come when she was sure Fazi was not at home.

As evidenced in above quotes, most of participants with different levels of religiosity and education encountered difficulty when trying to convince their parents to accept the idea of white marriage, however men more easily reveal the relationship. Difficulties in convincing parents arise because consensual solidarity among generations regarding white marriage is low and the conflicts are difficult to resolve. This explains why in many cases couples prefer to hide their relationship status, or to keep contact with family as minimal as possible so that they are not aware of the nature of the relationship. In this regard, there is no clear pattern among different groups of white marriage - almost all faced challenge or predict challenge in the case of revealing the relationship and trying to convince their parents. 
In other words, although inter-generational interaction exists in white marriages, some aspects of such relationships are minimal. The significance of this lack of intergenerational attachments is unique and somewhat alarming in the context of the sociodemographics of Iranian society, where interaction among generations is becoming more vital than nuclear family bonds for one's well-being and support over the course of a life. As Bengtson (2001) argues, the dramatic increase in the life expectancy of people is resulting in more years of shared lives among generations, thus opening up the opportunity for more help given and received, solidarity, or conflict or both. This point applies to Iranian families as life expectancy is increasing (Pourmalek, et al. ,2009), in addition to divorce and re-partenring. In other words, the rise in marital instability and dissolution, as well as serial marriages and being voluntarily single over the last few decades in Iranian society means there has been a decline in the reliance on support from nuclear families. The lack of generational bonds among family members are even more important in white marriages, because these relationships in self-regulated and postdivorce groups follow several re-partnering patterns.

As I mentioned, a lack of consensus solidarity limits inter-generational support. It is true that there are attitudinal shifts and that people prefer to rely on their partners rather than on their extended families, but in reality, white marriages do not last long (with the exception of those that document their marriage later). Therefore, the impact of an individual's choice regarding white marriage on his or her inter-generational relationships increases the possibility and potentiality of vulnerability and of being lift in a helpless situation. 
In summery, different forms of relationships were observed: low structural solidarity, moderate functional solidarity, and very low consensual solidarity. There is a gender difference in functional solidarity, with women exchanging more support with their families. Because of different generational value systems, almost all families, regardless of their differences, do not accept white marriage easily; however, to avoid contentious relationships with their extended families, women and men in white marriages usually have different strategies. Women usually hide the relationship for a while and men maintain minimal interaction with their families. When they feel that their relationship is stable enough, then they usually reveal the relationship (often not disclosing that they live together) and try to convince their parents. Another gender difference is that after revealing the relationship, women are more easily welcomed by their partner's family than vice versa. Reasons and motivations for white marriage vary in pre-marital, post-divorce, and self-regulated relationships. In pre-marital white marriages, the aim is testing the relationship or to delay marriage until financial or career establishment. In post-divorce white marriages, reasons and motivations are associated more with objections to marital norms and regulations. The last group, which conceives of white marriage as a self-regulated relationship, defines itself in terms of anti-authority struggles and resistance. Here, the couple pursues recognition of their chosen lifestyle, self-creation, and self-identification. In all three groups of white marriage, the relationship is assumed to be modern and reflective of western life-styles. Considering the contemporary rapid decline in birth rates and changes in attitudes regarding having children, childbearing is an important aspect of white marriage. In the next chapter, I examine childbearing in white marriage. 
This chapter highlights that the number of people in white marriages has been estimated at about nine per cent of the young urban population, mostly from the middle class and from a non-religious background. White marriages usually last less than six years and usually convert to marriages with the same person or lead to dissolution and repartnering with another person. Marriage to a different person after the dissolution of white marriage is another possible category, but my relatively small sample did not include such a case. Childbearing is not expected within white marriage relationships. The categorization of white marriage highlights three groups: post-divorce, premarital, and a self-regulated relationship. The reasons and motivation for white marriage varies depending on whether it is premarital, post-divorce or a self-regulated relationship. It seems that in the process of forming a relationship, the first motivation is to spend more time together; the second is to test the relationship; and finally, a rejection of the institution of marriage, regulations around divorce and the normative gendered culture of intimate relationships. Ultimately this is a way towards self-realization and selfdevelopment. Partners form a white marriage based on what they imagine to be the model of cohabitation in the West and their desire to be modern. Regardless of the form of white marriage, my interviews reveal low structural solidarity, medium functional solidarity and very low consensual solidarity among people in white marriage and their extended family. There is no clear association between different forms of solidarity and various groups of white marriage. However, when gender dynamics are examined, we see that women are less comfortable disclosing their relationship, but that they are more welcome in their partner's family. Moreover, women exchange more supports with their extended family than do men. 


\section{Chapter 5. WHITE MARRIAGE AND CHILDBEARING}

My research, similar to Amirmazaheri, et al. (2016), has determined that white marriage is a childless relationship. In this chapter, first I illustrate the relationship between white marriage and child-bearing from the perspective of people who are in this arrangement. Then, I trace the gradual transition in the perspective of Iranian politicians regarding white marriage in relation to childbearing.

In so doing, the main ideologies of and practical barriers to child-bearing for couples in white marriages are explained. It seems that young women and men's ideological opposition to childbearing are inspired by images of western ideology and the desire to be modern. The images further rest on three assumptions: first, a singular path of historical progress, second, Eurocentric modernity as utopia, and third, the binary opposition between Iranian traditions and modernity. Moreover, in practice, barriers to documentation are among the main reasons for white marriages remaining childless unions. I also found that the gradual transition in politicians' views regarding white marriage is attributable to demographics, public health, and the decline in birth rate and population targets for Iran's future. As mentioned, this is because of the fact that white marriage is childless and the increase in white marriage follows the decrease in birth rate, which is in opposition to current population policy.

To my knowledge and according to my research, studies regarding childbearing and white marriage in Iran are few. The related information is also not available in many other contexts such as India, China, and other countries in Southeast Asia where cohabitation is a relatively new phenomenon. However, the relationship between cohabitation and childbearing has been well-studied in other contexts such as in Europe, 
North America, and Australia (See: Kiernan, 2001; Loomis \& Landale, 1994; Thornton, A., \& Philipov, D. 2009; Buchler, Baxter, Haynes, \& Western, 2009) where common law partnership is well-stablished. In what follows, I first discuss selected studies.

As Kiernan (2001) argues, European countries have responded to childbearing behavior outside of marriage in various ways. Comparative studies have shown variations across Europe in terms of childbearing outside of marriage (Kiernan, 2001). In Nordic countries, childbearing is more prevalent in cohabitation. In western Europe countries intimate relationships usually have multiple stages and more commonly begins with cohabitation. In these countries the rate of childbearing outside of marriage is higher than in southern European countries where cohabitation is not a dominant part in the first steps of a relationship; consequently, the birth rate outside of marriage is also rare (Thornton \& Philipov, 2009). In the US, the variation in childbearing practices outside of marriage is more often associated with race and income (Olsen \& Farkas, 1990). In fact, Black women and low-income white women are more likely to have children outside of marital union (Loomis \& Landale ,1994). Similarly, in Russia, childbearing outside of wedlock is grounded in socio-economic status: lower-income women with less education demonstrate a higher birth rate in cohabitation (Perelli-Harris \&Gerber, 2011). In countries such as India, where cohabitation is taboo; childbearing is socially accepted only in wedlock. Likewise, in East Asia where cohabitation is stigmatized, childbearing outside of the marital union is unlikely. However, as cohabitation rates increase in Korea and Japan (Kojima, 2010), childbearing outside of marital unions has increased in recent times. In China, cohabitation is more prevalent in educated and socio-economically privileged classes, primarily in the generation born after 1980 (Yu \& Xie, 2015). More 
research and investigation into childbearing in such arrangements within China is needed.

Studies in the United States indicate the importance of marital status rather than common law status for more attitudes towards child bearing (Heaton, Jacobson \& Holland, 1999). This picture is complicated by the study of Edin and Kefalas (2005). They found that married low-income women are less likely to want to have children than common law partners with greater income. The conceptualization of cohabitation also plays a role in choosing childbearing. In Italy, cohabitation is conceptualized as a resistance to long-term commitment and sometimes to family norms. Given this cultural meaning, it is unsurprising that the experience of cohabitation, whether or not followed by marriage, increases the probability of choosing childlessness (Tanturri \& Mencarini, 2008). In contrast studies of the United States (Edin \& Kefalas, 2005), economic conditions do not seem to have an important role in predicting voluntary childlessness in Italy (Tanturri \& Mencarini, 2008). In addition to cultural meaning and economic challenges, other reasons for attitudes regarding childlessness include the general fragility of cohabitation (De Sandre, Rettaroli, and Salvini 1997) or what Giddens conceptualized as “ontological insecurity” (1992).

Like Italy and India, white marriage in Iran is also a childless relationship. The phenomenon of childlessness in white marriage is better understood in the broader context of an increasing rate of "families without children" and a decreasing birth rate in the post-revolutionary era (Aghajanian, 2001). In general, it is safe to indicate that childbearing is no longer the main function of a family, and couples' expectations reflect the growing complexity associated with new lifestyles and new societal expectations. In 
fact, as Azadarmaki \& Bahar, (2006) illustrate in their study about familial values in

Tehran, there has been a dramatic shift in norms among Tehrani people towards individualism and self-driven choices. Even though most of them are not turning away from marriage and parenthood, the shift has decreased the rate of birth. In the same vein, deliberate choices to have only one child have increased (Khalajabadi-Farahani \& Saraiy, 2016)). This decision about the time to have children is mostly made by mothers who wish to be a parent while pursuing goals of self-fulfillment (Khalajabadi Farahani \& Saraiy, 2015). Attitudes toward childbearing and birth rates are associated but not limited to social factors. Population control strategies also dramatically direct childbearing. To contextualize Iranians' changing attitudes towards giving birth, I discuss population control strategies after the revolution below, including three phases: first, pro-natal policy between 1978 to 1986, second, birth control policies from 1986 to 2007 and third, pronatal policy since 2007 .

\subsection{Population Control Strategies in Post-Revolutionary Iran}

After the revolution, many pro-natalist policies were issued; "on the grounds that Islam and Iran needed a large population" (Abrahamian, 1993, p. 140). The pro-natalist policies included the closing of family planning clinics, the lowering of the legal marriage age, the increasing in contraceptive prices, and providing financial support to newlyweds to ensure more marriages and more reproduction (Riddell, 2009).

During the war (1978-1988), family planning was still the main strategy to encourage population growth (Hoodfar, 1995). Iran lost many people in the war and the government encouraged increasing the national birth rate to fill the gap. Moreover, during this time, contraceptives were not easily and freely available (Hoodfar, 1995). By the end 
of 1986, the birthrate had reached approximately 6.2, which indicated a rapid and alarming growth in the population. For this reason, by the late 1980s, a well-designed and properly funded family planning policy (Vahidnia, 2007) began under a social/political program that employed volunteer women working from mosque-based organizations to attempt to reduce the birth rate to avoid overpopulation and its socioeconomic consequences. Supported by religious institutions that legitimized using contraceptives, based on a flexible understanding of Islam, the family planning policy led to a cultural acceptance of the use of birth control (Hoodfar,1995). The national family planning policy targeted various classes of women, including low-income, traditional, wealthy, and highly educated women, as well as those in rural areas. The plan successfully operated between 1986 to 2007 by the state to reduce the birth rate. Under this program volunteer women went door to door, not only to provide education regarding the necessity of using contraceptives and population control, but also to distribute free contraceptives (Bahramitash \& Kazemipour, 2006). The major achievement of Iran's national family planning policy was a considerable reduction in the birth rate. The population growth rate decreased to 1.4 per woman in 2002 (Bahramitash \& Kazemipour, 2006) from 6.2 per woman in 1986 (Aghajanian,1995) and was still declining in 2012. With these changes, the freedom of choice for Iranian women has expanded rapidly in a short time. As a result, women gained greater personal rights, not only over their physical bodies but also over their personal lives. Behind the transition is a dramatic shift in norms toward individualism, which is moving women away from early marriage and early parenthood. Having a child became more of a deliberate choice for greater self-fulfillment (Karamouzian, et al. 2014). However, the birth rate soon plummeted to a point of below 
the replacement level, resulting in low population growth and alarmed politicians regarding many socio-economic consequences. The increase in dependency rates and the demographic transition to an older population structure, and eventually a decline in population are some of the consequences. It seems that the successful family planning policy had overshot its aim (Karamouzian \& Haghdoost, 2015).

Iran's approach to family planning has gradually changed since 2007 when it adopted pro-natalist policies (Howse, 2016) in order to avoid population aging and its economic consequences. The Supreme Leader of Iran, Ayatollah Ali Khamenei, has expressed concern about the slow population growth. He believes that birth control policies should have ceased in the late 1990s to prevent the birth rate falling below the replacement level (Mohamadi, 2013).

In July 2012, the family planning budget was cut, and the public health sector stopped all routine public birth control services. The new strategy was launched. It targeted mostly women and promoted having three children by the age of 30 (Karamouzian, et al., 2014). In 2014, Howse (2016) further explains that, Iran's Majles, or parliament, passed a law that represented a formal reversal of the existing family planning strategy by ending the subsidization of birth control programmes that provide free access to contraceptives. The first step was to restrict access to contraceptives and birth-limiting surgeries. Although public access to free contraceptives was not banned (Karamouzian, et al. 2014), free access to most contraceptives was restricted only to vulnerable populations and further controlled through service-providing centres (drop-in centres for example) (Karamouzian \& Haghdoost, 2015). All attempts to increase the 
birthrate, however, have been unsuccessful. In 2015, the birthrate was still lower than replacement level, 1.68 births per woman (World Bank, 2015).

In summary, population policies in Iran have changed from pro-natal policy in 1978 to birth control policies in 1986 , to pro-natal policies in 2007 which promote childbearing and parenthood as desirable for socio-economic and demographic reasons. This is the demographic and ideological context within which some major concerns about white marriage take shape.

\subsection{Attitudes Regarding Childbearing in White Marriage}

White marriage is childless. Reasons for this choice in white marriage are somewhat similar to reasons explaining the dramatic decline in the national birthrate. However, there are still some observable differences. People in white marriages also place stress on individualistic values and self-development, and actively reflected on their ideological reasons for not having children. The legal barriers for documenting the birth of the child is also a practical reason. In other words, although people in white marriage welcome the challenges offered by choosing this lifestyle, they cannot ignore the practical difficulties associated with having children without a documented marriage.

I witnessed different forms of attitudes regarding childbearing among various white marriage groups. Firstly, a majority of interviewees in all groups shared their own ideological opposition to having children. Secondly, a few participants in self-regulated and post-divorce relationships mentioned that although they are interested in having children, the documentation barrier in white marriage relationships is a practical obstacle. Finally, some interviewees in pre-marital relationships expressed a desire for children conditional upon documented marriage, which not only reflects on the documentation 
barriers, but also the general symbolic value of marriage. I also talked informally to a couple of people who documented their relationship after being in white marriage for a while and had children later; however, they did not agree to an interview. Below I further explain the reasoning behind childlessness in white marriage relationships.

\section{Ideological Opposition to Childbearing}

Couples in white marriages are all childless. Among the many reasons that might influence their decision to be childless, either in premarital or post- divorce or selfregulated relationships, is an ideological opposition to childbearing, which is sometimes attributed to western culture. They generally point to the western childless lifestyles as a contributor to this "progressive" idea. I argue that the idea of western culture that makes it a value reference model for people in white marriages with respect to child-bearing, is rooted in three assumption: a belief in Eurocentric modernity as a utopia, a belief in a singular path of historical progress, and a belief in the duality of Iranian traditions and western culture. Below, I explain each assumption with related evidence taken from interviews.

Among the participants, Maryam was the person who most directly explained how she came cross the idea of white marriage and childbearing directly to western cultural products. Other interviewees explained the relationship between the choice of childlessness and western culture in a less direct manner.

I guess I watched this kind of relationship in Dr. Quinn, The Medicine Woman TV series. They lived together for a long time and then thought about marriage and having a child together. (Maryam, female, 35)

A common theme in almost all interviews is the idealization of the west. The interviewees see modernity and "progressiveness" in their perceptions of the western 
lifestyle. As I mention in Chapter 4, all interviewees had an active immigration file or a plan for it. It seems that even though Iran has never been formally colonized, it has been affected indirectly by the global dominance of western culture. The desire to emigrate to western countries in Bhabha's account (1994) is an indicator of its continuing neocolonial relationship. Neo-colonial relationships, according to Said's explanation, have created a systematic body of knowledge that reproduces images of colonized people primarily as deficient and primitive (Said,1985). Fanon (1961) and others (e.g., Hage, 2000; Loomba, 1998; Spivak, 1999) have asserted that colonized people have not been able to stand against these images even after the formal decline of European empires; some internalize it. This is due to the socio-economic and political subjugation of their countries, as well as internalization of their images as represented in colonial discourses (Ali, 2008).

El-Enany's explanation of Occidentalism (2006) is that in the Middle East, if Orientalism was/is about the denigration and the subjugation of the Oriental Other, then Occidentalism has fallen into the category of idealization of the Occidental Other (usually the west). Sometimes, this is combined with self-accusation, what Creighton (1995) names "self-Occidentalism." In Poya's case, he does not want to have children because of the shortages and disadvantages in his motherland. Although he has not lived in the west, he sees it as ideal.

Oil prices are falling. Morality is fading in society. Having a child is crossing the line for me. A child shouldn't grow up in Iran. People are not loyal to morality. Even the foreigners who travel here can see this. Most of my friends have left Iran, I'll leave too. (Poya, male, 32)

In a different part of interview, he added, Iran is not a place to have or to raise children. 
Childbearing is my red line. Kids should not grow up in Iran. There are too many risks. There is no commitment to morality here. (Poya, male, 32)

This point is also repeated in what Naz said about her partner, she explained it to demonstrate why her partner did not accept any negotiations about childbearing:

He used to live with his fears. He really thought that in 10 years the economy and water situation would make Iran like Somali. He really thought one of these days an earthquake would destroy Tehran and Alborz Volcano would erupt. Because of these fears he didn't wanted us to have a child. Thoughts of immigration destroyed everything. He wanted to go to The United States. (Naz, female, 30)

Farid also expresses ideological opposition to childbearing, however offering a different perspective; he believes that childbearing is immoral. Educated in and seemingly interested in western philosophy, he identified himself as an intellectual. As part of his philosophical framework, he avoids making decisions regarding his partner's body about using or not using contraceptives generally and in the case of unintended pregnancy specifically.

If she gets pregnant, she would abort it immediately. It is her body. I cannot decide for her. I would like to have kids, but she would not. Sara hates the idea of having children. I learned that it is immoral to make children. Child bearing is selfish. (Farid, male, 32)

Showing me a photograph of his nephew on his cell phone screen, he explains that he gives all his love to his nephew, and financially supports him, but will not take that same step into childbearing to bring another person into this "nasty" world for his "own sake".

As mentioned, most interviewees expressed an ideological opposition to childbearing, which makes a relationship between two people a childless setting. Grounded in an idealization of the west, they provide evidence from western culture to 
support their logic and arguments, which demonstrates they have not left "modernity as utopia behind" (Pieterse, 2009) and more importantly that they assume a singular course of progress as in the west ${ }^{30}$.

For example, Ebrahim is one of the interviewees who describes his opposition to childbearing as an ideology related to western culture. He repeatedly refers to western lifestyles to support his perspective and to challenge opposing views on different topics, including childbearing. He said that his logic is so self-evident and clear in a way that instead of having to explain why one does not have children, what is needed is explaining why they continue to have children.

Now in the west, people are wise enough to fulfill their parental instincts by taking care of pets, instead of having children. (Ebrahim, male, 32)

Then he mentions legislative barriers and again brings proof from western cultures:

Having children does not appeal to us. There is no way it can happen in Iran. We're talking about another person's destiny, another life. It is a child's right to have a legal life. Not having documentation would be a hassle. No one can have children within a white marriage. If one wants to leave the country, then perhaps it's possible. In Scandinavia, one could legally register the name of the child without being required to give the father's name. In Iran, that is impossible, as the child needs an ID. It's another person's life, right? If I want a kid, I'll get married. (Ebrahim, male, 32)

During my interviews, I was faced with the universalist notion of modernization that assumes developing countries are living the history of the West, accepting a single history and a single modernity.

30 - A singular course of progress is grounded in the teleological outlook that there is a single dominant direction that all societies will follow towards modernity, following the temporal statement of "first in the West, and then elsewhere" (Chakrabarty, 2009, p.6; see also Hall \& Gieben, 1992; Walby, 2009). 
For instance, in Hamid's perspective, who was in a white marriage for two years and who was preparing for marriage with the same woman, changes in sexual attitudes and the phenomenon of white marriage happened in Iran after the sexual revolution in the west but having children outside of wedlock has not happened in Iran "yet". He describes Iran's current situation as follows:

Having children should occur within marriage, not outside of it. That is the beauty of marriage. Today's societal situation is like Europe in the sixties. Society is molting (transforming). Sexual relationships outside of marriage and white marriage have largely launched, but still not having children (outside of marriage). (Hamid, male, 28)

In his perspective, what happened in the west would happen in Iran later. In other words, Iran's current situation regarding sexuality and childbearing parallel the past of the west.

As in the above Hamid quote, interviewees say that they believe white marriage is a signifier of a sexual revolution that is happening in present-day Iran after a fifty-year “delay." However, in Pieterse's view (2009) there is no one fixed and standard definition of modernity. Thus, in order to be modern there is no need to follow western culture in terms of intimate relationship or childbearing pattern. Pieterse (2009) suggests plural understandings, plural histories, and plural modernities, rather than one fixed and standard definition of modernity.

Recognizing that modernities are multiple and diverse and transcending ideal-type modernity and its Eurocentric legacy, acknowledges the multipolar realities of twenty-first century globalization and the 'rise of the rest'. Real-existing modernities are mixed social formations in that they straddle past and present and import and translate styles and customs from other cultures (Pieterse, 2009). 
Opposite to Pieterse (2009) explanation following interviewees' quotes suggest that people in white marriage believed in importing imaginaries of western culture life style to be progressive and modern in the case of childbearing, I repeat Ebrahim words below:

Now in the west, people are wise enough to fulfill their parental instincts by taking care of pets, instead of having children. (Ebrahim, male, 32)

In another part of the interview he mentioned that his partner adopted a cat to satisfy her maternal instinct. The point demonstrates that cultural adaptations follow after assuming western culture as progressive.

The same logic is seen in Naz's partner's perspective regarding childbearing. Her partner, similar to Ebrahim's opinion, prefers having pets to children. Having pets as an alternative to child-bearing is not normative behavior in Iranian culture, nevertheless, some people in white marriage believe that pets are substitutes for children in western households. Naz expresses her disappointment about her partner's view.

I wanted to get pregnant, but he said, "If you get pregnant, I'll get a dog and I won't accept any responsibility for the baby." A "dog" to take care of! (Naz, female, 30)

A pluralistic understanding of the "modern" and the creative deployment of modernity are, for example, reflected in Walton-Roberts and Pratt's study (2005) about the modern Indian immigrant family in Canada, whose experiences have been framed by class, gender, and sexuality "in differential, partial and sometimes ironic ways" in comparison to western-style modernity. These families have faced mobile and contradictory modernities that disrupt the duality of East and West and make room for a third space to discuss the creative arrangement of a plural understanding of modern and modernity (Walton-Roberts \& Pratt, 2005), and a plural understanding of past and present. 
Such creative understanding and deployment of modernities is also demonstrated in the hybridity of Muslim women in Canada which destabilizes inflexible, fixed and static assumptions about Muslim women who live in the West (Khan, 1998). Khan believes that a plural understanding of modern and modernities and some breaking from the traditional creates a third space to exhibit a hybrid identity that is both religious and modern. These studies demonstrate a recognition of a creative understanding and deployment of the modern that provides room for acknowledging plural presents and the multipolar realities of globalization. This is not the understanding of people in white marriage regarding modern and modernity.

During my interviews, I also realized that despite the "multi-layerness of modernities" (Pieterse, 2009) multipolar realities of modernities (Khan, 1998), some shared components, interconnectivity, and convergence among most modern societies that make up western modernity have been highlighted. For example, the fact that national birth rates have decreased in western cultures has received attention and was addressed in interviews several times. At the same time, other components based on socio-historical and cultural specifications have been largely ignored; for example different attitudes regarding childbearing among American sub cultures (Darabi \& Ortiz ,1987), among various religious communities (Amaro, 1988), among different forms of families (Goldberg, 2010) and among races (Burton, 1990): all in the United States, let alone variations across different cultures and societies in Europe. I believe that the ignorance of people in white marriages regarding heterogeneous western cultures in general and childbearing in specific is rooted in a simplistic, binaried assumption about the opposition between global and local cultures, being modern and being traditional, and 
- in the case of my research - between western and Iranian cultures. Based on this mentality, when people in white marriage want to select non-local reference values for lighter family-centred expectations, or prefer a more individualistic lifestyle (Tanturri, \& Mencarini, 2008), they point to the vague image of a western value system and assume it is a "homogeneous entity". Another point, as I mentioned, is idealization of the West and giving additional uncritical, romanticized value to western culture with respect to intimate relationships, as well as an acceptance of history as a singular path towards the modern West.

Samar, for example, idealizes western culture and believes in the duality of Iranian and western cultures. Despite a fascination with the imaginary of western culture, she rejects adapting to the western path. In fact, she believes that white marriage is a western lifestyle that does not work for Iranians, because of long-established marital norms and traditions that are hard to change. Though she glorifies western culture, she believes this ideal does not fit the Iranian context. Samar's partner, who made her dye and maintain her hair blond, left her and immigrated to the west. Samar believes:

Western men's love is really love. They are more loyal. Here we should be careful not to get fat, put on make-up always, Hamed liked blond hair, I had to keep my hair blond. (Samar, female,31)

Later in the interview she added:

White marriage was the worst experience of my life. It has never had much currency in our society and it's much better if it never has. We should marry with our own traditions, to have children, in order not to have the permanent fear of losing someone. Now I don't have much more time to get married and have children. My sister learned from my life and got married and has a child. I used to tell Hamed (her partner) that weren't you telling me everything has a solution but death? Why don't you plan for us to get married? Finally, he wrote an email while he was in airplane to leave Iran, I can show it to you, he said I am sorry, I know that 
I won't have a relationship with a woman as good as you, but I need to go, I'm sorry! (she cried) (Samar, female,31)

In Farsi-speaking media outside of Iran including BBC Farsi, Radio Farda (web site), DW Farsi (Deutsche Welle) ${ }^{31}$, which are based in Europe and in the US, white marriage is also usually seen as western, ideal, progressive, love-centered and reflects an egalitarian approach to sexuality. For example, DW Farsi in an article states that "living together without marriage is "still" a difficult choice to make (in Iran), Germany passed it (this stage) many years ago, so the comparison of two country is useful" (Ansari, 2015). The statement demonstrates the assumption that there is a singular path of historical progress, or "first the West, then others". On the same website, a different article about white marriage reviews the history of the sexual revolution in Germany and raises the issue of illegitimate children in white marriages. The article concludes that "in our time when love rather than religion legitimates having a baby, many societies have not used such inhumanitarian terms as illegitimate children" (Ansari, 2015). All photos related to cohabitation in the article show German women and men appearing to be happy and cheerful and, in some cases, a German bride and groom celebrating their wedding in the presence of their children. In the above statement, the author also suggests an oppositional binary between Iranian traditions, including religious traditions, and Eurocentric modernity. In addition, it idealizes western cohabitation as a means to a progressive and happy life. Later in this chapter, I also explain the fluctuating reactions of religious institutions to child-bearing within white marriages, specifically the

31 - Public international broadcaster based in Germany. The service is available in 30 languages, including Farsi (Wikipedia, 2018). 
circumstances surrounding a new published fatwa (declared religious opinion) that does not consider a child born within a white relationship illegitimate.

Regardless of ideological opposition to childbearing, another important barrier for considering this choice is documentation.

Farid for example asides from his ideological opposition to childbearing that I discussed above, highlights the advantage of documented marriage for having a child and prefers to stay in white marriage as he is not willing to have children.

Marriage works only for having a child or for inheritance. I do not affirm or value these concepts. When my sister and her boyfriend (after being in white marriage) decided to marry, I nixed their decision as much as possible. However, they were positive because they wanted children". (Farid, male, 32)

Along the same lines, Toranj and majority of interviewees associate documented marriage with childbearing and do not see any possibility outside of it :

I choose not to have children, so what is the reason for getting married? I have not reached the point where we need to marry. We will keep going in this direction. Mothers usually advise their daughters to marry so the guy will not leave so easily. But I do not believe this. If he wants to leave, he will leave anyway. (Toranj, female, 28)

Although, I expected to hear from the interviewees that economic challenges or the instability of white marriage were reasons for being childless, in fact most in all groups identified ideological reasons as a major cause for childless white marriages. I argue that three assumptions about western culture make it a value reference model for people in white marriage with respect to child-bearing, including: a belief in Eurocentric modernity as a utopia, a belief in a singular path of historical progress and a belief in the duality of Iranian traditions and western culture. Beyond couples' attitudes regarding childbearing, the fact that white marriage is positioned outside institutional recognition plays a 
significant role in a couple's choice to have children. This explains why the majority of the interviewees - both women and men - in all three groups do not consider childbearing an option within a white marriage. However, this early decision may change over time. Changes in decision regarding childbearing can be explained by gender, in different white marriage groups.

\subsection{Gender Difference in Attitudes Regarding Childbearing}

The joint nature of childbearing does not make it necessarily a mutual agreement or mutual decision. In almost all groups, the initial agreement among people in white marriage was to not have children; however, there is a gender difference in that women in post-divorce and pre-marital relationships were more likely to become interested in childbearing in time. Both men and women in self-regulated relationships though usually prefer to stay childless.

As reflected in the interviews, biological differences between men and women also differentiate their perspectives regarding childbearing. A woman's limited reproductive span is an important factor in women's decision-making in terms of whether or not to have a child (Heaton, et al.1999). Moreover, they usually postpone the decision to stabilize their lifestyle, which is related to external and social factors. In some countries such as France, men more often than women are voluntarily childless (Toulemon, 1982). In Italy, childlessness is more common among women in common-law partnerships and for less religious women or women with less religious partners. They generally delay child-bearing, which can lead to childlessness (Tanturri \& Mencarini, 2008). Moreover, Heaton, et al. (1999) found a dramatic number of shifts in child-bearing decisions and behavior over a six-year period in the United States. A sizable proportion of both men 
and women intend to have children, and the strongest factor predicting a change in childbearing intentions is a change in marital status from cohabitation or single to married. The authors argue that despite the significant attention the media pays to child rearing outside marriage, the decision to have children is still clearly and strongly associated to the decision to marry (Heaton, et al.1999). They conclude that "few early child-bearing intentions appear to be hard and firm" (Heaton, et al., 1999, p. 539). As mentioned, one explanation is that as some women fear that time is running out, they then change their minds about child-bearing after becoming established in the relationship. Under these circumstances, the decision about child-bearing appears to be more fluid for women than it is for men.

In my research, while most of the female respondents in self-regulated and postdivorce relationships make an early and permanent decision to be childless, others in premarital relationships simply postpone having children until marriage. Women in postdivorce relationships are more likely change their decisions regarding childbearing. Based on my interviews, the biological clock is an additional pressure on women to reconsider an initial decision. Naz and Maryam, for example, changed their decision about getting married and having children after a couple of years in a white marriage when they stabilized the relationship. Referring to the biological alarm, Samar regrets the time wasted in white marriage, which reduced her chance of being a mother.

The stress of getting pregnant was always with me, although it never happened. [In the case of pregnancy], we could not keep it without being married. Or maybe it would have been better if I got pregnant. Then he would have had to marry me! Now I don't have much time to get married and have children. My sister learned from my experience and got married. (Samar, female, 30) 
In addition to concerns and anxiety about pregnancy voiced by Neda in the following quote, she also changed her mind about childbearing after marrying her partner.

I want a baby. I would like to get pregnant (after getting married to my partner), but back then (while my partner and I were in a white marriage) I was scared to get pregnant. He used to assure me that if it happened, we could count on our moms. We thought we knew what to do to avoid it happening and it really didn't happen". (Neda, female, 31)

In contrast, men's decisions in all groups mostly remain unchanging, even in the case of unintended pregnancy and difficulties of abortion for their partner, which is illegal, usually unsafe, and expensive. Nastoh mentions the biological clock, but it does not change his mind:

If it (pregnancy) happens, she would get an abortion. An unwanted baby should be aborted. Generally, I don't like kids. At parties when kids make noise, I'll leave, or in an airplane, I would change my seat. By the way, we are gradually getting too old for this. We will marry after twenty years of friendship and living together for a couple of years. The apex of my life has passed. (Nastoh, male, 32)

Poya also does not consider the possibility of keeping children.

We had her monthly period under control (they used contraceptives but to be extra conscious made sure not to miss a period). We agreed that if pregnancy happened, we would get an abortion, but we were very careful. We had safe sex. It was one of the first things we agreed on". (Poya, male, 32)

Unintended pregnancy however was acknowledged as a turning point that in some cases could change women's mind about childbearing. Sepideh, for example shared:

Having children is not in my next ten years' plan; however, the moment that a woman realizes she is pregnant, a new world may open to her. Today won't be the same as tomorrow. I need to be in the situation before I can tell. I don't know [if I would keep it or not]. I cannot anticipate. (Sepideh, female, 25)

Similarly, Elaheh believes that an unintended pregnancy might change her decision; however, she has strong opinions against planned pregnancy and having children. 
Pregnancy . . . no, I never thought about it as an option, neither when I was married nor now that I'm in a white marriage. It is too heavy a responsibility to carry, now that I see my nephew. Too difficult! My exhusband did not like children. Although, I like them, I believe it is so unfair to deliver another person into this world before finding ourselves, and our lessons to pass on. After all, it is neither possible nor logical for a person who is 60 years old (her partner's age) to have children. If it happens, I may have a different feeling, but at this point I would say that I would not keep it. (Elaheh, female, 35)

Navid is an exception among men, who has a different view about unintended pregnancies. Although he does not want children, he changed his mind in the event of an unintended pregnancy. Similar to others, he does not see the possibility of childbearing outside of wedlock.

Once we suspected that she was pregnant, I told her I did not want to take a life. Still, we had seven months to get married, so I had no problem to marry and to keep the child. Taking a life would affect our relationship. She agreed. Finally, we realized that it was an error and she was not pregnant. (Navid, male, 32)

The gender difference regarding childbearing within a white marriage is echoed in the different opinions of women and men. Although both partners in all groups of white marriage agree on avoiding pregnancy, women in pre-marital and post-divorce relationships sometimes change their minds about an initial agreement to not have children. The change is usually because of three reasons: first, because of being more settled in their lives, second because of a ticking biological clock, and third because of unintended pregnancy. In all situations, people in white marriages prefer to get married to bear children or to keep the pregnancy. However, in some cases, women's desire to produce children is unwillingly suspended and leads either to not having children or creates a conflict. In self-regulated relationships, usually both women and men firmly do not want children and in all groups, women are more concerned about unintended 
pregnancy and its consequences. This point demonstrates the unequal social and physical burden on women in white marriage.

\subsection{The Unequal Social and Physical Burden on Women in Untended Pregnancy}

I would like to open room to discuss part of the unequal social and physical burdens on women in white marriage in the case of unintended pregnancy. This issue is one of the most frequently mentioned concerns in official media (Goyanews, 2018; Mashreghnews, 2018; Irna, 2018) and also is one of the most frequently asked questions that I encountered both in conferences and in daily conversations with people. Moreover, during the interviews, some of the participants shared their difficult experiences with health services in the case of unintended pregnancy. Portraying this challenging situation demonstrates how women are determined to choose white marriage as a counter discourse over documented marriage.

It is true that abortion is conditionally illegal ${ }^{32}$ in Iran, however couples in white marriages and specially women face a double-edged challenge: the unacceptability of children outside of marriage and also difficult access to safe abortion services. Thus, in the case of unintended pregnancy there is a general stigma and cultural disdain for the relationship itself, in addition to documentation barriers that do not allow them to keep the child on one hand and do not give them access to safe abortion services on the other. This is a double-edged challenge that creates a stressful situation and often results in the choice of women to not seek medical and familial support. The situation leaves them in a state of absolute vulnerability. The double-edged challenge also explains why almost all

32 - Based on current legislation abortion is illegal except lift-threatening conditions for mothers or diagnosed specific illnesses for fetus. 
people in white marriages avoid pregnancy and prefer to remain childless as long as they are in this relationship.

Fazi was only 21 years old when she got pregnant. Fazi and his partner ended the relationship after abortion and she moved back to her family, but after a while they moved in again.

When I got pregnant, we went to a private doctor's office for an abortion. The doctor shouted and asked us to leave the office when he learned we were not married. My partner and I cried and begged him to do the abortion. After the abortion, I was depressed for a long time. We were badly humiliated. We also used all our savings, and we found out later was more than the normal cost of an abortion. (Fazi, female, 30)

In Naz's experience, visiting health services for regular physicals resulted in a negative experience:

I visited a doctor for a checkup. She asked me if I was on the pill and about my marital status. When I told her that I was living with my boyfriend, she kicked me out of her office. I was terrified that she would call the police. I was lucky that she did not. (Naz, female, 30)

Ebrahim's experience demonstrates in detail the lived experience of couples in white marriage unions in a situation in which abortion is illegal and white marriage is not accepted.

Abortion can happen. It happened for us. After working hours, in a private doctor's office, at a high cost, without any anesthesia or even numbness, my partner could have an abortion if she was willing to tolerate the pain. It (the embryo) had no heartbeat; it was not yet a person. But if someone told me, you killed it, I would say that society killed it, by calling it illegitimate. In fact, whoever issued this nasty law is illegitimate. After the abortion, her whole uterus was injured and infected. The doctor did not answer our phone calls and we went to another doctor to treat the side effects. It ended in a serious surgery and they were able to save her uterus. It happens to many people. (Ebrahim, male, 32) 
Navid's experience also explains how women's health is affected within the framework of white marriage and unintended pregnancy. In this case, abortion led to infertility.

In her last relationships she aborted two times. We think she cannot get pregnant anymore. Although we have unprotected sex, her body rejects it. (Navid, male,32)

As evidenced above, the stigmatization of white marriage, documentation barriers with respect to childbearing, and the inaccessibility to safe abortion services come with heavy costs to public health in general and to women's health in particular. This point became a centre of attention in official media discussions; I extensively discuss it in the next section.

\subsection{Media, White Marriage and the Issue of Childbearing}

Childbearing in white marriages, either having illegitimate children or having no children, is the main concern expressed about white marriage in the media. After a period of silence in the media about white marriage which was a new, taboo, and unknown phenomenon, the expressed concerns about childbearing within white marriages engaged different discourses that simultaneously discussed the issue. It began with more emphasis on religious and moral views that encouraged prohibition policies. Gradually media debates emphasized health and population concerns that supported management of the phenomenon, in ways which suggests a gradual move from sovereign power to biopower around the problematizaiton of white marriage.

Biopolitics has root in modern history. Foucault (1978) argued that in the seventeenth and eighteenth centuries in Europe, political interests gradually shifted from decisions over life and death or control over territory to the management of "life." If the 
sovereign has the power to let live or cause to die, then biopower has the power to protect life or allow to die. The management of life in the case of white marriage is that the political system gradually becomes interested in childbearing and concerned with protecting life in white marriage unions for population purposes. The protection of life in this case means giving the opportunity for child-bearing with legal protection for couples in white marriages. This would begin with recognition of and management of the issue.

Before 2010, the term "white marriage" was non-existent or barely used in the media $^{33}$. Later, based on my research, the phrase white marriage was gradually and more frequently used on online official news websites rather than in printed newspapers. Gradually, after a time of silence, the media warned that not speaking about white marriage would increase its consequences. For example, in 2015 Ananews interviewed sociologist Ahmad Bokharaiy, a member of the Iranian sociological association, about white marriage. He is one of the first academics who warned against staying silent about white marriage and stressed the importance of discussing the phenomenon in public: "Keeping silent (about white marriage) is not a solution". He added that we should not be afraid to engage in dialogue about the social harms, that rather we need to empower young people with knowledge (Ananews, 2015).

With more debates about white marriage occurring in the media, later in the same year, Golzari, Assistant Deputy Minister of Youngs, Moaven vazir javanan, in an interview with Farsnews in Rodehen denied the issue, asserting, "We believe that we do not have white marriage in our society" (Fararo, 2015). In the same interview, he also

33 - Nevertheless, based on my personal observations and as evidenced in the interviews, the practice of what is now described as white marriage existed on a very small scale at least a decade before 2010 . 
criticized debates about it in media, as he claimed that there were no statistics to support the prevalence or existence of the phenomenon (Fararo, 2015). At that time, white marriage was problematized in the news usually with moralistic and religious views and the emphasis was on the necessity of moral regulations with prohibition policies. For example, attitudes concerning white marriage in the media suggest that it is defined as a threat to religious values, norms, and interests. Thus people in white marriages are portrayed as dangerously deviant and therefore a menace to society (Alhoseini, 2014). Pictures printed in articles usually did not show the faces of people in white marriages and implied that they were criminal (Yjcnews, 2014). Using metaphors to describe white marriage such as "bomb" (Alamolhoda, 2016), poisonous food (BBCFarsi, 2015), sonami (Ana News, 2015), terrifying nightmare (Dananews, 2017, Jamejam, 2015) and DAESH (Isnanews, 2016) and also making associations between white marriage and addiction (Yjcnews, 2017, Etemad, 2015), sex work (Farsnews, 2017) pornography, alcohol consumption, which are religiously and socially taboo, the media generally crystallized public anxiety and represented white marriage as a sign of the collapse of morality and damage to the future moral and religious climate (Etemad, 2015; Isnanews, 2015). Such a description, rather than any analysis, demonstrates that society is in a state of moral panic. As Garland (2008) argues, moral panic occurs when a condition, an affair, a person or a group of persons emerges and is defined as a threat to social values, norms and interests; its nature is raised by and associated with mass media. Indeed, moral panic is a unified, societal reaction against the perceived source of a defined threat-which can be an individual, group, community, or culture-that seems dangerously deviant and therefore a menace to society (Garland, 2008), which is in this case people bearing illegitimate 
children within white marriage. This is seen as a threat to the concept of normative marriage and the normative family setting.

In those discussions, white marriage was framed in moral and religious discourses that condemned the practice as a haram, or forbidden relationship. In 2014, an article that published in Isnanews agency and republished in many other news-websites called white marriage another name for illegitimate, forbidden, and haram relationships (Yjc News, 2014). The article directly grouped white marriage as a taboo and religiously forbidden sexual relationship. In the same year - 2014 - at the opening ceremony of a new project of the Barekat organization, the Chief of Staff to the Supreme Leader, Rais daftar rahbar, Mohammadi Golpayegani, who is one of the first outspoken critics of white marriage, and whose remarks received extensive media coverage in many different news websites, focused on the relationship between white marriage and childbearing (Isnanews, 2014). In his lecture he states, "After a while, people who choose this lifestyle (white marriage) would lose their Halal (religious term meaning legitimate) generation and (their generation) would transform to Haramzadeh (illegitimate) generation". He concludes that the Islamic government should stand against it (Isnanews,2014) which clearly encouraged the prohibition approach to curb the phenomenon. The same approach was echoed in other media discussions calling for a stand against the phenomenon, arguing that it would lead to social harm (Ananews, 2014; IRNA, 2016).

Meanwhile, the phenomenon has been framed as a western lifestyle and a "conspiracy of the west for a soft and cultural war" (Ananews, 2014). One of many such instances is Ferdosi's speech, university professor at Shahid Beheshty, in a conference at Azad university in Hamedan. She spoke about effective interaction with young people at 
the time of social crisis. She said white marriage is a serious alarm bell for Iranian society and with such plans (promoting white marriage) which are rooted in western culture, the enemy wants to change young people's cultural identity (from Islamic to western) (Ananews, 2015). She suggested Jahadi, fighting approach to face the phenomenon. In another article, "White Marriage and Divorce Celebration are Both Conspiracies," Shahbazi states, "All (social) problems are rooted in the family, and enemies of this country and of Islamic societies aim to make the family weak, because if the family weakens, then all aspects of the society are affected." (Shahbazi, 2015, Ananews, 2014) The conspiracy, from their point of view, is that they assume a cultural aim of western societies to change or destroy family and familial values in other countries (mostly Eastern). It is believed that western cultural goals to affect familial values are driven by producing immoral films and TV programs and broadcasting them via information technology and satellite. In their view, white marriage is the same as the western trend of cohabitation and it is one of the immoral concepts imported via information technology and satellite (Ananews, 2015). All these discussions encourage prohibition and control of the phenomenon.

Gradually after discussing the religious and moral concerns of childbearing in white marriage, in late 2015 and early 2016, the media started to engage in population discourse, rationalities, and justification. In other words, after a period of silence and denial, then a period of moral and religious denunciations, since late 2015 the main logic in the official media has shifted to a concern with the population; in particular, that the extensiveness of white marriage is resulting in a decline in Iran's fertility rates (Ananews, 2016; Shargh, 2015; IRNA, 2015). They argue that young women lose and waste the 
reproductive capacities of their bodies in unstable relationships such as white marriage. For example, Asghary, the author of the newspaper (Shargh) article "Women Who Will Never Be Mothers," writes about general birth rate concerns related to women who remain single or choose white marriage (Asghary, 2015). Asghary (2015) explains that the ubiquity of both celibacy and white marriage among Iranian women result in a decline in the birth rate. She assumes that women's unwritten duty to their society is childbearing. Regardless of the cultural challenge of being an unmarried woman, the author claims mental and physical health would increase as women who do not use their childbearing capacity age. She concludes that women are not responsible for the birth rate decline, but that they are victims in a society that takes away their opportunity to experience the pleasure of motherhood (Asghary, 2015).

Here, we see the emergence of a discourse that exposes the danger for women in white marriages by referring to demographics, the realities of the birth rate and women's health, rather than religious and moral discourse. Taking the same approach, Bayaty (2016), in the article "Consequences of White Marriage from a Psychological View", points to childbearing as one of the main concerns regarding white marriage. $\mathrm{He}$ discusses unstable relationships such as white marriage, suggesting that they reduce the childbearing rate and the chances of women to become mothers (due to the time restraint of the biological clock). He also implies that the potential for men to be a father is not affected by aging. As a result, women have more to lose than do men, who still can have a family. Regardless of the accuracy of the presented information, this article, like many others (Keyhan Londaon, 2015), draws upon the demographic discourse and upon the belief that women have a cultural commitment to be a mother. 
In 2016, a quote from Mohammad Eslami in an interview with Ilnanews agency again attracted the attention of the media to the subject of white marriage (Keyhan, 2016). In 2016 in an interview with Ilnanews agency, Assistant Deputy Minister of Population and Health, Moven fani daftar salamat jamiat vezarat behdasht, Mohammad Eslami proposed that the rise of white marriage will reduce the birth rate and that targets of family plans meant to increase the birth rate will not be met. Along the same lines, Eslami also states that Iran's citizens are responsible for their society's health. As white marriage will negatively influence society's and individuals' health, we (our organization) are ready to help, but we have no statistics about white marriage (Etemad, 2017). This new emphasis on the discourse of "health," citizen responsibility, and an appeal to the birth rate and demography can be understood in the context of Iran's biopolitics, whereby the strength of the population becomes a political question.

As mentioned earlier, biopower is concerned with managing population groups through a biopolitics of the population. Biopower through "series of interventions and regulatory controls" influences "propagation, births and mortality, the level of health, life expectancy and longevity, with all the conditions that can cause these to vary" (Foucault 1978: 139). Their supervision was affected through "an entire series of interventions and regulatory controls:" (Foucault 1978: 139). As I explained before in this chapter, the strength of the population could change policies three times in about thirty years 1978 to 2007. As is evident in media debates, there are some signs of demographic concerns in the management of white marriage. The importance of population may this time gradually change the policy about white marriage from prohibition to management. That is why I contend that the concept of biopower and biopolitics are useful for understanding 
these gradual shifts in population policy and their implications for people in white marriages.

Discussions in the media continued until an important step in late 2015 that ensured that childbearing in white marriage was recognized as religiously approved. Following this acknowledgment, two fatwas, or official opinions of religious clerics, were published recognizing children born in white marriages as Halalzadeh, or legitimate: Ayatallah Shobeiry Zanjani and Ayatallah Sobhani addressed the question of legitimacy of white marriage by asking couples in white marriages who are willing to be together by heart to accept, recognize and say to each other that they are husband and wife with religious words and terms. Under this condition, their relationship would be legitimate. The only condition that Ayatallah Shobeiry Zanjani emphasized was that if it is the first marriage, the woman should get permission from her father to marry. More importantly, both clerics agreed that in a white marriage relationship, children are legitimate (Alef, 2015). None of my interviewees mentioned the change in the religious perspective, as they are not religious people. The change can affect their lives only if the religious recognition can change legislation and ends documentation barriers or if it can decrease stigmatization of the phenomenon.

Most recent media discussions demonstrate that biopower is navigating a policy to manage people in white marriage in an effort to ensure population growth. The current problem is that on the one hand, there is a significant effort to encourage a higher fertility rate and child-bearing in young families; while, on the other hand, the lack of legal recognition affects the choice of people in white marriage to have children. As I have explained, and as evident in the media, with a more fluid understanding of Islam, instead 
of the key policy of prohibition and denial, the road has been paved to accept white marriage and its management for population growth, but still there is a long way to go.

In this chapter, I explained that white marriages are childless relationships, even if setting aside those who have a western-inspired, ideological opposition to childbearing. Those who consider child-bearing in white marriages face documentation barriers. Moreover, the current family planning policy makes access to safe and inexpensive abortions very difficult, which could cause long-term health consequences for women in white relationships. Then, in the event of unintended pregnancy, white marriage partners can neither keep the pregnancy nor can they easily access safe abortion. That is why people in white marriage firmly avoid pregnancy. Media discussions, however, indicate that there are emerging signs of understanding white marriage and a need to legitimize child-bearing within this form of relationship from a religious perspective, which would facilitate documentation and recognition within Iran's governmental and cultural setting. This follows the change in population policy that favors an increase in the birthrate. The shift from denial and prohibition of white marriage to management of the issue for population purposes, in Foucauldian terms, is a shift from sovereign power to biopower. This shift also demonstrates another example of a fluid understanding of Islam based on political and demographic interests.

Childbearing is a controversial aspect of white marriage both inside of the relationship and outside in the society. There is an initial agreement between couples to avoid pregnancy for ideological reasons and/or for documentation barriers. However, there is a gender difference in the willingness to change the decision with women being more likely to reconsider child-bearing during the relationship. The reconsideration that 
sometimes results is either planning for documented marriage or dissolution of the relationship. Childbearing within this relationship is also controversial in the sense that an increase in the rate of white marriage comes with a decrease in the birth rate. This is in contradiction with the aims of current population policy. Thus, it seems after denial and prohibition of white marriage, politicians tend to manage it in order to increase the birth rate. As people in white marriage are the first generation to experience this form of relationship, social norms around childbearing are still developing. Another unexplored social norm in white marriage is commitment in the relationship. I have devoted a chapter to explaining the meaning of commitment and the commitment-making process in white marriage. 


\section{Chapter 6. COMMITMENT IN WHITE MARRIAGE}

In this chapter, I illustrate and analyze the meaning of commitment in white marriage. I intentionally avoid an extended discussion or criticism of goodness/badness of ideal marital commitment (Amato \& DeBoer, 2001) as it is in the area of ethics or moral philosophy and is beyond the scope of my thesis. Instead, I define commitment, then contextualize and analyze commitment in white marriage in three areas: media representation of commitment in white marriage; commitment in the lived experience of people in white marriage; and normative cultural power in defining intimate commitment.

\subsection{What Is Commitment?}

Before defining commitment, I note that I understand commitment as a socially constructed phenomenon shaped by historical, political and cultural forces within a globalized world. Given that, I review common cultural assumptions about marital commitment. The dominant view about marital commitment is based on general norms of permanent monogamous marriage with a specific partner for intimacy (Elizabeth \& Baker, 2014). Marital commitment usually refers to the tendency to continue a relationship throughout one's life through hardship and in spite of appealing alternatives to the marital condition for the whole life (Amato \& DeBoer, 2001). Marital permanency and monogamy between partners are assumed in this definition. In Iran the divorce rate was very low in last generations (Aghajanian,1986). So, most of marriages were permanent. Moreover, polygamy is despised, but can be found in rural areas and the 
fraction of rate by urban population ${ }^{34}$ (Aghajanian, 2001). Consequently, most of marriages are monogamous. Both the low divorce rate and the low rate of polygamy demonstrates that a definition of commitment based on monogamy and permanency despite of life difficulties is generally accepted and practiced in Iranian society. However, divorce rate for younger Iranian people is fast-changing in last decades, that is why conceptualisation of commitment also needs more scrutiny. Conceptualization of commitment among some young Iranians is heterogeneous. To explain the heterogeneity of commitment, I unpack marital permanency and marital monogamy in Iranian context.

\section{Marital Permanency}

As I explained in the introductory chapter, Iranian legislation categorizes marriage as either permanent marriage or temporary marriage. Then, permanency in legal view is not assumed for all marriages. However, low divorce rate ${ }^{35}$ in last generations demonstrate that permanent marital relationships was the case for the last century (Aghajanian,1986). However, the level of faith in marital permanence is subject to significant generational change. As explained in chapter 3, based on Mirmiri, (2011) argument, romantic love among young Iranians (especially among urban middle class) is characterized by temporality and plurality. Unlike the idea of Ta akhar omr be khobi o khoshi ba ham zendegi kardan (living happily ever after), or ba lebas sefid rafty ba lebas sefid bia biron (Go to husband's house with white dress and back with white dress, shroud), ${ }^{36}$ the younger generation understands a romantic relationship as an experience that happens

${ }^{34}$ Based on the 1994 population sample survey, there were 8.5 men married to more than one women in Iran for each 1000 married men (Iran Statistical Center, 1996).

${ }^{35}$ Only t 34,000 divorces registered in 1984 and the Iran population was about 45 million.

${ }^{36}$ An idiom, which reminds brides that they need to be in a marital union for life. 
several times during a lifetime and for temporary periods. Bauman (2003) explains the ideal relationship is the one that is easy to engage in and easy to exist for many young people in the west. In Iranian context, it seems the ideal permanent marriage is shifting. Based on Mirmiry's study (2011) the change in understanding romantic love, plural and temporal, as a base for marriage is one of the contributing factors for higher divorce rate (BBC, 2018), higher remarriage rate (Asanjarani,etal. 2017) and increasing extra-marital relationships (Rostaiy, etal. 2016). Aghajanian \& Tompson (2013), for example, argue that by 1997, the rate of divorce began to increase slowly. By 2001, it jumped to 94 out of 1,000 marriages and by 2011, it reached a high of 153 divorces per 1,000 marriages. This latter rate demonstrates an increase of almost 45 per cent over the 2006 rate. In 2016, the rate was still increasing (BBC, 2018). The level of divorce in Iran during the first decade of the twenty-first century moved the nation into the category of a highdivorce country in the world, along with the United States, Canada, Japan, Denmark, France, Germany, Ireland, Italy, Netherland, Spain, Sweden and United Kingdom (Aghajanian, \& Thompson, 2013). The rate of remarriage also increased significantly during the same period (Asanjarani, etal.2017). These rates also show that it is not easy to impart previous generations' ideals about marital permanence to younger generations. In fact, due to the rate of marital instability and dissolution, young people seemingly hold a comparatively weak obligation for what was once the norm of lifelong marriages. Back to the definition of commitment based on permanent marriage, we need to be more skeptical about its relevancy to young people. The next assumption in the normative definition of commitment for last generations is monogamy or having intimate relationship with a specific partner. 


\section{Marital Monogamy}

Another aspect of commitment as Farber (1987) explains is considering not having another intimate partner outside of the marital relationship. This definition moves further from a physical contact model to a more flexible conceptualization of contact that takes attention, time and focus from the primary relationship to an alternative (Owens, 2006), for both women and men.

In Iranian context, complexity arises because polygamy for men, while undesirable culturally, is permitted legally and religiously (Afay, 2009). In other words, marriage symbolizes conversion into a long-term commitment (Reczek, et. al, 2009) from a cultural viewpoint, but not from the legal/religious perspective. Legal permissiveness of patriarchal polygamy is associated with men's understanding of commitment and extramarital relationships, because being in a relationship with a woman outside of marriage legally and religiously is accepted as a process to remarriage and temporary marriage.

The gender differences in the understanding of marital commitment is also evidenced in a study about people who file for divorce due to a partner's extramarital relationships: men usually tend to react to wives' extramarital relationships with violence and an immediate filing for divorce, whereas women usually file for divorce only if extramarital relationships persist or after at least six months (HabibiAsgarabadi, Hajiheidary, 2015). Alitabar et.al argue that the attitude towards extramarital relationships engenders with an increase in the level of information technology use and in the level of education (Alitabar, et.al, 2014). Based on this study, belief in monogamous commitment decreases with more access to information technology that makes people 
rethink about sexual interaction. The results of another study (Rostaie, et. al, 2016) also demonstrate a strong, significant relationship between extramarital relationships and the use of satellite, which is dominated by western cultural products such as talk shows, movies, TV series and music videos. Based on these studies, attitudes to sexual inclusivity are associated to the consumption of western cultural products among young generations.

In sum, there are two complexities to examine when studying marital commitment among young people in Iran. Firstly, based on the increasing rate of divorce and remarriage there is a generational difference in understanding commitment in terms of permanency for young people. Secondly, based on legal/religious grounds, polygamy is permitted for men. Similarly, men who pursue extramarital relationships are more tolerated by the society than women. Then, it is safe to state that, in Iran, discussions about commitment is about women's commitment. However, for young women and men in white marriage, their normative reference for commitment should not be found in legal/ religious ground regarding temporality and polygamy in marital system; rather, it is more likely shaped by a resistance to governance of marriage in a globalized world. People in white marriage tend to come from secular middle class, with high employment and high education. They barley watch national TV, and are more interested to satellite programs and usually, own high-tech devices such as iPad and iPhone. I turn to the question of how they understand commitment in the next section. 


\subsection{Contradicting Official Media ${ }^{37}$ Portrayal of Commitment in White Marriage}

In this section, I describe the official media portrayal of commitment among people in white marriage and explain why it is problematic and unreliable and how it is contradicted by my research findings. In doing so, I selected some quotes in the media that reveal the most frequent and a quite consistent theme associated with commitment in white marriage.

As mentioned earlier in the dissertation, people in white marriage are the silent object of discussions in official media. The most frequent theme that surfaces in the media about couples in white marriage is that irresponsibility, lack of commitment, and general sexual immorality characterize them. Official media coverage also is dominated by moral and ideological concerns. In almost all of media coverage that I analyzed, it is unclear whether associated data about the quality of commitment in white marriage is survey-based and interview-driven or if it is an assumed fact (Ananews, 2015; Yjcnews, 2014; Isnanews, 2016, Montazerolmahdi, 2013). In the following quote, people in white marriage are stigmatized as irresponsible.

Unfortunately, nowadays, virtual social networks, satellite and information technologies have resulted in intimate relationships such as white marriages, and people who are extremely irresponsible... (IRNA, 2016)

Similarly, the following quote highlights non-commitment, but it is unclear if the description is based on research or on assumption.

In white marriage there is no mutual responsibility. (Ananews, 2015)

\footnotetext{
${ }^{37}$ I did not find relevant discussion about commitment in overseas media.
} 
In the following quote, there is no indication of the evidence for supporting the claim that "less or no responsibility" is a motivation for men to form white relationships.

Pejman Babaei, a sociologist based in Iran, was quoted to have pointed to the falsehood of this marriage, stated that a lack of sense of responsibility is one of the main reasons for men to have such a marriage (white marriage) (Yjcnews, 2016).

In the next example, lack of commitment is associated to an instability of the relationship.

It's living in common without commitment and responsibility, which means one can leave it in the blink of an eye. (Isnanews, 2015)

Lack of responsibility in the next example is presented as a generational problem.

Nowadays, the reasons for the increasing tendency (to white marriage) are problems of legal marriages, as well as a lower level of responsibility in (young) individuals. Our families do not teach responsibility to their children. (Etemad, 2017)

In official media coverage, too, formation of white marriage in general and the understanding of commitment in particular are usually associated with information technologies and western films.

Overall, the official media presents an unclear image of the quality of commitment and the commitment-making process in white marriage; instead, the dominant representation of white union is living irresponsibly and without commitment. Exposing these forms of representation and their implied ideological/religious assumptions can be an important step in weakening their conceptual hold and the construction of negative messages regarding an understanding of the people who are choosing a different lifestyle. Moreover, information technologies and the consumption of western films are presented as culprits to a lack of commitment in white marriage. However, the official media 
portrayal of white marriage in terms of commitment and responsibility is contradicted by my research findings.

\subsection{Commitment in White Marriage}

Unlike documented marriage, couples in white marriages do not register their relationships, arrange public ceremonies, or perform any significant act to symbolize and craft their commitment. In fact, like cohabitations elsewhere, for people in white marriage, normative commitment-making trajectories (Reczek, et. at, 2009) are absent in the relationship and it develops from "ambiguity to an agreed-upon" commitment (Elizabeth \& Baker,2015, p. 53). In this section I examine the meanings of commitment for people in white marriage. The factors that are important in commitment-making processes include: firstly, a couple's understanding of the relationship either as a step towards documented marriage, as a post-divorce relationship or as a self-regulated marriage; secondly, the way a union forms. Moreover, driven by the normative definition

of commitment, I highlight three concepts in the process of commitment-making: permanency of the relationship, sexual exclusivity (monogamy) and marital responsibility during crises.

\section{Commitment and Understanding of White Marriage}

In this section, I demonstrate that the meaning of commitment in white marriage is not fixed or standard, because people in white marriage understand their relationship in different ways. For people who understand white marriage as a premarital stage, commitment is usually assumed permanent and monogamous, however for people who understand it as a self-regulated relationship commitment is usually an agreed-upon 
concept that may or may not include sexual exclusivity for both women and men. It usually ends with breaking up and re-partnering. Post-divorce white marriage is also usually assumed as a self-regulated relationship and commitment is based on agreement.

As I explained in the introduction chapter, there are three main perspectives regarding cohabitation in the West, which I found useful in considering the case of white marriage in Iran. The first approach to cohabitation is a variation of marriage; the second approach stresses cohabitation as a variation to being single; and the third approach views cohabitation as an introduction to marriage (Xie, et. al, 2003).

The first view of cohabitation as a variation of marriage sheds light on the similarities between cohabitation and marriage. They both share the same pillars of a sexual relationship: commitment, companionship, shared household duties, and childbearing (Rindfuss \& Van den Heuvel, 1990). For a number of reasons, this view is not comparable to white marriage. Firstly, there are legal/religious barriers to understand white marriage as documented marriage. Secondly, as I will explain in chapter 5, white marriage does not involve childbearing. And thirdly, documented marriage in Iran usually involves extended family obligations. However white marriage is an individualized decision which usually involves minimal extended family obligations (See Chapter 4). Therefore, white marriage is not a variation of documented marriage.

The second view, which conceptualizes cohabitation as a variation of being single, underlines the dissimilarities between cohabitation and marriage. For example, Rindfuss and Vanden (1990) showed that common-law partners more closely resembled single men and women than did married couples in their attitudes and family activities. This view also influences the understanding of commitment, as planning for a common future 
plays an important role in locating the relationship in a long-term big picture of life. This view, as I will discuss later in this section, resonates more with white marriage in terms of commitment, because white union is usually short-lived and lasts only six years or less (Amirmazaheri, 2016).

The conceptualization of cohabitation as a precursor to marriage in the third view, which considers cohabitation as a temporary state between singlehood and marriage, does not deny the qualitative differences between marriage and cohabitation. This point of view argues that common-law partnerships are typically short in duration and that a large proportion of cohabiting unions end up in marriage (Bumpass \& Lu, 2000). Understanding white marriage as a precursor to marriage - which was the case for a few of the participants I interviewed for this research and for many who I contacted but who did not agree to be interviewed - also influences the concept of commitment, because couples examine each other in preparation for the next step of their lives which is documented marriage.

Similar to documented marriage, both partners in some cases relied on a monogamous and permanent definition of commitment; these were people who planned for eventual documented marriage. For example, from their facial expression, I understood that my interviewees Shirin and Nastoh found the question of commitment (“Are you and your partner committed to each other?") offensive. I explained that I asked everyone this question and that not all people have the same understanding of commitment.

Shirin, Nastoh and Hamid had the same understanding of commitment: 
It is clear we are totally committed. No need to talk about it. (Nastoh, male, 32)

For Hamid, not only does commitment have a fixed definition, but also does imply marriage in the end.

Our relationship will end in marriage. We'll get married within a year when we are ready economically. In this society, marriage makes your commitment official and acceptable to others. Others' acceptance and having an official marriage are important to us. To apply for a visa, we need to be married and it's more beautiful. It's like we are saying we want to be together forever and have children. In marriage, doors are closed and getting out of it is harder. (Hamid, male, 29)

An understanding of white marriage affects the understanding of commitment. Couples who have a plan for marriage such as Nastoh, Hamid and who are already married such as Shirin and Neda usually understand commitment as similar to the definition of commitment in documented marriage in a cultural point of view, characterized as sexual exclusivity and permanency of the relationship. However, the commitment-making process is more complex as union formation is usually unplanned.

\section{Commitment and Gradual Formation of White Marriage}

Unlike documented marriage, white marriage has a different union formation, which influences commitment-making processes. In terms of union formation, another qualitative difference between white marriage and marriage, like cohabitation and marriage in the West, is that it appears most couples "slide" or "drift" (Elizabeth \& Baker, 2015,p. 55) into living together and living together generally operates as a variation or continuation of being single (Manning and Smock, 2005; Lindsay, 2000; Lewis et al., 2002; Sassler, 2004; Carmichael and Whittaker, 2007; Baker and Elizabeth, 2014). In many cases, when I asked interviewees who initiated living together, they did 
not remember clearly, saying, "It just happened" (Torang, female, 28). This point is also mentioned in the following two quotes:

We met first on a trip with a group of travellers at a place called Dalan $e$ Behesht or "Paradise Tunnel". Gradually, he started coming to my place after each trip. More and more personal stuff was left at my place and we noticed his suitcase never went back to his parents' home (stayed at my place) week after week (laughing), then he brought more personal stuff and compliantly moved in. (Naz, female, 30)

The point is also reflected in Maryam's case.

It was after the election in 1388 (2009). He was a political activist and afraid of being arrested. He came to my place to be safe. It was the beginning of our romantic relationship. We lived together for three years. (Maryam, female, 35)

Moreover, sliding or drifting in white marriage in most cases is a "rational" (Lindsay, 2000), albeit not necessarily planned step that enables the couple to spend more time together. Sepideh mentioned this point as a rational way to spend time with her partner without believing in traditional steps for establishment of normative commitment making.

We used to meet each other a lot, up to the point of everyday. Then why not live together?

In other part of the interview she added that:

Nowadays, young women and men have sex together and there is no problem. (Sepideh, female, 25)

The following quotes demonstrate that people in white marriage seriously rethink the solid cultural system for organizing sexual commitment, resulting in a variety of personalized commitments. Rethinking in commitment - that is a set of well-organized and established norms - deliberately ignores religion and culture. Religion and culture by their own registers of symbolic punishments and rewards try to form marriage-based 
commitment norms and further serve to embody these norms. Seemingly, operations of cultural and religious power over individuals to protect rules relating to sexuality does not function for many people in white marriage, because the constitution of acceptable forms of commitment in white marriage vary.

Most of interviewees explained that documenting marriage or following traditions do not help to keep commitment. Moreover, they did not value a prescribed, fixed and standard commitment and understand it as a barrier for transparency in the relationship and true commitment. Instead, they believed in agreed-upon commitment. Fazi, for example, explained:

What made us committed in the relationship was our hese khob positive feeling or hese refaghat intimate feeling, I trust that feelings much more than any traditions or documentation. Documentation even makes people to stay in a relationship without feeling. (Fazi, female, 30)

Ebrahim also understands marital tradition as a barrier for commitment, he told a story about his friend as a proof:

My friend married to the daughter of his old family-friend after couple of formal parties with their families. The father in law gave them a luxury apartment and a car and his father paid all costs of their stunning wedding celebration and honey moon. Soon, he realized that the bride is a lesbian! Could they divorce after such splurge! With such a complicated familial relationship! No, they are still living together. What commitment means here? Of course, nothing. (Ebrahim, male, 32)

Due to disbelief in prescribed and fixed definition, commitment-making in white marriage is a gradual and a challenging process in most cases. 


\section{Gradual Formation of Commitment}

Sliding or drifting into a shared household makes commitment in early stages ambiguous. In the following quotation from Toranj reflected on the gradual evolution of her relationship with Nima.

At first it was an open relationship, then gradually it became limited. It was accepted that we could be naughty outside of the relationship, but then we established some rules. For example, we agreed not to be in a sexual relationship with a person that both of us knew. (In the beginning, when our relationship wasn't strong, there was a woman among his family friends, who is the goddess of feminine feelings, and she made me jealous, so I asked him not to continue any relationship with her. After that, we set a rule not to have any relationship with mutual friends). It also happened for me. (Nima didn't have a problem with me being involved in a romantic relationship, but he cared that the other person had a clear understanding about open relationships and didn't judge. In the case of that particular relationship, Nima said it wasn't OK because the third person judges and doesn't understand an open relationship, so I cut it off.)

Gradually, we reached the point when we wanted to be with each other only. That's how I see it. Till now, there has been no commitment such as a promise to stay with each other, but many times we have discussed that we think we can't have this kind of relationship with anyone else or build a relationship like this and I think this shows commitment. There are many other guys around us, but we don't see them. This means commitment. We will stay together as long as we have this feeling, and this is commitment. (Toranj, female, 28)

Toranj's quote covers points about the process of commitment-making discussed in some western literature: ambiguity in sexual exclusivity at early stages, decreasing spontaneity as the relationship develops, setting rules and codes of conduct, and finally reaching an agreed-upon commitment (Elizabeth \& Baker, 2015). The last sentence of the quote demonstrates that her understanding of commitment extends as long as the relationship exists, but it is conditioned on mutual satisfaction. 
In her experience, Neda expressed frustration during early stages toward a committed relationship. Neda's white marriage eventually led to marriage. She explained her insecurities about her partner's commitment in the relationship.

What made me angry was his behavior with other women. He flirted and was not serious in our relationship. His permissiveness made me angry, until a counselor (psychologist) told me he has the kind of personality that cannot say no. He (her partner) told me that other women would ultimately face a closed door, and not to worry. Moreover, family and friends warned me that when he travelled to the U.S., he would forget me, and even told me to move to his father's house until he came back. But he came back, and we got married. (Neda, female, 31)

I also observed in interviews that commitment for people in early stages of their relationships is unclear, subjective, confusing, or difficult to articulate. After a few unsuccessful relationships, Navid who has been in white marriage for less than a year explains conceptualization of commitment first for himself and then for his partner. Here is an instance of such an interview:

Navid: When I am too involved with somebody, it is against commitment.

Me: What do you mean by "too involved?"

Navid: If a woman occupies my mind so deeply that I cannot stop thinking about her. Also, I expect that Sayeh (his partner) does not engage with people with a negative "aura"

Me: How would she know or recognize others' negative aura?

Navid: She knows.

Me: Would you please give me an example?

Navid: Well, we were "high" after smoking weed at a party and a person with a negative aura wanted to give Sayeh a massage. I told her something bad would happen to our relationship if she accepted. Then we left the party. 


\subsection{Multiple Forms of Commitment}

After passing the ambiguity stage, couples usually define and craft their own definitions of commitment, which are not necessarily homogeneous. Amirmazaheri, et. al (2016) study about white marriage also documented a variety of answers, from "complete commitment including sexual and emotional" to "open relationship". However, unlike my analysis that emphases on heterogeneity of commitment, Amirmazaheri, et. al (2016) assumed a fixed definition of commitment and concluded that mutual commitment in white marriage was low . As I mentioned for Hamid, Shirin and Nastoh, Naz and Poya mutually agreed commitment was monogamous and permanent. For Ebrahim and Farid, the mutually agreed commitment involves sexual inclusivity. For them, much like how Owens (2006) characterized it, commitment in the era of cyber space and on-line relationships is a flexible notion; which is avoiding any contacts that take attention, time and focus away from the primary relationship. Sexual relationship outside of white marriage may or may not break this definition of commitment.

After a while, we talked about it. I am fine (with extramarital relationships) as long as I am the main man for my friend. I told her if you want to be with someone else, first of all, do not tell me; secondly, do not bring him into my bed. (Ebrahim, male, 32)

Our definition of commitment is similar to that of an "open marriage". We both have the right to" privacy", to have our own relationships outside. But if that outside relationship reached a point when we did not see a reason to be in our primary relationship, we can break up. That outside relationship may or may not hurt our relationship. If it hurts it, then it contradicts our commitment. Then, our definition of commitment is that the outside relationship should not hurt us. Anyway, we have the right to have outside relationships. When we do not love each other anymore, we break up, but sometimes you love someone and want to be with them and it does not hurt the relationship. Within this condition, there is no other boundary for the secondary relationship. It can include sex. There is no need to tell each other either. I know that she has used this right. She has a boyfriend, but I do not have a girlfriend. It does not 
matter, because it does not hurt my emotions nor our life together. Emotions matter. I'm an emotional person, dependent on Sara [...] and my family. She satisfies me one hundred per cent, so I keep the relationship. But I do not satisfy her sometimes [so she can be in sexual relationship with someone else]. I cannot behave fanatically. It is none of my business. This is her secret. It is not necessary that I know hers or that she know mine. [he is trying to say that she can have sexual relationship with someone else and it is her right] (Farid, male, 32)

Faid used the component "open relationship" and "privacy" and "fanatically" in English. Using English words was common in most of interviews, but it was more frequently used in answering questions about commitment, something that was especially obvious in interviews with Fazi, Ebrahim, Toranj, Poya and Poria. That might explain the normative source of the conceptualization in western culture.

Changing one's relationship dynamics in terms of commitment from ambiguity to an agreed-upon commitment requires someone to take the initiative and for both parties to agree to set rules; these conditions are not always easy to achieve. Samar, a young female participant in white marriage, now separated, talked about the challenges regarding commitment. It seems her male partner had an upper hand or veto power in the commitment-making process.

When someone tells you there is no other girl in their life except you, but you see other girls' numbers in his phone, it shows that he is lying, although he keeps saying, 'No. No.' His mother once said he was always on the phone. 'Is he talking to you?' One day, while we were in white marriage, we went to register for a class. They asked us about our marital status. I said, 'I'm engaged.' He said, "I am single”. There I should have known (his lack of commitment). It was the reason that I didn't have him forever. When everything was good, I was even more worried about losing him. (Samar, female, 31)

Like Samar, Fazi's experience affirms the challenges of defining commitment in one of her relationships. 
First, we agreed to be in an open relationship, but he was monitoring and controlling me. It was open only for him! He could not see me with another person. He just heard something (open relationship) without understanding it. (Fazi, female, 30)

Based on Samar and Fazi's comments, I found a relationship between gender and commitment-making process.

\section{Gendered Commitment}

Amirmazaheri, et. al (2016) study revealed that it was more common for women to express a desire for affirmation of their partner's sexual exclusivity through the commitment-making process. However, in my research women also described situations where their partners asked for sexual exclusivity. In fact, for defining commitment, women usually refer to what their partners set as commitment roles. This point demonstrates that men still have upper hand to define commitment. It seems women usually agree with what their partners ask them to keep the committed relationship. Men, however, described their own roles for commitment making.

Elaheh, Maryam and Sepideh shared their personal experience about commitment and their partners' reaction that ultimately help them to define border lines in commitment making.

I remember a case that made him (her partner) mad. My male classmate asked me to borrow my note and I said sure, I'll leave it for you on the desk. He said let's meet outside of the college if possible as I do not come to the college anymore. I said ok, I'll bring it for you outside of the college. But my partner said don't you understand that his intention is not your note, he wants to meet you! Eventually, I cancelled and just left notes for him on the desk. (Elaheh, female, 35)

One of our major conflicts happened when I sent heart and chatted online with one of my male relatives who lives abroad and used to be my suitor. My partner saw it in my phone and the nightmare begun, he beat 
me and then himself. We agreed not to do that again. (Sepideh, female, 25)

Maryam: We had a guest, our common friend. When he left, my partner said your flirting behavior with him will ends up with sex. If you do not want it, then stop the hidden agenda (laughing).

Me: $\quad$ So frankly!

Maryam: Yes, we talk about everything.

(Maryam, female, 35)

The only exception among men was Farid who introduced his partner as a source of inspiration for setting roles regarding commitment.

As I have shown, the meaning of commitment depends on couples' understanding of relationship and union formation. Understanding the relationship as a process towards documented marriage and planned union formation were associated with an understanding of commitment as monogamous and permanent. However, understanding the relationship as a variation of being single and possibly drifting into the union was associated with an "ambiguous" (Elizabeth \& Baker, 2015) understanding of commitment in early stages of the relationship, constructed and shaped by couples as the relationship develops. In fact, publicly shared or fixed meanings of commitment in white marriage do not exist. I suggest that the meaning of commitment for couples in white marriage represented in my study is not static, but fluid and changeable over time. Couples in white marriage define commitment within the development of their relationship based on their situational experience, which is not always consistent with such monogamous assumptions of commitment. Gender difference is another aspect that distinguish white marriage in commitment-making process. Despite the fact that women and men both require commitment-making during the relationship in equal way, men still 
have veto power and upper hand to offer "dos and don'ts" in the relationship. Men generally explained what commitment was in their point of view and women described what their partner asked them to do or not to do regarding commitment. Gender differences also affect understanding permanency in commitment.

\section{Permanency in Commitment}

Besides monogamy, another characteristic of commitment in documented marriage is the idea of marital permanency; however, many people in white marriage do not recognize their relationship as a permanent or even a long-term union; nor is their commitment permanent. They believe they are purely devoted and purely in love at the present time, but unable to make promises for the future. In my interviews, I observe a gender difference in the understanding of a permanent relationship. With a few exceptions, most men added a temporal perspective to their analysis and assumed that separation would be a part of the relationship. For example, Navid says:

I don't know whether this relationship is going to last more than six months. Psychology suggests a relationship can't last more than nine years. Of course, there are exceptions. (Navid, male, 32)

Referring to biology, Ebrahim explains:

Here is the process of a relationship: People meet each other, hold hands, kiss, go to the cinema, sleep together, live together, may or may not have a baby, then they gradually get tired of each other and finally want to split up. Biologically, humans cannot have a relationship for more than five or six years. If you talk to a man and a woman who have limited themselves to a long-term relationship, you'll see that they're suppressing themselves. Self-suppression exists in this relationship. Our relationship is not going to last either. (Ebrahim, male, 32)

After living in a relationship for thirteen years, Farid shared his uncertainty about a common future. 
There is no guarantee that you will love the one you love now the same way ten years later. Relationships melt away in everyday life. Relationships have ups and downs, like a flowing stream. [...] We have lived together for thirteen years, but I do not foresee a future. (Farid, male,32)

Pouria who was divorced and had a daughter and also experienced white marriage two times, explained his reaction to his partner's decision for leaving in his first white marriage. When the relationship dissolved, he reminded himself about the assumptions they had made about the relationship.

When she said her visa for immigration was accepted and that she would leave me, at first it hurt me, but this relationship was one with an open door. (Pouria, male, 40)

The majority of women in white marriage, however, planned for the long run. For most women, white marriage did not reduce their willingness to create and honor lifelong partnerships. Contrary to men who think that white marriage demonstrates weaker sense of commitment to long-term relationships, most women strongly stressed their 'commitment' or their wishes for a long-term relationship. In other words, while most women expressed their private hopes for long term relationship, men saw romantic relationships as usually short-term.

In Neda's words:

He had had short-time relationships before and I did not want to be one of them. (Neda, female,31)

Naz, after ending her three-year relationship with a man who have had experienced divorce, expressed her disappointment:

I thought I was making my life. I was anticipating a life partner for a common future and I changed him from a depressed unconfident person to a strong man. I do not want anything left of what I made. All the amount of effort and energy I spent is wasted. I regret it. (Naz, female, 30) 
Fazi and Sepideh were exceptional instances among 9 female interviewees in that she understood her relationship was not a long-term commitment:

He says, "stay with me until we are changing each other's diapers" (laughing), but it depends on where I go with my job. If he comes with me, he is more than welcome. If he does not come, I would still leave. (Fazi, female, 30)

In summary, based on my research, men in white marriage who slide or drift into a relationship usually do not promise a lifelong permanent commitment. Women in this form of relationship have a higher tendency to make it long-term. Regardless of this gender difference, the agreed-upon commitment definition and conditions usually apply to both couples equally. This is different from religious and legal commitment that permits polygamy only for men. However, their understanding of commitment as a temporal promise is not grounded in religious thoughts regarding temporary marriage. They are from secular middle class. Therefore, their understanding of commitment is not grounded in religious thoughts regarding polygamy and temporary marriage. Rather, it is more likely shaped by a resistance to governance of marriage in a globalized world.

\subsection{White Marriage and Commitment During Life Crises}

In last two sections I discussed monogamy and permanency as two pillars of commitment in marriage. In this section referring to the third pillar of commitment as a tendency to continue in a relationship, even through life's hardships or when faced with appealing alternatives to marriages (Amato \& DeBoer, 2001), I discuss how people in white marriage remain committed during difficulties.

Traditionally, family members (spouses, adult children, and parents) are the main providers of emotional support and practical assistance (Raveis, \& Siegel, 1991) during 
life crises such as severe financial burdens or illness. White marriage is an individualized decision, and traditional sources of informal support and assistance may be weak or nonexistent, usually leaving the partner as the only caregiver. This point is even more important in an Iranian context, because alternative sources of social support such as volunteers are not easily available and formal support is expensive.

People in white marriage are usually described as "weak in commitment" or "irresponsible" by the official media. I highlight different aspects of marital commitment among white couples in various situations. The role of spouses in crises management was an important theme that most of interviewees were interested to discuss. I paid attention to ways of providing support by spouses. The key characteristic was that the support was mutual and far from standard gender roles. For instance, without gender differences, both men and women provide financial support and also receive/give care in times of illness.

In the following case, Neda's partner is not only her source of psychological support, but also takes some responsibility for Neda's mother when she is in need.

When my mother got cancer, he (her partner) had my back and supported me so much. Sometimes he bought her medicine. I had his car and sometimes he would stay with my mom till I got there. When my mother passed away, I was depressed and on medication and he was there for me. (Neda, female, 31)

When Farid faced the possibility of arrest, he had no one to trust but his partner:

After the presidential election in 1388 (2009) and the unexpected result, I thought I would be arrested for my political activism. While the national broadcast was announcing the result, I was packing to escape. Where did I have to go? Jahrom, Sara's city. (Farid, male, 32)

He also relies on his partner during a time of financial crisis:

I gamble. I have lost everything through gambling. I borrowed from her and lost her money too. She is the only person I can always rely on. To pay back I bought an apartment for her. (Farid, male, 32) 
Taking the responsibility of unattended pregnancy is one of important themes that media discuss. Although, couples in white marriage union did not usually consider any solution for unattended pregnancy expect abortion, in most of cases men took the responsibility and, as I will explain in Chapter 5, men were usually involved in the process up to recovery of their partner. Take Fazi's experience for example, her partner took the responsibility for her unattended pregnancy when his family was shocked:

When I got pregnant, we visited a private doctor's office to have an abortion. Mohammed's mother found the doctor's business card in Mohammed's pocket and made a phone call to the doctor and realized what had happened. Mohammed's family came to my parent's place, shouting in the neighborhood to ruin our reputation. It was truly a nightmare! We had to move from that neighborhood eventually. Taking my side, Mohammed cut off his relationship with his parents though. (Fazi, female, 30)

The last case is about caregiving to the partner in times of illness. Ebrahim's partner had cancer and she did not have much time left. Ebrahim was the only caregiver for her because she cut her relationship with her family ever since they started the white marriage:

Now that my partner is fighting cancer, I have become even more determined (to be in a white relationship). When we have chemotherapy, uh! I even say 'we' not she! (tearing up). Yeah, I was saying after each chemotherapy we take a trip and stay in a cottage in the north. I take her to the bathroom, trim her nails, and brush her hair. After all, she has only me! So I do it all. (Ebrahim, male, 32)

In a different part of the interview, he explains his views about responsibility in white union:

White marriage is the most humane kind of relationship because individuals become involved by choice and stay together by choice. More importantly, they accept all responsibilities themselves, not because of norms, religion or law. (Ebrahim, male, 32) 
In this section, I explained that, based on my interviews, many people in white marriage commit to the relationship during difficulties, including illnesses, financial problems and political issues. Regardless of gender differences and gender stereotypes that categorize women as caregiver and men as breadwinner, both partners were involved in crisis management. Meanwhile, they avoided overprotection to restrict the other partner's freedom. This is contrary to the official media portrayal of them as irresponsible and untrustworthy when it comes to hardship. Moreover, white marriage is an individualized decision that usually comes with familial network disagreement or disapproval. Consequently, informal support and assistance from family may be cut off, which usually leads the partners to be co-dependent entirely on each other. Most of interviewees mentioned that tension with their parents encourages their commitment to each other in life tribulations.

\subsection{Marital Commitment, Moralities and Cultural Power}

I unpack the relationship between cultural and moral power, as well as resistance in the context of an intimate commitment in white marriage. According to Michel Foucault, discipline is a form of power that aims to regulate people based on what is assumed to be normal (Chen, 2005). The exercise of discipline is based on producing knowledge and tries to internalize self-regulation and tries to normalize people. In fact, power brings into play a whole series of norms about the proper way to live. Once norms are internalized, individuals are self-controlling. At this stage, norms used by those in power are translated to ethics or the proper way of living (Hunt \& Wickham, 1994). As I explained, prescribed commitment, determined by religion and culture is what couples in white marriage 
complain about. They seek freedom from prescribed commitment through rejection and through making up an alternative; which is usually finding an agreed-upon definition.

As I have already explained, considering the legality of polygamy, the definition of commitment in Iran is based on patriarchal assumptions that honoring a marital commitment is more relevant to women than it is to men. Many couples in white marriage craft their own definition of commitment in different but egalitarian ways. I argue that entering into a white marriage relationship is not only a rejection of the "legal/religious" understanding of commitment, but also it makes possible an alternative discourse, which aims to challenge "cultural" power in defining intimate morality. For example, Toranj explains how she and her partner challenged cultural power in their own definition of commitment.

We managed (to clarify any confusion about commitment in the early days) and it caused no problems in our relationship. This is so important for me -- that there is no cheating. But we have our own definition of cheating, which is lying, and we will live it. It's not necessary to adopt others' definitions of cheating and to act accordingly. The definition of cheating from my point of view is when your partner does not know about a relationship you have with another person. I mean, I have to know from the beginning -- where it started and where I stand in relation to it -- then I can decide what to do. Yes, if it happens anyway, I should know about it. (Toranj, female, 28)

For Toranj, transparency is the main factor in a mutual commitment, even if another parallel intimate relationship exists, for both parties, outside of white marriage relationship. However, transparency in the case of extramarital relationships is not universal. For example, large-scale data breaches of Ashley Madison, a dating website in Canada for people looking for extra-marital relationships, ended up with two suicide and many family dissolutions (Baraniuk, 2015). The reason as Mansfield-Devine explains was the shameful situation of "people who have used a site dedicated to infidelity being 
exposed to public gaze" $(2015$, p. 8$)$. I recognize this as one of definitions of commitment in white marriage.

White marriage opens a space that enables alternative understanding about commitment and engagement against cultural normative power to take place. Couples in white marriage resist the power of cultural norm by inventing their definitions of commitment.

In this chapter, I examined various definitions of commitment in white marriage. Commitment in white marriage is generally egalitarian, temporary and may or may not include sexual exclusivity. Union formation and gender influence understanding of commitment. As most people in white marriage slide or drift into the relationship, commitment is ambiguous in early stages. As the relationship develops, however, couples usually reach an agreed-upon definition, which generally challenges normative cultural power of defining intimate commitment in a fixed, prescribed and standard way. Gender difference in understanding of commitment was significant, as women more likely understood the relationship as permanent compared to men and commitment roles usually were inspired by male partner. Moreover, I pointed out that as people in white marriage self-identify as secular the normative source of complex meaning of commitment does not be understood as religious permissiveness of polygamy, but rather in the sense of globalization and western cultural consumption. Finally, unlike the portrayal in the media, I showed that couples in white marriage, in my sample, commit to each other through life's tribulations. 


\section{Chapter 7. CONCLUSION}

This dissertation uses the phenomenon of "white marriage" among young heterosexual middle class Iranian women and men as the empirical focus to provide a window into the transformation of intimacy in Iran within the globalized world. While white marriage has captured a lot of media attention within Iran, little is known about it outside of the country or in academia. This dissertation is based upon interviews with people in white marriages as well as a content analysis of textual data

The main research question that I have posed is how Iranian middle class women and men in white marriages understand this mode of intimate relationship within the context of Iran's marriage norms and the global dominance of western culture. My overall argument is that white marriage signifies that sexuality, gender, and class are emerging as lines of fracture in contemporary Iranian society, with notions of intimacy, love, body, and self being constructed by Iranian middle class women and men in reaction to western culture and to marital norms in Iran. Iranians in white marriages formulate their desires and construct their subculture in relation to global cultural forces on the one hand and articulate their understanding of cultural marital norms in Iran on the other. I identified three kinds of understanding of white marriage among couples: as a premarital, as a post divorce, and as a self-regulated relationship. This research is important because it extends the understanding of white marriage as a new form of intimate relationship emerging in the shadow of imaginaries of the western lifestyle in resistance to marital norms and in pursuit of making a modern self.

Specifically, I have come to focus on a series of sub-questions in the research process: firstly, do people in white marriages reveal their relationship to their parents and 
how do they interact with their extended families? Secondly, do couples commit to the relationship? Thirdly, what is their perspective regarding childbearing and the possibility of unintended pregnancy? Finally, what happens after dissolution? Ultimately, what are the extents to which public health and biopolitics discourse, Occidentalist imaginaries of the west (Chen, 1995), or resistance to the governance of families contribute to the emergence and evolution of white marriage practices? Official and overseas media representation of white marriage usually suggests a fixed and homogeneous category; it apparently dismisses observations that do not match accounts of white marriage as an oppositional binary between the modern western model and documented marriage as a traditional Iranian and Islamic modality. These official and overseas views obscure the reality of white marriage as a heterogeneous and hybrid phenomenon. To fill this gap, I have demonstrated the heterogeneity of white marriage in three identified categories: premarital, post-divorce, and self-regulated relationships. Motivations for white marriage vary among the different categories. In premarital relationships, participants had a plan for marriage. For this group, white marriage is an opportunity to test the relationship, to develop a career, and to finish an education. Their main objection and resistance comes from a desire to be totally independent regarding partner selection, without relying on approval from the extended family. In the case of a marriage plan, women tend to follow marital norms more often than men do. In a post-divorce white marriage, participants resist marital and divorce legislation, thus avoiding marriage. They also wish to avoid the old established gender roles of documented marriage. Finally, white marriage as a selfregulated relationship combines all of the foregoing motivations as well as an emphasis 
by participants on an anti-authority struggle to make room for an alternative way to experience intimate relationships and lifestyles.

Despite the official media claims, people in white marriage do have relationships with their families. I found Bengtson's cathegorization (2001, p.1) useful for demonstrating different aspects of the relationship. The geographic distance between people in white marriage and their parents provides low "structural solidarity" and a low level of relationship. Moreover, as "consensual solidarity," or agreement with the ideas, values and lifestyles between parents and couples in white relationships is very low, women in the initial stages of white marriage usually hide the relationship, while men keep their interaction with parents at a minimum level. However, "functional" relationships (Bengtson, 2001, p.1) or the giving and receiving of support across generations, including the exchange of active assistance and services as well as emotional support, is moderate; women are more engaged in receiving and giving care from/to their family. Finally, a man's family is more likely to accept his partner than a woman's family.

White marriage is a childless relationship and this fact has provoked controversy in the media and has gradually changed media discussions about white marriage. I identify three phases in media discussions related to white marriage: the first is silence and denial; the second is a prohibitive approach with religious and moralistic overtones, and the third is a management approach with discourse focused on health and population. Thus, a diverse set of organized interests come into play to settle the phenomenon of white marriage in a variety of ways. The friction among those who speak for people in white marriage seems to favour population and health discourse. That is due to the change in 
population policies from birth control to a pro-natal approach. The increase in the white marriage population as a childless relationship would further the decrease in the birth rate, which contradicts the current population policy. The two published fatwas that announced that children from white marriage are not illegitimate is a sign that religious institutions also support the change. Regardless of the problem of recognition and documentation for childbearing as a practical barrier within a white relationship, participants in all groups also reflect on their ideological opposition to childbearing. Moreover, despite an initial agreement to avoid childbearing, there is a gender difference with respect to changing attitudes, with women in the premarital and post-divorce groups being more likely to change their minds regarding childbearing after a couple of years. I explored three reasons for this change: first proper settlement within the relationship, second the biological clock alarm, and third, unintended pregnancy. Women in selfregulated relationship, however, usually do not change their decisions. I also unpacked the unequal social and physical burdens on women in white marriages that needs immediate public health attention from.

Conceptualization of commitment and commitment-making processes are a controversial aspect of white marriage, because the official media accuses couples in this form of relationship of infidelity. The source of misunderstanding is that the conceptualization of commitment in white marriages is unlike that of documented marriage; the former is hybrid, fluid, and mutually agreed upon. In a way, the conceptual setting is not fixed or pre-given. Rather commitment shapes and develops throughout the relationship. In addition to sexual commitment, I examined other forms of commitment to life challenges such as a financial crisis or illness. My investigation shows that in most of 
cases, while external supports are largely absent, couples in white marriage offer each other mutual support. This is why, as evidence shows, couples in white marriages are mostly committed to each other during life crises.

White marriage (and many other phenomena in the contemporary world) cannot be studied as a singularity detached from the global context, neither should internal power dynamics be underestimated. I emphasize both the internal dynamics of marital norms and practices that cause people in white marriages to push back against normative power; as well as the external power dynamics of the global context which give them an understanding of western norms of intimate relationships as progressive and prestigious. With this post-colonial approach and by situating white marriage in the broader social context within which it surfaced, I investigate and explain the processes that have enabled the cultural emergence of white marriage in a third space. The third space is neither modern nor traditional, while being both.

Using post-colonial tools, I have developed critical analyses about the tendency of people in white marriage in believing in "modernity as utopia" (Pieterse, 2009) and, more importantly, that their assumption about a singular course of progress as in the West. Their understanding of modernity as a single dominant historical path that all societies follow towards, in keeping with the statement, "First in the West, and then elsewhere" (Chakrabarty, 2009, p.6; see also Hall \& Gieben, 1992; Walby, 2009), has been very important in shaping the idea of white marriage. Asides from idealizing western modernity, they also believe in the universalist notion of modernization that assumes developing countries are living the history of the west, thus accepting a single history and a single modernity. This explains why white marriage is presumed to be a signifier of a 
progressive future, in opposition to a primarily deficient and primitive form of documented marriage. This point in fact points to the internalization of images represented in colonial discourse, which results in selfaccusation or what Creighton (1995) terms "self-Occidentalism." However, this is only one side of the coin.

On the one hand, people in white marriages take the normative validation of a white marriage from their understanding of cohabitation practices in the west; assuming the current situation in Iran to be equivalent to Europe's past, they believe that their form of intimate relationship will be dominant in the future as it is now in Europe. On the other hand, people in white marriages believe that their relationship is a foil to the patriarchal roots of documented marriage hidden within marital laws, norms and practices, and offers alternative notions of equality, self-development, self-fulfilment and agency.

I also contributed a Foucault inspired analysis in two respects: first, resistance and counter discourse; and second, different forms of power that explain the regulation of white marriage. In order to explore different forms of power, Foucault calls us to listen to the excluded voices of resistance. In other words, resistance can shed light on different forms of power that shape a specific social phenomenon (Hartsock, 1990). The power of cultural norms attempts to marginalize (by stigmatization) (Ghodosi \& Bayat, 2015), to silence (by not giving the opportunity for self-presentation) (IRNA, 2015, ISNA, 2015, Keyhan, 2014), and to exclude white marriage relations from the accepted forms of intimate relationships (IRNA, 2014). Yet, the marginalized, silenced and excluded people are present, are increasing in number, and are resisting in different forms. Their forms of resistance are consistent with Foucault's explanation that highlights a locality and a 
plurality of resistances rather than a single locus of a "great refusal", revolutionary approach (Foucault, 1978: 95-96). Locality and plurality of resistance can be seen in a series of opposing behaviours in white marriage, which have developed in Iranian society over the last decade, in reaction to the effects of power linked to knowledge and norms. There has been resistance to the privilege of specific forms of knowledge and norms in sexual morality that are connected to cultural, legal and religious power (Foucault, 1982).

White marriage as a form of excluded voice of resistance stands against accepted forms of intimate relationships. In other words, people in white marriage are the formerly voiceless people who push back against marital norms and regulations. They initiate the relationship in order to articulate their desires to counter the domination of the main authoritative discourses (Moussa \& Scapp, 1996) regarding intimacy. Foucault included in his call to listen to the excluded voices of resistance, the call to find counter discourses (Moussa \& Scapp, 1996). Inspirited by his approach, I found the Foucauldian concerns with resistance and counter discourse useful for explaining how the formerly voiceless might begin to speak or to act in different way, which is an attempt for self-recognition and self-development, for different lifestyle.

Second, I have charted and examined the shift in authorities' reaction to white marriage that could reveal different forms of power for regulating white marriage. Initially, media discussions condemned white marriage as being in opposition to moral and religious values, and emphasized a prohibitive approach to control the phenomenon. They encouraged an "exclusionary practice" (Shahrokni, 2013, p.12) to limit white marriage, supported by religious and moralistic discourses. Gradually, population 
concerns, and women's health discussions related to white marriage came into account and were supported by two representatives of religious institutions. Many seminars about white marriage have opened up discussion of the phenomenon in different fields of social science (Ananews, 2015, Khabaranline, 2016) and called for management of the phenomenon instead of a policing and controlling approach. This marks a shift to an "inclusionary practice" (Shahrokni, 2013, p.14) aimed at facilitating tolerance and acceptance of white marriage, carried out under health and demographic discourses (Shahrokni, 2013). That is why the exclusionary practice of problematizing or omitting white marriage does not function effectively. Population concerns and policies that favour childbearing enabled these gradual shifts from "authoritarian sovereign power" to governmental "biopower" seeking to manage problems for the sake of population vitality (Foucault, 2007).

A limitation of the present study is the difficulty in accessing people in white marriages. Sex-related, illegal and taboo phenomena usually present access challenges. Nevertheless, I was able to find an adequate sample with the help of my journalist friends and hairdressers. Without that support, trust-making would have been difficult and timeconsuming. Another limitation was the difficulty in accessing statistics related to the population of white families. Apparently, there are no nation-wide statistics or if there are, they are not publicly accessible. Fortunately, by the end of my dissertation, I was able to find a reliable estimation about the population that shed light on the prevalence of the phenomenon among the urban middle class in Tehran.

White marriage is widespread in various large cities and there is no systematic study of the population in other cities or across various cultural settings in Iran. We need more 
independent studies about white marriage and comparative studies. Such comparative studies could highlight how ethnic marital norms and practices are related to resistance among young people. A comparative study also could evaluate contributing factors to the choice of alternatives to documented marriage, such as white marriage. To explore these connections in different cities and to compare them, we need to pay attention to the process of family formation, reasons for family formation and the process of meaning regarding self, body, love, commitment, agency, and family. Future research should give us a clearer picture of the possible cultural, political, and social connections between different populations' experiences in Iran.

As white marriage is heterogeneous, future research should focus on investigating premarital, post-divorce, and self-regulated relationships separately. We still need to know much more about the similarities and the differences between each category, including re-partnering patterns. My hope is that comparative studies of different forms of white marriage will shed new light on debates about the relationship between the role of legislation, religious institutions, marital norms and western discourse in shaping the everyday reality of each distinct group of white marriage independently.

Women's agency in forming and continuing in such relationships, and the dissolution process, something that is beyond the scope of the present study, deserves further attention, I only been able to touch on the very interesting data that demonstrates a change in understanding of gender and gender roles by mostly educated and employed women who choose white marriage. Further studies in this direction would extend our understanding of gender in our globalized and yet very local world. 
It is tempting to view white marriage as a unique and atypical case from which comparisons to other Islamic societies cannot be drawn. Nevertheless, the recent surge of cohabitation practices in Islamic contexts as diverse as Egypt (Rashad \& Roudi-Fahimi, 2005), Turkey (Ustek-Spilda \& Alyanak, 2016), and Singapore (Jones,2012) point to a global process of changing ideas regarding intimacy. Still, there is a gap in the literature regarding such statistics. That is why independent and comparative studies would help identify interconnections and differences. My research adds to the emerging scholarship seeking to understand these social changes in non-western societies, but many more studies along these lines are needed.

Regarding the relevance of my findings to policies, I suggest the following: first, white marriage should be acknowledged as a form of family by the media and by the political system; second, white marriage should be considered as heterogeneous phenomenon; and third, making stereotypes in the official media should be avoided. In doing so, people in white marriages should be allowed to represent themselves in public discussion. This helps to raise awareness about their concerns and desires, as well as to decrease stigmatization. The reasons and motivations for each group of white marriage are different. Based on that, a further suggestion that I make is that divorce and marital laws be reformed in more egalitarian manner that mirrors young people understanding of relationships. Finally, legal recognition for self-regulated and post-divorce white marriage, whose members reject documented marriage is required. legal recognition will decrease vulnerability of people in white marriage especially among women. Ultimately, marital norms and traditions should be tailored based on couples' specific situations, 
desires, and wishes. Hopefully, developing research-informed programs based on Iranian culture will direct goals on the track to success. 


\section{Bibliography}

Abbasi-Shavazi, M. J., Morgan, S. P., Hossein-Chavoshi, M., \& Mcdonald, P. (2009). Family Change and Continuity in Iran: Birth Control Use Before First Pregnancy. Journal of Marriage and Family, 71(5), 1309-1324.

Abrahamian, E. (1993). Khomeinism: Essays on the Islamic Republic. London: Tauris.

Abu-Lughod, L. (2002). Do Muslim women really need saving? Anthropological reflections on cultural relativism and its others. American Anthropologist, 104(3), 783790.

Afary, J. (2009). Sexual politics in modern Iran. Cambridge: Cambridge University Press.

Afary, J. (2009). The sexual economy of the Islamic Republic. Iranian Studies, 42(1), 526.

Afary, J., \& Anderson, K. B. (2010). Foucault and the Iranian revolution: Gender and the seductions of Islamism. University of Chicago Press.

Aghajanian, A. (1986), Some Notes on Divorce in Iran: Journal of Marriage and Family, 48(4) 749-755.

Aghajanian, A. (2001). Family and family change in Iran. Department of Sociology Fayetteville State University. Fayetteville NC, 28301.

Aghajanian, A., \& Thompson, V. (2013). Recent divorce trend in Iran. Journal of Divorce \& Remarriage, 54(2), 112-125.

Aghajanian, A., Vaezzade, S., Kohan, J. A., \& Thompson, V. (2018). Recent Trends of Marriage in Iran. The Open Family Studies Journal, 10(1).

Aghajanian, Akbar. (02/2013). Recent Divorce Trend in Iran. Journal of divorce \& remarriage. (54)2. p.112 - 125.

Aguiar, M. (2013), Arranged Marriage: Cultural Regeneration in Transnational South Asian Popular Culture. Cultural Critique, 84 (1), 181-213.

Agustino, L., \& Mohamed, B. A. (2015), The Paradox of Social Media: The Dedemocratization of Malaysia. Insignia Journal of International Relations, 2(02), 52-66.

Ahmadi Khorasani, N. \& Ardalan, P. (2003), Senator: Mehrangiz Manochehrian's activity for women legal rights in Iran, Toseeh, Tehran, Iran.

Ahmadi khorasani, N. (2012), Hijab and Intellectuals, Tehran, Iran. 
Ahmadi, KH. (2015), Analysis of the role of the Internet in marriage and betrayal, Iranian Consultation Organization, conference paper, Tehran, Iran.

Alavi, N. (2005). We are Iran. The Persian Blogs. Vancouver: Soft Skull Press.

Alef, (2015). Responses of two Marja Taghlid regarding white marriage, Retrieved from:http://old.alef.ir/vdcaeinu049nmw1.k5k4.html?256037

Algar, H. (2015). Roots of the Islamic Revolution in Iran. London: Open Press.

Alhoseini, N. (2014), White marriage, life without meaning,

Retrieved from:

http://sahebkhabar.ir/news/3628548/\%D8\%A7\%D8\%B2\%D8\%AF\%D9\%88\%D8\%A7\% D8\%AC-\%D8\%B3\%D9\%81\%D9\%8A\%D8\%AF-\%D8\%AA\%D9\%87\%D9\%8A$\% \mathrm{D} 8 \% \mathrm{~B} 4 \% \mathrm{D} 8 \% \mathrm{AF} \% \mathrm{D} 9 \% 86-\% \mathrm{D} 8 \% \mathrm{~B} 2 \% \mathrm{D} 9 \% 86 \% \mathrm{D} 8 \% \mathrm{AF} \% \mathrm{DA} \% \mathrm{AF} \% \mathrm{D} 9 \% 8 \mathrm{~A}-$ $\% \mathrm{D} 8 \% \mathrm{~A} 7 \% \mathrm{D} 8 \% \mathrm{~B} 2-\% \mathrm{D} 9 \% 85 \% \mathrm{D} 8 \% \mathrm{~B} 9 \% \mathrm{D} 9 \% 86 \% \mathrm{D} 8 \% \mathrm{~A} 7$

Ali, M. A. (2008). Loss of parenting self-efficacy among immigrant parents. Contemporary Issues in Early Childhood, 9(2), 148-160.

Alikhah, F. (2007). The politics of satellite television in Iran. In Media, Culture and Society in Iran (pp. 110-126). Routledge.

Alitabar, S., Ghanbari, A., Mohammadizadeh, M., Habibi, SH. (2014). The Relationship Between Premarital Sex and Attitudes Toward Infidelity. Family Research, 10 (2) 255267.

Amaro, H. (1988). Women in the Mexican-American community: Religion, culture, and reproductive attitudes and experiences. Journal of Community Psychology, 16(1), 6-20.

Amato, P. R., \& DeBoer, D. D. (2001). The transmission of marital instability across generations: Relationship skills or commitment to marriage? Journal of Marriage and Family, 63(4), 1038-1051.

Amirmazaheri, A., Shiri Gheydari, L., \& Shahidi, M. (2016). Spreading Modern Rationality and forming the New Patterns of Family; a Study of Cohabitation Style in Tehran. IAU International Journal of Social Sciences, 6(4), 45-54.

Ananews,(2015) White marriage a bell alarm for our society. Retrieved from:

http://ana.ir/fa/news/101/540/\%D8\%AF\%D9\%88-

$\% D 8 \% B 9 \% D 8 \% A 7 \% D 9 \% 85 \% D 9 \% 84-$

$\% D 8 \% B 2 \% D B \% 8 C \% D 8 \% A 7 \% D 9 \% 86 \% D 8 \% A 8 \% D 8 \% A 7 \% D 8 \% B 1-$

$\% D 8 \% A 7 \% D 8 \% B 3 \% D 8 \% A A \% D 9 \% 81 \% D 8 \% A 7 \% D 8 \% A F \% D 9 \% 87-$

$\% D 9 \% 86 \% D 8 \% A 7 \% D 8 \% A F \% D 8 \% B 1 \% D 8 \% B 3 \% D 8 \% A A-$ 
$\% D 8 \% A C \% D 9 \% 88 \% D 8 \% A 7 \% D 9 \% 86 \% D 8 \% A 7 \% D 9 \% 86-\% D 8 \% A 7 \% D 8 \% B 2-$

$\% D 8 \% B 4 \% D 8 \% A 8 \% D A \% A 9 \% D 9 \% 87 \% E 2 \% 80 \% 8 C \% D 9 \% 87 \% D 8 \% A 7 \% D B \% 8 C-$

$\% D 8 \% A 7 \% D 8 \% A C \% D 8 \% A A \% D 9 \% 85 \% D 8 \% A 7 \% D 8 \% B 9 \% D B \% 8 C \% D 8 \% A 7 \% D 8 \% B$

$2 \% D 8 \% A F \% D 9 \% 88 \% D 8 \% A 7 \% D 8 \% A C-\% D 8 \% B 3 \% D 9 \% 81 \% D B \% 8 C \% D 8 \% A F-$

$\% D 8 \% B 2 \% D 9 \% 86 \% D A \% A F-\% D 8 \% A E \% D 8 \% B 7 \% D 8 \% B 1 \% D B \% 8 C-$

$\% D 8 \% A C \% D 8 \% A F \% D B \% 8 C-\% D 8 \% A 8 \% D 8 \% B 1 \% D 8 \% A 7 \% D B \% 8 C$ -

$\% D 8 \% A C \% D 8 \% A 7 \% D 9 \% 85 \% D 8 \% B 9 \% D 9 \% 87$

Ananews, (2015), White marriage and divorce celebration are rebellion against social order, Retrieved from:

http://ana.ir/fa/news/43/1920/\%D8\%A7\%D8\%B2\%D8\%AF\%D9\%88\%D8\%A7\%D8\%A C-\%D8\%B3\%D9\%81\%DB\%8C\%D8\%AF-\%D9\%88-\%D8\%AC\%D8\%B4\%D9\%86-

$\% \mathrm{D} 8 \% \mathrm{~B} 7 \% \mathrm{D} 9 \% 84 \% \mathrm{D} 8 \% \mathrm{~A} 7 \% \mathrm{D} 9 \% 82-$

$\% \mathrm{D} 8 \% \mathrm{B3} \% \mathrm{D} 9 \% 88 \% \mathrm{D} 9 \% 86 \% \mathrm{D} 8 \% \mathrm{~A} 7 \% \mathrm{D} 9 \% 85 \% \mathrm{DB} \% 8 \mathrm{C}-$

$\% \mathrm{D} 8 \% \mathrm{~A} 7 \% \mathrm{D} 8 \% \mathrm{AC} \% \mathrm{D} 8 \% \mathrm{AA} \% \mathrm{D} 9 \% 85 \% \mathrm{D} 8 \% \mathrm{~A} 7 \% \mathrm{D} 8 \% \mathrm{~B} 9 \% \mathrm{DB} \% 8 \mathrm{C}-$

\%D8\%B9\%D9\%84\%DB\%8C\%D9\%87-\%D9\%86\%D8\%B8\%D8\%A7\%D9\%85-

\%D8\%AE\%D8\%A7\%D9\%86\%D9\%88\%D8\%A7\%D8\%AF\%D9\%87-

$\% \mathrm{D} 8 \% \mathrm{~A} 7 \% \mathrm{D} 8 \% \mathrm{~B} 3 \% \mathrm{D} 8 \% \mathrm{AA}$

Ananews, (2017), Islamic Azad University News Agency, Retrieved from: http://ana.ir

Ananews (2015), A Hot debate about white marriage, Retrieved from:

http://ana.ir/fa/news/91/56191/\%D9\%85\%D9\%86\%D8\%A7\%D8\%B8\%D8\%B1\%D9\%8

7\%E2\%80\%8C $\%$ D8\%A7\%DB\%8C-\%D8\%AF\%D8\%A7\%D8\%BA-

$\% \mathrm{D} 8 \% \mathrm{~A} 7 \% \mathrm{D} 8 \% \mathrm{~B} 2-\% \mathrm{D} 8 \% \mathrm{AC} \% \mathrm{D} 9 \% 86 \% \mathrm{D} 8 \% \mathrm{~B} 3-$

$\% \mathrm{D} 8 \% \mathrm{~A} 7 \% \mathrm{D} 8 \% \mathrm{~B} 2 \% \mathrm{D} 8 \% \mathrm{AF} \% \mathrm{D} 9 \% 88 \% \mathrm{D} 8 \% \mathrm{~A} 7 \% \mathrm{D} 8 \% \mathrm{AC}-$

$\% \mathrm{D} 8 \% \mathrm{~B} 3 \% \mathrm{D} 9 \% 81 \% \mathrm{DB} \% 8 \mathrm{C} \% \mathrm{D} 8 \% \mathrm{AF}$

Ansari, M. (2015), White marriage, Comparison between two experiences, DW. Retrieved from:

https://www.dw.com/fa-ir/\%D8\%B9\%D8\%B7\%D8\%A7-\%D9\%88-

$\% \mathrm{D} 9 \% 84 \% \mathrm{D} 9 \% 82 \% \mathrm{D} 8 \% \mathrm{~A} 7 \% \mathrm{DB} \% 8 \mathrm{C}-$

$\% \mathrm{D} 8 \% \mathrm{~A} 7 \% \mathrm{D} 8 \% \mathrm{~B} 2 \% \mathrm{D} 8 \% \mathrm{AF} \% \mathrm{D} 9 \% 88 \% \mathrm{D} 8 \% \mathrm{~A} 7 \% \mathrm{D} 8 \% \mathrm{AC}-$

$\% \mathrm{D} 8 \% \mathrm{~B} 3 \% \mathrm{D} 9 \% 81 \% \mathrm{DB} \% 8 \mathrm{C} \% \mathrm{D} 8 \% \mathrm{AF}-$

$\% \mathrm{D} 9 \% 85 \% \mathrm{D} 9 \% 82 \% \mathrm{D} 8 \% \mathrm{A7} \% \mathrm{DB} \% 8 \mathrm{C} \% \mathrm{D} 8 \% \mathrm{B3} \% \mathrm{D} 9 \% 87-\% \mathrm{D} 8 \% \mathrm{AF} \% \mathrm{D} 9 \% 88-$

$\%$ D8\%AA\%D8\%AC\%D8\%B1\%D8\%A8\%D9\%87/a-18315641

Arjomand, S. A. (1988). The turban for the crown: The Islamic revolution in Iran. New York: Oxford University Press.

Aryan, S., Aryan, H., \& Halderman, J. A. (2013). Internet Censorship in Iran: A First Look. In USENIX Workshop on Free and Open Communications on the Internet (FOCI). 
Asanjarani, F., Jazayeri, R. S., Fatehizade, M., Etemadi, O., \& Demol, J. (2017). Exploring factors affecting post-divorce adjustment in Iranian women: A qualitative study. Social Determinants of Health, 3(1), 15-25.

Axinn, W. G., \& Thornton, A. (1992). The relationship between cohabitation and divorce: Selectivity or causal influence?. Demography, 29(3), 357-374.

Azad, A. T., Sharifisaiy, M. H., Eisari, M., \& Talebi, S. (2011). Typology of Pre- marital Sex in Iran. Jameh Pazhohi Farhangi (Social Cultural Research), 2(2), 1-34.

Azadarmaki, T., \& Bahar, M. (2006). Families in Iran: Changes, challenges and future. Journal of Comparative Family Studies, 589-608.

Baraniuk, C. (2015). Ashley Madison:'Suicides' over website hack. BBC News, 24.

Bahramitash, R. (2013). Gender and entrepreneurship in Iran: microenterprise and the informal sector. Springer.

Bahramitash, R., \& Esfahani, H. S. (Eds.). (2011). Veiled employment: Islamism and the political economy of women's employment in Iran. Syracuse University Press.

Bahramitash, R., \& Hooglund, E. (2011). Gender in contemporary Iran: pushing the boundaries . Taylor \& Francis.

Bahramitash, R., \& Kazemipour, S. (2006). Myths and realities of the impact of Islam on women: Changing marital status in Iran. Critique: Critical Middle Eastern Studies, 15(2), 111-128.

Bahramitash, R., \& Olmsted, J. C. (2014). Choice and Constraint in paid work: Women from low-income households in Tehran. Feminist Economics,20(4), 260-280.

Baker, M. (2010). Choices and constraints in family life. Oxford University Press.

Baker, M., \& Elizabeth, V. (2014). A 'brave thing to do'or a normative practice? Marriage after long-term cohabitation. Journal of Sociology, 50(4), 393-407.

Bakhash, S. (1984). The reign of the Ayatollahs: Iran and the Islamic Revolution. New York: Basic Books.

Baranowska-Rataj, A. (2014). What would your parents say? The impact of cohabitation among young people on their relationships with their parents. Journal of Happiness Studies, 15(6), 1313-1332.

BBC (2016) White marriage, a relationship outside of marriage, Retrieved from:

http://www.bbc.com/persian/iran-39213566 
BBC (2018) Divorce record broke in Iran, 175000 divorce was registered in 2017, Retrieved from:

http://www.bbc.com/persian/iran-43683683

Beck, U., Giddens, A \& Lash, S., (1994), Reflexive Modernization: Politics, Tradition and Aesthetics in the Modern Social Order Stanford University Press: Stanford.

Behnia, B. (1993), Reflections on the reproduction of dictatorship in Iran: communication and dictatorship', Alternate Routes, 10: 85-111.

Bengtson, V. L. (2001). Beyond the Nuclear Family: The Increasing Importance of Multigenerational Bonds: THE BURGESS AWARD LECTURE. Journal of marriage and family, 63(1), 1-16.

Bernard, H. R. (2011). Research methods in anthropology: Qualitative and quantitative approaches. Rowman Altamira press, UK.

Bettie, J. (2003), Women without class: girls, race, and identity. University of California Press: Berkeley.

Bhabha, H. K., \& Rutherford, J. (2006). Third space. Multitudes, (3), 95-107.

Bhambra, G. (2007). Rethinking modernity: Postcolonialism and the sociological imagination. Springer.

Bhambra, G. K. (2011). Historical sociology, modernity, and postcolonial critique. The American historical review, 116(3), 653-662.

Boghraty,N. (2016), Failure in fighting with sexual freedom, Rdiofarda, Retrieved from:

https://www.radiofarda.com/a/b52-6th-hour-sexual-freedom/27778271.html

Bourdieu, P. \& Wacquant, L. (1992), 'The Logic of Fields' and 'Interest, Habitus, Rationality, from An Invitation to Reflexive Sociology, the university of Chicago press.

Bowman, G. C.(2004), Legal Treatment of Cohabitation in the United States, Law \& Policy, 26(1), 119-151.

Brown,S.L \& Booth, A(1996), Cohabitation versus Marriage: A Comparison of Relationship Quality, Marriage and Family, 58, (3), 668-678.

Bumpass, L. L. and H.H. Lu. 2000. Trends in Cohabitation and Implications for Children's Family Contexts in the United States. Population Studies 54, 29-41.

Burawoy, M. (1991). Ethnography unbound: Power and resistance in the modern metropolis. Univercity of California Press 
Burton, L. M. (1990). Teenage childbearing as an alternative life-course strategy in multigeneration black families. Human nature, 1(2), 123-143.

Carmichael, G. A., \& Whittaker, A. (2007). Living together in Australia: Qualitative insights into a complex phenomenon. Journal of Family Studies, 13(2), 202-223.

Carrabine, E. (2000) 'Discourse, governmentality and translation: Towards a social theory of imprisonment', Theoretical Criminology 4(3): 309-31.

Carrier, J. G. (Ed.). (1995). Occidentalism: Images of the West: Images of the West. Clarendon Press.

Chakrabarty, D. (2000). Subaltern studies and postcolonial historiography. Nepantla: Views from South, 1(1), 9-32.

Chakrabarty, D. (2009). Provincializing Europe: Postcolonial thought and historical difference. Princeton University Press.

Charrad, M. M. (2011). Gender in the Middle East: Islam, state, agency. Annual Review of Sociology, 37, 417-437.

Chen, X. (2002). Occidentalism: a theory of counter-discourse in post-Mao China. Cambridge: Rowman \& Littlefield.

Cherlin, A. J. (2004). The deinstitutionalization of American marriage. Journal of Marriage and Family, 66, 848-861.

Cohen, S. (2002), Deviance and Moral Panics, The Inventory, Reaction: Opinion and Attitude Themes, and Context and Backgrounds: Youth in the Sixties, in Folk Devils and Moral Panics (third edition). Routledge: New York.

Comacchio, C. R. (1999). The infinite bonds of family: Domesticity in Canada, 18501940 (Vol. 4). University of Toronto Press.

Coontz, S.(2010). The evolution of American families. In B. J. Risman (Ed.), Families as they really are (pp. 30-47). New York: W. W. Nortan \& Company.

Cooper, A. (1998). Sexuality and the Internet: Surfing into the new millennium. CyberPsychology \& Behavior, 1(2), 187-193.

Creighton, M. R. (1995). Imaging the other in Japanese advertising campaigns. Occidentalism: Images of the west, 135-160.

Creswell, J. 1998. Qualitative inquiry and research design: Choosing among five traditions. Thousand Oaks, CA: Sage. 
Csordas, T. J. (Ed.). (1994). Embodiment and experience: The existential ground of culture and self (Vol. 2). Cambridge University Press. UK.

Dabashi, H. (1993) Theology of discontent: the ideological foundations of the Islamic Revolution in Iran, New York, New York University Press.

Dananews, (2017): Shame of white marriage on women, Zahedan and Chabahar, the highest rate of white marriage in the province, retrieved from:

http://www.dana.ir/news/1180169.html/\%D8\%B1\%D9\%88\%D8\%B3\%DB\%8C\%D8\%A

$7 \% D 9 \% 87 \% D B \% 8 C-\% D 8 \% A 7 \% D 8 \% B 2 \% D 8 \% A F \% D 9 \% 88 \% D 8 \% A 7 \% D 8 \% A C$ -

$\% D 8 \% B 3 \% D 9 \% 81 \% D B \% 8 C \% D 8 \% A F-\% D 8 \% A 8 \% D 8 \% B 1-$

$\% D A \% 86 \% D 9 \% 87 \% D 8 \% B 1 \% D 9 \% 87-$

$\% D 8 \% A F \% D 8 \% A E \% D 8 \% A A \% D 8 \% B 1 \% D 8 \% A 7 \% D 9 \% 86--$

$\% D 8 \% B 2 \% D 8 \% A 7 \% D 9 \% 87 \% D 8 \% A F \% D 8 \% A 7 \% D 9 \% 86-\% D 9 \% 88$ -

$\% D A \% 86 \% D 8 \% A 7 \% D 8 \% A 8 \% D 9 \% 87 \% D 8 \% A 7 \% D 8 \% B 1-$

$\% D 8 \% B 1 \% D A \% A 9 \% D 9 \% 88 \% D 8 \% B 1 \% D 8 \% A F \% D 8 \% A F \% D 8 \% A 7 \% D 8 \% B 1-$

$\% D 8 \% A 8 \% D B \% 8 C \% D 8 \% B 4 \% D 8 \% A A \% D 8 \% B 1 \% D B \% 8 C \% D 9 \% 86-$

$\% D 8 \% A 2 \% D 9 \% 85 \% D 8 \% A 7 \% D 8 \% B 1-$

$\% D 8 \% A 7 \% D 8 \% B 2 \% D 8 \% A F \% D 9 \% 88 \% D 8 \% A 7 \% D 8 \% A C-$

$\% D 8 \% B 3 \% D 9 \% 81 \% D B \% 8 C \% D 8 \% A F-\% D 8 \% A F \% D 8 \% B 1-$

$\% D 8 \% A 7 \% D 8 \% B 3 \% D 8 \% A A \% D 8 \% A 7 \% D 9 \% 86$

Darabi, K. F., \& Ortiz, V. (1987). Childbearing among young Latino women in the United States. American Journal of Public Health, 77(1), 25-28.

De Sandre P., Ongaro F., Rettaroli R., Salvini S. (1997). (eds). Matrimonio e figli: tra rinvio e rinuncia, Bologna: il Mulino.

Derakhshan, H, (2017), Aljazeera, How Social media kills open web. Rederived fromhttps:/www.aljazeera.com/programmes/listeningpost/2017/04/hossein-derakhshansocial-media-kills-open-web-170415112135200.html

Delanty, G. (2004). An interview with SN Eisenstadt: Pluralism and the multiple forms of modernity. European Journal of social theory, 7(3), 391-404.

Dosekun, S. (2015). For western girls only? Post-feminism as transnational culture. Feminist Media Studies, 15(6), 960-975.

DW.(2014). White marriage and narratives of glassy houses inhabitents (Ezdevaj Sefid Va Hekayat Sakenan Khaneh Hay Shysheh iy), Retrieved from:

https://www.dw.com/fa-ir/\%D8\%A7\%D8\%B2\%D8\%AF\%D9\%88\%D8\%A7\%D8\%AC-

$\% D 8 \% B 3 \% D 9 \% 81 \% D B \% 8 C \% D 8 \% A F-\% D 9 \% 88$ -

$\% D 8 \% A D \% D A \% A 9 \% D 8 \% A 7 \% D B \% 8 C \% D 8 \% A A-$

$\% D 8 \% B 3 \% D 8 \% A 7 \% D A \% A 9 \% D 9 \% 86 \% D 8 \% A 7 \% D 9 \% 86-$ 
$\% D 8 \% A E \% D 8 \% A 7 \% D 9 \% 86 \% D 9 \% 87-$

$\% D 8 \% B 4 \% D B \% 8 C \% D 8 \% B 4 \% D 9 \% 87 \% D 8 \% A 7 \% D B \% 8 C / g-18108188$

Ebrahimi, M. (2014). BBC, Living together without marriage and effects on the quality of intimacy (Zendegi Moshtark Bedon Ezdevaj Va Tasir An Bar Keyfiat Zanashouiy), Retrieved from:

http://www.bbc.com/persian/science/2014/09/140828_me_marriage_premarital_cohabitai on_relationship

Edin, K. and M. Kefalas. 2005. Promises I Can Keep: Why Poor Women Put Motherhood Before Marriage. Berkeley, CA: University of California Press.

Eggebeen, D. J. (2005). Cohabitation and exchanges of support. Social forces, 83(3), 1097-1110.

Egharevba, I. (2001). Researching an-'other'minority ethnic community: Reflections of a black female researcher on the intersections of race, gender and other power positions on the research process. International Journal of Social Research Methodology, 4(3), 225241.

Elizabeth, V., \& Baker, M. (2015). Transiting through cohabitation to marriage: emerging commitment and diminishing ambiguity. Families, Relationships and Societies, 4(1), 53-70.

Esmaili, F., \& Sepehrnia, R. (2016) Iranian women creative approach to the internet, Innovation and creativity in human science, 5(4); 249-276

Etehadieh, M. Sadvandian, S (1992), The memories of Tajalsaltaneh, Iran's history, Tehran, Iran, 26-28.

Etemad, (2017), Interior Ministry involves to solve the problem of white marriage, Retrieved from: https://www.telexiran.com/News/\%D8\%B1\%D9\%88\%D8\%B2\%D9\%86\%D8\%A7\%D9 $\% 85 \% \mathrm{D} 9 \% 87-$

$\% \mathrm{D} 8 \% \mathrm{~A} 7 \% \mathrm{D} 8 \% \mathrm{~B} 9 \% \mathrm{D} 8 \% \mathrm{AA} \% \mathrm{D} 9 \% 85 \% \mathrm{D} 8 \% \mathrm{~A} 7 \% \mathrm{D} 8 \% \mathrm{AF} / \% \mathrm{D} 8 \% \mathrm{~B} 1 \% \mathrm{D} \% \% 88 \% \mathrm{D} 8 \%$ B2\%D9\%86\%D8\%A7\%D9\%85\%D9\%87-

$\% \mathrm{D} 8 \% \mathrm{~A} 7 \% \mathrm{D} 8 \% \mathrm{~B} 9 \% \mathrm{D} 8 \% \mathrm{AA} \% \mathrm{D} 9 \% 85 \% \mathrm{D} 8 \% \mathrm{~A} 7 \% \mathrm{D} 8 \% \mathrm{AF} / \% \mathrm{D} 8 \% \mathrm{AE} \% \mathrm{D} 8 \% \mathrm{~A} 8 \% \mathrm{D} 8$

$\% \mathrm{~B} 1 / \% \mathrm{D} 9 \% 88 \% \mathrm{D} 8 \% \mathrm{~B} 2 \% \mathrm{D} 8 \% \mathrm{~A} 7 \% \mathrm{D} 8 \% \mathrm{~B} 1 \% \mathrm{D} 8 \% \mathrm{AA}-$

$\% \mathrm{DA} \% \mathrm{~A} 9 \% \mathrm{D} 8 \% \mathrm{~B} 4 \% \mathrm{D} 9 \% 88 \% \mathrm{D} 8 \% \mathrm{~B} 1-\% \mathrm{D} 8 \% \mathrm{~A} 8 \% \mathrm{D} 9 \% 87-$

$\% \mathrm{D} 8 \% \mathrm{~A} 7 \% \mathrm{D} 8 \% \mathrm{~B} 2 \% \mathrm{D} 8 \% \mathrm{AF} \% \mathrm{D} 9 \% 88 \% \mathrm{D} 8 \% \mathrm{~A} 7 \% \mathrm{D} 8 \% \mathrm{AC}-$

$\%$ D8\%B3\%D9\%81\%DB\%8C\%D8\%AF-\%D9\%88\%D8\%B1\%D9\%88\%D8\%AF-

$\% \mathrm{D} 9 \% 85 \% \mathrm{DB} \% 8 \mathrm{C} \% \mathrm{E} 2 \% 80 \% 8 \mathrm{C} \% \mathrm{DA} \% \mathrm{~A} 9 \% \mathrm{D} 9 \% 86 \% \mathrm{D} 8 \% \mathrm{AF}$

Fagan, P. F. (2010). The Family GDP: How Marriage and Fertility Drive the Economy. The Family in America, 24(2), 135-149. 
Fanon, F. (1961). On national culture. Postcolonialisms: An Anthology of Cultural Theory and Criticism, 198-219.

Farahani, F. (2007). Diasporic narratives of sexuality: Identity formation among IranianSwedish women (Doctoral dissertation, Acta Universitatis Stockholmiensis).

Farsnews, (2016). What is the legal punishment for white marriage. Retrieved from:

http://www.bartarinha.ir/fa/news/720615/\%D9\%85\%D8\%AC\%D8\%A7\%D8\%B2\%D8\% A7\%D8\%AA-\%D9\%82\%D8\%A7\%D9\%86\%D9\%88\%D9\%86\%DB\%8C$\% \mathrm{D} 8 \% \mathrm{~A} 7 \% \mathrm{D} 8 \% \mathrm{~B} 2 \% \mathrm{D} 8 \% \mathrm{AF} \% \mathrm{D} \% \% 88 \% \mathrm{D} 8 \% \mathrm{~A} 7 \% \mathrm{D} 8 \% \mathrm{AC}-$ $\% \mathrm{D} 8 \% \mathrm{~B} 3 \% \mathrm{D} \% \% 81 \% \mathrm{DB} \% 8 \mathrm{C} \% \mathrm{D} 8 \% \mathrm{AF}-\% \mathrm{DA} \% 86 \% \mathrm{DB} \% 8 \mathrm{C} \% \mathrm{D} 8 \% \mathrm{~B} 3 \% \mathrm{D} 8 \% \mathrm{AA}$

Farber, B. (1987). The future of the American family: A dialectical account. Journal of Family Issues, 8(4), 431-433.

Fathi, M. (2004) Ladies' Center: The Historical Roots of Women's Movements in Iran, Iranian Contemporary Historical Studies, Tehran, Iran. Retrieved from:

http://frooyesh.ir/browse.php?a_id=198\&sid=1\&slc_lang=fa

Fararo, (2015), The ministry of sport: we do not have white marriage in Iran, Retrieved from:

https://fararu.com/fa/news/215567/\%D9\%88\%D8\%B2\%D8\%A7\%D8\%B1\%D8\%AA$\% \mathrm{D} 9 \% 88 \% \mathrm{D} 8 \% \mathrm{~B} 1 \% \mathrm{D} 8 \% \mathrm{~B} 2 \% \mathrm{D} 8 \% \mathrm{~B} 4-$ $\% \mathrm{D} 8 \% \mathrm{~A} 7 \% \mathrm{D} 8 \% \mathrm{~B} 2 \% \mathrm{D} 8 \% \mathrm{AF} \% \mathrm{D} 9 \% 88 \% \mathrm{D} 8 \% \mathrm{~A} 7 \% \mathrm{D} 8 \% \mathrm{AC}-$ $\% \mathrm{D} 8 \% \mathrm{~B} 3 \% \mathrm{D} 9 \% 81 \% \mathrm{DB} \% 8 \mathrm{C} \% \mathrm{D} 8 \% \mathrm{AF}-\% \mathrm{D} 8 \% \mathrm{AF} \% \mathrm{D} 8 \% \mathrm{~B} 1-$ $\% \mathrm{D} 8 \% \mathrm{~A} 7 \% \mathrm{DB} \% 8 \mathrm{C} \% \mathrm{D} 8 \% \mathrm{~B} 1 \% \mathrm{D} 8 \% \mathrm{~A} 7 \% \mathrm{D} \% \% 86-$ $\% \mathrm{D} 9 \% 88 \% \mathrm{D} 8 \% \mathrm{AC} \% \mathrm{D} 9 \% 88 \% \mathrm{D} 8 \% \mathrm{AF}-$ $\% \mathrm{D} \% \% 86 \% \mathrm{D} 8 \% \mathrm{AF} \% \mathrm{D} 8 \% \mathrm{~A} 7 \% \mathrm{D} 8 \% \mathrm{~B} 1 \% \mathrm{D} 8 \% \mathrm{AF}$

Foucault, M. (1975), Discipline and Punish: the Birth of the Prison, New York: Random House.

Foucault, M. (1978). The history of sexuality: Vol I. London: Penguin.

Foucault, M. (1982). The subject and power. Critical inquiry, 8(4), 777-795.

Foucault, M. (1991). 'Governmentality', trans. Rosi Braidotti and revised by Colin Gordon, in Burchell,G. Gordon,C \& Miller,P. (1991), The Foucault Effect: Studies in Governmentality, Chicago, IL: University of Chicago Press.

Foucault, M. (1991). The Foucault effect: Studies in governmentality. University of Chicago Press. 
Foucault, M. (2007). Security, territory, population: lectures at the Collège de France, 1977-78. Springer.

Franke, K. M. (2006). The politics of same-sex marriage politics. Colum. J. Gender \& L., $15,236$.

Gandhi, L. (1998). Postcolonial theory: A critical introduction. Columbia University Press.

Garland, D. (2008), On the Concept of Moral Panic, Crime, Media, Culture 4(1): 9-30.

Gastil, R. D. (1958). Middle Class Impediments to Iranian Modernization. The Public Opinion Quarterly, 22(3), 325-329.

Ghoddosi, S. Bayat, F.(2014). White Marriage: Pain or Treatment, Study of Unofficial Marriages in Iran, Zanan Emroz, 5: 7-15.

Giddens, A. (1992). The transformation of intimacy: sexuality, love and eroticism in modern societies, California, Stanford University Press.

Gieben, B., \& Hall, S. (Eds.). (1992). The Formations of Modernity. Polity Press.

Goldberg, A. E. (2010). Lesbian and gay parents and their children: Research on the family life cycle. Washington, DC: American Psychological Association.

Golkar, S. (2011). Liberation or suppression technologies? The Internet, the Green Movement and the regime in Iran. International Journal of Emerging Technologies and Society, $9(1), 50$

Goyanews, (2018). White marriage a change in life style or a social issue, Retrieved from: https://news.gooya.com/2018/08/post-17939.php

Gross, N. \&Simmons, S. (2002). Intimacy as a Double-Edged Phenomenon? An Empirical Test of Giddens, Social Forces, 81, (2):531-555.

HabibiAsgarAbadi, M., HajiHeidary, Z. (2015). reasons for adultery among people who are in court for divorce. Family studies, 11(2) 165-188. Retrieved from:

http://jfr.sbu.ac.ir/article/view/8327/4511

Haeri, SH. (1993). The Law of Desire: Temporary Marriage in Iran, I.B. Tauris \& Co Ltd, India.

Hage, G. (2012). White nation: Fantasies of white supremacy in a multicultural society. Annandale, PA: Pluto Press. 
Hall, S. (1992). The West and the Rest: Discourse and Power. In Stuart Hall \& Brem Gieben, red: Formations of Modernity. Cambridge, UK: Polity Press

Hareven, T. K. (Ed.). (2013). Transitions: The family and the life course in historical perspective. New York: Academic Press.

Hartsock, N. (1990). Foucault on power: a theory for women? In L.J. Nicholson, (ed): Feminism/Postmodernism, New York and London: Routledge

Heaton, T. B \& Vaughn, R. A. (1991). CallSource: The Role of Cohabitation in Declining Rates of Marriage, Marriage and Family, 53(4): 913-927.

Heaton, T. B., Jacobson, C. K., \& Holland, K. (1999). Persistence and change in decisions to remain childless. Journal of Marriage and the Family, 531-539.

Heaton, T. B., \& Call, V. R. A. (1995). Modeling family dynamics with event history techniques. Journal of Marriage and the Family, 57, 1078-1090

Hemmasi, F. (2010). Iranian popular music in Los Angeles: Mobilizing media, nation, and politics. Columbia University

Hogerbrugge, M. J., \& Dykstra, P. A. (2009). The family ties of unmarried cohabiting and married persons in the Netherlands. Journal of Marriage and Family, 71(1), 135-145.

Holmes, M. (2010). The Emotionalization of Reflexivity, Sociology, 44 (1): 139-154.

Hoodfar, H. (1995). Population policy and gender equity in post- revolutionary Iran. In Family, Gender, and Population in the Middle East: Policy in Context. Ed. Carla Makhlouf Obermeyer. Cairo: The American University in Cairo Press.

Hoodfar, H., \& Sadr, S. (2010). Islamic politics and women's quest for gender equality in Iran. Third world quarterly, 31(6), 885-903.

Hoodfar, H., Sadr, S., Religion, P., \& Equality, G. (2009). Can women act as agents of a democratization of theocracy in Iran? Geneva, Switzerland: United Nations Research Institute for Social Development (UNRISD, 2009, pp. 3-37)

Hoseinkhah, N. (2017), Feminist constitutionalist founders of women movements in Iran, Retrieved from:

http://www.aasoo.org/fa/articles/\%D8\%AF\%D8\%B3\%D8\%AA\%D8\%A7\%D9\%88\%D8 $\% \mathrm{~B} 1 \% \mathrm{D} 8 \% \mathrm{AF} \% \mathrm{D} \% \% 87 \% \mathrm{D} 8 \% \mathrm{~A} 7 \% \mathrm{DB} \% 8 \mathrm{C}-\% \mathrm{D} 8 \% \mathrm{AC} \% \mathrm{D} \%$ \%6\%D8\%A8\%D8\%B4$\%$ D8\%B2\%D9\%86\%D8\%A7\%D9\%86-\%D8\%AF\%D8\%B1$\% \mathrm{D} 8 \% \mathrm{AF} \% \mathrm{D} 9 \% 88 \% \mathrm{D} 8 \% \mathrm{~B} 1 \% \mathrm{D} 9 \% 87 \% \mathrm{E} 2 \% 80 \% 8 \mathrm{C} \% \mathrm{DB} \% 8 \mathrm{C}-$

$\% \mathrm{D} 9 \% 85 \% \mathrm{D} 8 \% \mathrm{~B} 4 \% \mathrm{D} 8 \% \mathrm{~B} 1 \% \mathrm{D} 9 \% 88 \% \mathrm{D} 8 \% \mathrm{~B} 7 \% \mathrm{D} \% \% 7$

Hoseinkhah. N. (2018), Women movement's achievement in constitutional period, 
Retrieved from:

http://www.aasoo.org/fa/articles/\%D9\%81\%D9\%85\%DB\%8C $\%$ D9\%86\%DB $\% 8 \mathrm{C} \% \mathrm{D} 8$ $\%$ B3\%D8\%AA\%E2\%80\%8C\%D9\%87\%D8\%A7\%DB\%8C-

$\%$ D9\%85\%D8\%B4\%D8\%B1\%D9\%88\%D8\%B7\%D9\%87\%E2\%80\%8C\%D8\%AE\%D9

$\% 88 \% \mathrm{D} 8 \% \mathrm{~A} 7 \% \mathrm{D} 9 \% 87 \% \mathrm{D} 8 \% 8 \mathrm{C}-$

$\% \mathrm{D} \% \% \mathrm{BE} \% \mathrm{D} 8 \% \mathrm{~A} 7 \% \mathrm{DB} \% 8 \mathrm{C} \% \mathrm{D} 9 \% 87 \% \mathrm{E} 2 \% 80 \% 8 \mathrm{C} \% \mathrm{DA} \% \mathrm{AF} \% \mathrm{D} 8 \% \mathrm{~B} 0 \% \mathrm{D} 8 \% \mathrm{~A} 7 \%$

D8\%B1\%D8\%A7\%D9\%86-\%D8\%AC\%D9\%86\%D8\%A8\%D8\%B4-

$\% \mathrm{D} 8 \% \mathrm{~B} 2 \% \mathrm{D} 9 \% 86 \% \mathrm{D} 8 \% \mathrm{~A} 7 \% \mathrm{D} 9 \% 86-\% \mathrm{D} 8 \% \mathrm{AF} \% \mathrm{D} 8 \% \mathrm{~B} 1-$

$\% \mathrm{D} 8 \% \mathrm{~A} 7 \% \mathrm{DB} \% 8 \mathrm{C} \% \mathrm{D} 8 \% \mathrm{~B} 1 \% \mathrm{D} 8 \% \mathrm{~A} 7 \% \mathrm{D} 9 \% 86$

Howse, K. (2016). Revisionism in the Rationale for Population Policies. Population Horizons, 13(1), 1-8.

Hunt, A. 1999. Governing Morals: A Social History of Moral Regulation. Cambridge: Cambridge University Press.

Hunt, A., \& Wickham, G. (1994). Foucault and law: Towards a sociology of law as governance. Pluto Press: s: London.

Ignatow, G. (2016). Theoretical Foundations for Digital Text Analysis Theoretical Foundations for Digital Text Analysis. Journal for the theory of social behaviour. 14685914. Available at: http://dx.doi.org/10.1111/ jtsb.12086

Illouz, E. (1997). Consuming the romantic utopia: Love and the cultural contradictions of capitalism. Univ of California Press.

Inglehart, R. (1997). Modernization a dostmodernization. Cultural, economic and political change in 43 societies. Princeton, NJ: Princeton University Press.

Irna (2018), Scrutiny in different aspect of white marriage, Retrieved from:

http://www.irna.ir/fa/News/82847200

Isnanews, (2016), Challenges of living alone, Retrieved from:

https://www.isna.ir/news/97050703439/\%D9\%85\%D8\%B5\%D8\%A7\%D8\%A6\%D8\%A $8-\% \mathrm{D} 8 \% \mathrm{~B} 2 \% \mathrm{D} 9 \% 86 \% \mathrm{D} 8 \% \mathrm{AF} \% \mathrm{DA} \% \mathrm{AF} \% \mathrm{DB} \% 8 \mathrm{C}-$

$\% \mathrm{D} 9 \% 85 \% \mathrm{D} 8 \% \mathrm{AC} \% \mathrm{D} 8 \% \mathrm{~B} 1 \% \mathrm{D} 8 \% \mathrm{AF} \% \mathrm{DB} \% 8 \mathrm{C}$

Jackson, S. (1993). Even sociologists fall in love: An exploration in the sociology of emotions. Sociology, 27(2), 201-220.

Jalaeipour, H.R. (2015). Family in the time of moderation (Khanevadeh dar doreh Etedal), in Theoretical and Sociological Foundations of Moderation, Tisa Press, Tehran, Iran. 
Jalali, B. (1996). Iranian families. In M. McGoldrick, J. Giordano, \& J. K. Pearce (Eds.), Ethnicity and family therapy. New York: Guilford Press.

Jalali, B. (1996). Iranian families. In M. McGoldrick, J. Giordano, \& J. K. Pearce (Eds.), Ethnicity and family therapy. New York: Guilford Press.

Jankowiak, W. R., \& Fischer, E. F. (1992). A cross-cultural perspective on romantic love. Ethnology, 31(2), 149-155.

Jamejam, (2015), A building without plan without bricks, Retrieved from:

http://jamejamonline.ir/sara/1885553664986558367

Javidan, M., \& Dastmalchian, A. (2003). Culture and leadership in Iran: The land of individual achievers, strong family ties, and powerful elite. Academy of Management Perspectives, 17(4), 127-142.

Jones, G. (2012). Late marriage and low fertility in Singapore: the limits of policy. The Japanese Journal of Population, 10(1), 89-101.

Keyhan London, (2015), Hambashi is an individual decision for any citizen, Retrieved from:

https://kayhan.london/fa/1394/03/18/\%D9\%85\%D9\%87\%D8\%B1\%D8\%AF\%D8\%A7\% $\mathrm{D} 8 \% \mathrm{AF}-$

$\% \mathrm{D} 8 \% \mathrm{AF} \% \mathrm{D} 8 \% \mathrm{~B} 1 \% \mathrm{D} 9 \% 88 \% \mathrm{DB} \% 8 \mathrm{C} \% \mathrm{D} 8 \% \mathrm{~B} 4 \% \mathrm{E} 2 \% 80 \% 8 \mathrm{C} \% \mathrm{D} 9 \% \mathrm{BE} \% \mathrm{D} 9 \% 88 \% \mathrm{D}$ 8\%B1-\%D8\%AF\%D8\%B1\%D8\%A8\%D8\%A7\%D8\%B1\%D9\%87-

$\% \mathrm{D} 8 \% \mathrm{~A} 7 \% \mathrm{D} 8 \% \mathrm{~B} 2 \% \mathrm{D} 8 \% \mathrm{AF} \% \mathrm{D} 9 \% 88 \% \mathrm{D} 8 \% \mathrm{~A} 7 \% \mathrm{D} 8 \% \mathrm{AC}-$

$\% \mathrm{D} 8 \% \mathrm{~B} 3 \% \mathrm{D} \% \% 81 \% \mathrm{DB} \% 8 \mathrm{C} \% \mathrm{D} 8 \% \mathrm{AF}$

Yjcnews, (2017), White marriage beginning of darkness, addiction and unsafe abortion threatens women. Retrieved from:

https:/www.yjc.ir/fa/news/6328376/\%D8\%A7\%D8\%B2\%D8\%AF\%D9\%88\%D8\%A7\% D8\%AC-\%D8\%B3\%D9\%81\%DB\%8C\%D8\%AF-\%D9\%88-

$\% \mathrm{D} 8 \% \mathrm{~A} 2 \% \mathrm{D} 8 \% \mathrm{BA} \% \mathrm{D} 8 \% \mathrm{~A} 7 \% \mathrm{D} 8 \% \mathrm{~B} 2-$

$\% \mathrm{D} \% \% \mathrm{~B} 3 \% \mathrm{DB} \% 8 \mathrm{C} \% \mathrm{D} 8 \% \mathrm{~A} 7 \% \mathrm{D} 9 \% 87 \% \mathrm{DB} \% 8 \mathrm{C} \% \mathrm{E2} \% 80 \% 8 \mathrm{C} \% \mathrm{D} 9 \% 87 \% \mathrm{D} 8 \% \mathrm{~A} 7-$

$\% \mathrm{D} 8 \% \mathrm{~A} 7 \% \mathrm{D} 8 \% \mathrm{~B} 9 \% \mathrm{D} 8 \% \mathrm{AA} \% \mathrm{DB} \% 8 \mathrm{C} \% \mathrm{D} 8 \% \mathrm{~A} 7 \% \mathrm{D} 8 \% \mathrm{AF}-\% \mathrm{D} 9 \% 88-$

$\% \mathrm{D} 8 \% \mathrm{~B} 3 \% \mathrm{D} 9 \% 82 \% \mathrm{D} 8 \% \mathrm{~B} 7 \% \mathrm{E} 2 \% 80 \% 8 \mathrm{C} \% \mathrm{D} 9 \% 87 \% \mathrm{D} 8 \% \mathrm{~A} 7 \% \mathrm{DB} \% 8 \mathrm{C}-$

$\% \mathrm{D} 8 \% \mathrm{~B} 2 \% \mathrm{DB} \% 8 \mathrm{C} \% \mathrm{D} 8 \% \mathrm{~B} 1 \% \mathrm{D} 8 \% \mathrm{~B} 2 \% \mathrm{D} 9 \% 85 \% \mathrm{DB} \% 8 \mathrm{C} \% \mathrm{D} \% \% 86 \% \mathrm{DB} \% 8 \mathrm{C}-$

$\% \mathrm{D} 8 \% \mathrm{AF} \% \mathrm{D} 8 \% \mathrm{~B} 1-\% \mathrm{DA} \% \mathrm{~A} 9 \% \mathrm{D} 9 \% 85 \% \mathrm{DB} \% 8 \mathrm{C} \% \mathrm{D} 9 \% 86-$

$\% \mathrm{D} 8 \% \mathrm{AF} \% \mathrm{D} 8 \% \mathrm{AE} \% \mathrm{D} 8 \% \mathrm{AA} \% \mathrm{D} 8 \% \mathrm{~B} 1 \% \mathrm{D} 8 \% \mathrm{~A} 7 \% \mathrm{D} 9 \% 86$

Khabaranline (2016), Analyzed at Tehran university, whether white marriage is a private matter? Retrieved from: 
https://www.khabaronline.ir/news/528184/\%D8\%AF\%D8\%B1-

$\% \mathrm{D} 8 \% \mathrm{AF} \% \mathrm{D} 8 \% \mathrm{~A} 7 \% \mathrm{D} 9 \% 86 \% \mathrm{D} 8 \% \mathrm{~B} 4 \% \mathrm{DA} \% \mathrm{AF} \% \mathrm{D} 8 \% \mathrm{~A} 7 \% \mathrm{D} \%$ \%7-

$\% \mathrm{D} 8 \% \mathrm{AA} \% \mathrm{D} 9 \% 87 \% \mathrm{D} 8 \% \mathrm{~B} 1 \% \mathrm{D} 8 \% \mathrm{~A} 7 \% \mathrm{D} 9 \% 86-$

$\% \mathrm{D} 8 \% \mathrm{~A} 8 \% \mathrm{D} 8 \% \mathrm{~B} 1 \% \mathrm{D} 8 \% \mathrm{~B} 1 \% \mathrm{D} 8 \% \mathrm{~B} 3 \% \mathrm{DB} \% 8 \mathrm{C}-\% \mathrm{D} 8 \% \mathrm{~B} 4 \% \mathrm{D} 8 \% \mathrm{AF}-$

$\% \mathrm{D} 8 \% \mathrm{~A} 2 \% \mathrm{DB} \% 8 \mathrm{C} \% \mathrm{D} 8 \% \mathrm{~A} 7-$

$\% \mathrm{D} 8 \% \mathrm{~A} 7 \% \mathrm{D} 8 \% \mathrm{~B} 2 \% \mathrm{D} 8 \% \mathrm{AF} \% \mathrm{D} 9 \% 88 \% \mathrm{D} 8 \% \mathrm{~A} 7 \% \mathrm{D} 8 \% \mathrm{AC}-$

$\% \mathrm{D} 8 \% \mathrm{~B} 3 \% \mathrm{D} \% \% 81 \% \mathrm{DB} \% 8 \mathrm{C} \% \mathrm{D} 8 \% \mathrm{AF}-\% \mathrm{D} 8 \% \mathrm{AC} \% \mathrm{D} 8 \% \mathrm{~B} 2 \% \mathrm{D} \% 88-$

$\% \mathrm{D} 8 \% \mathrm{AD} \% \mathrm{D} 8 \% \mathrm{~B} 1 \% \mathrm{DB} \% 8 \mathrm{C} \% \mathrm{D} 9 \% 85-$

\%D8\%AE\%D8\%B5\%D9\%88\%D8\%B5\%DB\%8C-\%D8\%A7\%D8\%B3\%D8\%AA

Karamouzian, M., \& Haghdoost, A. A. (2015). Population control policies in Iran. The Lancet, 385(9973), 1071. Retrieved from:

https://www.thelancet.com/journals/lancet/article/PIIS0140-6736(15)60596-

7/fulltext?code=lancet-site

Karamouzian, M., Sharifi, H., \& Haghdoost, A. A. (2014). Iran's shift in family planning policies: concerns and challenges. International journal of health policy and management, 3(5), 231.

KarimiMajd, R (2015), White Marriage a Room with Open Doors, Radiofarda, Retrieved from:

https://www.radiofarda.com/a/f3-white-marriage-iran/27776567.html

Kastoryano, R. (2002). Negotiating Identities: States and Immigrants in France and Germany. Princeton, NJ: Princeton University Press.

Keddie, N. R., \& Richard, Y. (2006). Modern Iran: Roots and results of revolution. Yale University Press.

Khalajabadi-Farahani \& Saraiy, (2016), Investigation on reasons for having only one child in Tehran, Strategic Women Studies, 18 (1) 29-58.

Khan, S. (1998). Muslim women: Negotiations in the third space. Signs, 23(2), 463-494.

Khezr-Heydary, F. (2018). Reverse marital age difference, judgments and challenges, $D W$, Retrieved from:

https://www.radiofarda.com/a/taboo-e76-age-difference-in-marriagecontroversies/29194403.html

Khodayarifard, M; Alavinejad, S; Sajjadi Anari, S; Zandi, S (2016), Efficacy of family therapy combined with CBT techniques on treatment of sexual variety seeking, Germination of Psychology, 17(4), 85-116. Retrieved from: file://C:/Users/mehrn/Desktop/commitment/khianat\%20dar\%20khanevadeh\%20irani.pdf 
Kian, A. (1995). Gendered occupation and women's status in post-revolutionary Iran. Middle Eastern Studies, 31(3), 407-421.

Kiernan, K. E. (1999, April). European perspectives on non-marital childbearing. Paper presented at the Conference on Nonmarital Childbearing, Institute for Research on Poverty, University of Wisconsin, Mad- ison

Kiernan, K. (2001). The rise of cohabitation and childbearing outside marriage in Western Europe. International journal of law, policy and the family, 15(1), 1-21.

Kojima, H. (2010). Premarital Cohabitation and the Timing of Family Formation in East Asia and the West. Retrieved from:

https://iussp.org/sites/default/files/event_call_for_papers/iusspKojima.pdf

Kobayashi, K., \& Kampen, R. (2015). Cohabitation in Asia. Routledge handbook offamilies in Asia. Abingdon, Oxon, N.-Y.: Routledge, 377-397.

Kurdek, L. A., \& Schmitt, J. P. (1987). Perceived emotional support from family and friends in members of homosexual, married, and heterosexual cohabiting couples. Journal of homosexuality, 14(3-4), 57-68.

Kurzman, C. (1996). Structural opportunity and perceived opportunity in socialmovement theory: the Iranian revolution of 1979. American Sociological Review, 61 (1), 153-170.

Laplante, B. (2004). The diffusion of cohabitation in Québec and Ontario and the power of norms in religion. Institut national de la recherché scientifique (INRS)-Urbanisation, Culture et societe, Montreal, Canada.

Lesthaeghe, R., \& Surkyn, J. (1988). Cultural dynamics and economic theories of fertility change. Population and development review, 14 (1),1-45.

Lewis, C., Papacosta, A., \& Warin, J. (2002). Cohabitation, Separation, and Fatherhood. York: Joseph Rowntree Foundation.

Lindsay, J. M. (2000). An ambiguous commitment: Moving in to a cohabiting relationship. Journal of Family Studies, 6(1), 120-134.

Loomba, A., Survir, K., Matti, B.,Antoinette, B., \& Jed E.(2005) Post-colonial studies and Beyond. Durham and London: Duke University Press

Loomba, A. (1998). Colonial/Postcolonial. London: Routledge.

Loomis, L. S., \& Landale, N. S. (1994). Nonmarital cohabitation and childbearing among black and white American women. Journal of Marriage and the Family, 56, 949-962. 
Luttrell, W. (2000). " Good enough" methods for ethnographic research. Harvard Educational Review, 70(4), 499-523.

Lutz, H., A. Phoenix and N. Yuval-Davis (1995) 'Introduction: Nationalism, Racism and Gender - European Crossfires', pp. 1-25 in H. Lutz, A. Phoenix and N. Yuval-Davis (eds) Crossfires: Nationalism, Racism and Gender in Europe. London and East Haven, CT: Pluto Press.

M. Yaukacheva, 'The Feminist Movement in Persia,' Central Asian Review (1959), $7(1): 75$

Mahboobi, E. (2016). " White Marriage" in Contemporary Iran. Imperial Journal of Interdisciplinary Research, 2(12).206-211.

Mansfield-Devine, S. (2015). The Ashley Madison affair. Network Security Elsevier September 2015, 2015(9), 8-16.

Mahdavi, P. (2009). Passionate uprisings: Iran's sexual revolution. Stanford University Press.

Mashreghnews, (2018) Misery in white marriage, Retrieved from:

https://www.mashreghnews.ir/news/865305/\%D8\%B3\%DB\%8C\%D8\%A7\%D9\%87-

$\% \mathrm{D} 8 \% \mathrm{~A} 8 \% \mathrm{D} 8 \% \mathrm{AE} \% \mathrm{D} 8 \% \mathrm{AA} \% \mathrm{DB} \% 8 \mathrm{C}-\% \mathrm{D} 8 \% \mathrm{AF} \% \mathrm{D} 8 \% \mathrm{~B} 1-$

$\% \mathrm{D} 8 \% \mathrm{~A} 7 \% \mathrm{D} 8 \% \mathrm{~B} 2 \% \mathrm{D} 8 \% \mathrm{AF} \% \mathrm{D} \% \% 88 \% \mathrm{D} 8 \% \mathrm{~A} 7 \% \mathrm{D} 8 \% \mathrm{AC}-$

$\%$ D9\%87\%D8\%A7\%DB\%8C-\%D8\%B3\%D9\%81\%DB\%8C\%D8\%AF

Mayer, K. U. (2004). Whose lives? How history, societies and institutions define and shape life courses. Research in Human Development, 1, 161-187.

McNay, L. (1999), Gender habitus and the field: Pierre Bourdieu and the limits of reflexivity. Theory, Culture and Society, 16(1), 95-117.

McNay, L. (2009). Self as enterprise: Dilemmas of control and resistance in Foucault's The Birth of Biopolitics. Theory, Culture \& Society, 26(6), 55-77.

Mehran, G. (2003). The paradox of tradition and modernity in female education in the Islamic Republic of Iran. Comparative Education Review, 47(3), 269-286.

Rhoads, C., Fassihi, F., \& Gonzalez, A. (2011). Iran vows to unplug internet. Wall Street Journal, Retrieved from:

https://www.wsj.com/articles/SB10001424052748704889404576277391449002016n the Islamic Republic of Iran. Comparative Education Review, 47(3), 269-286.

Milani, M. M. (2018). The making of Iran's Islamic revolution: from monarchy to Islamic republic. Routledge. 
Mirmiry, H. (2011). Love as a social construction in Iranian's narratives in $1960^{\text {th }}$, $1980^{\text {th }}$, 2000 ${ }^{\text {th }}$, Master's Thesis, The university of Elm va Farhang Tehran.

Mirza, M. (1998) 'Same voices, same lives?': revisiting black feminist standpoint epistemology. In P. Connolly and B. Troyna (eds) Researching Racism in Education: Politics, Theory and Practice (Buckingham: Open University), pp. 79-94.

Mirzaie, M. (1998). "Swings in fertility limitations in Iran", Working Paper in Demography, No. 72, Canberra: Australian National University.

Moghadam, V. M. (1999). Revolution, religion, and gender politics: Iran and Afghanistan compared. Journal of Women's History, 10(4), 172-195.

Moghadam, V. M. (2002). Islamic feminism and its discontents: Toward a resolution of the debate. Signs: Journal of Women in Culture and Society, 27(4), 1135-1171.

Moghadam, V. M., \& Haghighatjoo, F. (2016). Women and Political Leadership in an Authoritarian Context: A Case Study oaghaf the Sixth Parliament in the Islamic Republic of Iran. Politics \& Gender, 12(1), 168-197.

Moghissi, H. (2016). Populism and feminism in Iran: Women's struggle in a maledefined revolutionary movement. Springer.

Mohamadi, M., (2018). A decline in the average of marital age for women in Iran, why?. $B B C$ Farsi, Retrieved from:

http://www.bbc.com/persian/blog-viewpoints-43618722

Mohamadi,M. (2013), New population policy, Government intervention, Citizen's resistance, $B B C$ Farsi. Retrieved from:

http://www.bbc.com/persian/blogs/2013/10/131019_144_nazeran_new_population_policy Mohanty, C. T. (2003). "Under western eyes" revisited: feminist solidarity through anticapitalist struggles. Signs, 28(2), 499-535.

Mohr, J. W., \& Bogdanov, P. (2013). Introduction-Topic models: What they are and why they matter. Poetics, 41(6), 545-569.

Moidfar, S. (2004). The generational gap or cultural break up, Social science letter, 24(4), 55-80.

Moussa, M., \& Scapp, R. (1996). The practical theorizing of Michel Foucault: Politics and counter-discourse. Cultural Critique, 33, 87-112.

Müller-Freienfels, W. (1987). Cohabitation and marriage law-a comparative study. International Journal of Law, Policy and the Family, 1(2), 259-294. 
Mynarska, M., Baranowska-Rataj, A., \& Matysiak, A. (2014). Free to stay, free to leave: Insights from Poland into the meaning of cohabitation. Demographic Research, 31, 11071136.

Montazerolmahdi, S. (2013). White marriage or living black. IRAN,

Retrieved from: http://www.magiran.com/npview.asp? ID=3073290

Nagi, M. H. (1984). Trends and Differentials in Moslem fertility. Biosocial Science, $16,189-204$.

Najmabadi, A. (2004). The morning after: Travail of sexuality and love in modern Iran. International Journal of Middle East Studies, 36(3), 367-385.

Nasirzadeh, B. (2014). Negotiations in the Third Space: Visualization of the Complexity of an Iranian Woman's Identity (Doctoral dissertation, York University Toronto).

Nassehi-Behnam, V. (1985). Change and the Iranian family. Current anthropology, $26(5), 557-562$.

Nazio, T., \& Blossfeld, H. P. (2003). The diffusion of cohabitation among young women in West Germany, East Germany and Italy. European Journal of Population/Revue europeenne de demographie, 19(1), 47-82.

Nazio, T., \& Saraceno, C. (2012). Does cohabitation lead to weaker intergenerational bonds than marriage? A comparison between Italy and the United Kingdom. European sociological review, 29(3), 549-564.

Nock, S. L. (1995). A comparison of marriages and cohabiting relationships. Family Issues, 16, 53-76.

Osanloo, A. (2006). "Islamico-Civil 'Rights Talk': Women, Subjectivity, and Law in Iranian Family Court." American Ethnologist, 33 (2): 191-209.

Owens, E. (2007). The sociology of love, courtship and dating. 21st Century Sociology, 266-271.

Paidar, P. (1997). Women and the political process in twentieth-century Iran (Vol. 1). Cambridge University Press.

Panahi, H. (2004). The generation gap and its influence on education in Iran, Social Science, 27(3), 1-41

Penn, R. (2011). Arranged marriages in Western Europe: Media representations and social reality. Journal of Comparative Family Studies, 637-650. 
Perelli-Harris, B., \& Gerber, T. P. (2011). Nonmarital childbearing in Russia: Second demographic transition or pattern of disadvantage? Demography, 48(1), 317-342.

Perelli-Harris, B., Kreyenfeld, M., Sigle-Rushton, W., Keizer, R., Lappegård, T., Jasilioniene, A., ... \& Di Giulio, P. (2012). Changes in union status during the transition to parenthood in eleven European countries, 1970s to early 2000s. Population studies, 66(2), 167-182.

Pieterse, J. N. (2009). Multipolarity means thinking plural: Modernities. Protosociology, 26, 19-35.

Pollard, M. S., \& Wu, Z. (1998). Divergence of marriage patterns in Quebec and elsewhere in Canada. Population and Development Review, 329-356.

Pourmalek, F., Abolhassani, F., Naghavi, M., Mohammad, K., Majdzadeh, R., Naeini, K. H., \& Fotouhi, A. (2009). Direct estimation of life expectancy in the Islamic Republic of Iran in 2003. World health organization. Retrieved from:

http://apps.who.int/iris/handle/10665/117610

Prasad, A. (2003). Postcolonial theory and organizational analysis: A critical engagement. Springer.

Rahimi, B. (2007). The politics of the Internet in Iran. In Media, culture and society in Iran (pp. 53-72). Routledge.

Ramazani, N. (1993), Women in Iran: The Revolutionary, Middle East Journal, 47, (3). 409-428.

Rashad, H., Osman, M., \& Roudi-Fahimi, F. (2005). Marriage in the Arab world. Washington, DC: Population Reference Bureau.1-8

Rasler, K. (1996). Concessions, repression, and political protest in the Iranian revolution. American Sociological Review, 132-152.

Raveis, V. H., \& Siegel, K. (1991). The impact of care giving on informal or familial care givers. AIDS Patient Care, 5(1), 39-43.

Reczek, C., Elliott, S., \& Umberson, D. (2009). Commitment without marriage: Union formation among long-term same-sex couples. Journal of Family Issues, 30(6), 738-756.

Riddell, Katrina (2009). Islam and the Secularization of Population Policies. Burlington: Ashgate.

Rindfuss, R.R \& Vanden, H.A. (1990) Cohabitation: A Precursor to Marriage or an Alternative to Being Single? Population and Development Review, 16(4), 703-726. 
Rofel, L. (2007). Desiring China: Experiments in neoliberalism, sexuality, and public culture. Duke University Press.

Rosina, A., \& Fraboni, R. (2004). Is marriage losing its centrality in Italy?. Demographic research, 11, 149-172.

Rostaie,M. Badihi Zeraaty,F. Porakbaran E., Rjabzadeh,Z. (2016). Investigating the impact of emerging media (Internet, satellite, and cell phones) on couples' emotional betrayal and influential factors, Mental Health Fundamentals, 18, 419-421.

Ruiz, J. R. (2009). Sociological discourse analysis: Methods and logic. In Forum Qualitative Sozialforschung/Forum: Qualitative Social Research,10 (2).

Ryder, N. B. (1967). The Character of Modern Fertility, Annals of the American Academy of Political and Social Science 369:26-36.

Sachsenmaier, D. (2006). Global history and critiques of western perspectives. Comparative Education, 42(3), 451-470.

Sachsenmaier, D. (2009). Recent Trends in European History: The World beyond Europe and Alternative Historical Spaces. Journal of Modern European History, 7(1), 5-25.

Sadeghi, F. (2008). Negotiating with modernity: Young women and sexuality in Iran. Comparative Studies of South Asia, Africa and the Middle East, 28(2), 250-259.

Sanasarian, E. (1982). The Women's Rights Movement in Iran Mutiny, Appeasement, and Repression From 1900 to Khomeini, Akhtaran, Tehran, Iran

Sarkar, A. (2011). Romancing with a brand: a conceptual analysis of romantic consumerbrand relationship. Management \& Marketing, 6(1), 79.

Sarokhani,B., Sedaghatyfar.M .(2010)., Social science search letter, Generational gap in Iranian family, Perspectives and insights,. 3(2)7-31.

Sassler, S. (2004). The process of entering into cohabiting unions. Journal of Marriage and Family, 66(2), 491-505.

Schröder-Butterfill, E. (2004). Inter-generational family support provided by older people in Indonesia. Ageing \& Society, 24(4), 497-530.

Seidman, S. (1996). Empire and knowledge: more troubles, new opportunities for sociology. Contemporary Sociology ,25 (3),313-316.

Seidman, S. (1994). The postmodern turn: New perspectives on social theory. Cambridge University Press. 
Shahidian, H. (1994). The Iranian left and the "woman question" in the revolution of 1978-79. International Journal of Middle East Studies, 26(2), 223-247.

Shahrokni, N. (2013). State and the Paradox of Gender Segregation in Iran (Doctoral dissertation, University of California, Berkeley).

Shahrokni, N. (2014). The Mothers' Paradise: Women-Only Parks and the Dynamics of State Power in the Islamic Republic of Iran. Journal of Middle East Women's Studies, 10(3), 87-108.

Shirazi, Faegheh (2001), The Veil Unveiled: Hijab in Modern Culture, Gainesville, University Press of Florida.

Skew, A., Evans, A., \& Gray, E. (2009). Repartnering in the United Kingdom and Australia. Journal of Comparative Family Studies, 563-585.

Skopek, J., Schulz, F., \& Blossfeld, H. P. (2010). Who contacts whom? Educational homophily in online mate selection. European Sociological Review, 27(2), 180-195.

Smock, P. J., Manning, W. D., \& Porter, M. (2005). "Everything's there except money": How money shapes decisions to marry among cohabitors. Journal of Marriage and Family, 67(3), 680-696.

Spivak, G. C. (1999). A critique of postcolonial reason. Harvard university press.

Sreberny, A., \& Khiabany, G. (2010). Blogistan: The internet and politics in Iran (Vol. 18). IB Tauris.

Stempel, J. D. (1981). Inside the Iranian revolution. Bloomington: Indiana University Press.

Susan, L. B., \& Booth, A (1996). Cohabitation versus Marriage: A Comparison of Relationship, Journal of Marriage and the Family, 58:668-78.

Tabnak (2016), The Shadow Of White Marriage On Consulting Services (Sayeh Ezdevaj Sefid Bar Khadamat Moshavereh), Retrieved from:

http://www.tabnak.ir/fa/news/632545/\%D8\%B3\%D8\%A7\%DB\%8C\%D9\%87-

$\% \mathrm{D} 8 \% \mathrm{~A} 7 \% \mathrm{D} 8 \% \mathrm{~B} 2 \% \mathrm{D} 8 \% \mathrm{AF} \% \mathrm{D} \% \% 88 \% \mathrm{D} 8 \% \mathrm{~A} 7 \% \mathrm{D} 8 \% \mathrm{AC}-$

$\% \mathrm{D} 8 \% \mathrm{~B} 3 \% \mathrm{D} 9 \% 81 \% \mathrm{DB} \% 8 \mathrm{C} \% \mathrm{D} 8 \% \mathrm{AF}-\% \mathrm{D} 8 \% \mathrm{~A} 8 \% \mathrm{D} 8 \% \mathrm{~B} 1-$

$\% \mathrm{D} 8 \% \mathrm{AE} \% \mathrm{D} 8 \% \mathrm{AF} \% \mathrm{D} \% \% 85 \% \mathrm{D} 8 \% \mathrm{~A} 7 \% \mathrm{D} 8 \% \mathrm{AA}-$

$\% \mathrm{D} 9 \% 85 \% \mathrm{D} 8 \% \mathrm{~B} 4 \% \mathrm{D} 8 \% \mathrm{~A} 7 \% \mathrm{D} 9 \% 88 \% \mathrm{D} 8 \% \mathrm{~B} 1 \% \mathrm{D} 9 \% 87 \% \mathrm{E} 2 \% 80 \% 8 \mathrm{C} \% \mathrm{D} 8 \% \mathrm{~A} 7 \% \mathrm{DB}$ $\% 8 \mathrm{C}$

Taheri, A. (1985). The spirit of Allah: Khomeini and the Islamic revolution . London: Hutchinson. 
Tanturri, M. L., \& Mencarini, L. (2008). Childless or childfree? Paths to voluntary childlessness in Italy. Population and development review, 34(1), 51-77.

Thornton, A., \& Philipov, D. (2009). Sweeping changes in marriage, cohabitation and childbearing in Central and Eastern Europe: New insights from the developmental idealism framework. European Journal of Population/Revue européenne de Démographie, 25(2), 123-156.

Torfeh, M., \& Sreberny, A. (2010). The BBC Persian service and the Islamic revolution of 1979. Middle East Journal of Culture and Communication, 3(2), 216-241.

Torre, A. (2018). Micro/Macro: Local/Global? The Problem of the Locality in a Specialized History. Historia Crítica, 69, 37-67.

Toulemon, L. (1996). Very few couples remain voluntarily childless. Population An English Selection, 1-27.

Trading economics, (2018): Retrieved from:

https://tradingeconomics.com/iran/urban-population-percent-of-total-wb-data.html

Ustek-Spilda, F. U., \& Alyanak, O. (2016). The Case of Children Born out of Wedlock in Turkey: an" Empty" Category?. AG About Gender-Rivista internazionale di studi di genere, 5(10).

Vahidnia, F. (2007). Case study: fertility decline in Iran. Population and environment, 28(4-5), 259-266.

Village, A., Williams, E. and Francis, L. J. (2010) 'Living in Sin? Religion and Cohabitation. in Britain 1985-2005', Marriage \& Family Review, 46(6), 468 - 479.

Waite, J.L. \& lee, A. (1991) Children and Marital Disruption, Lillard The American Journal of Sociology, 96(4), 930-953.

Wagner, P. (2002). A sociology of modernity: Liberty and discipline. Routledge.

Walby, S. (2009). Globalization and inequalities: Complexity and contested modernities. Sage.

Wall, K., Aboim, S., Cunha, V., \& Vasconcelos, P. (2001). Families and informal support networks in Portugal: the reproduction of inequality. Journal of European Social Policy, 11(3), 213-233.

Walton-Roberts, M., \& Pratt, G. (2005). Mobile modernities: a South Asian family negotiates immigration, gender and class in Canada. Gender, Place \& Culture, 12(2), 173-195. 
Welch, M., Fenwick, M., \& Roberts, M. (1997). Primary definitions of crime and moral panic: A content analysis of experts' quotes in feature newspaper articles on crime. Journal of Research in Crime and Delinquency, 34(4), 474-494.

Wexman, V. W., \& Wexman, V. W. (1993). Creating the couple: Love, marriage, and Hollywood performance. Princeton University Press.

Wikipedia (2017), Yjcnews, Retrieved from:

https://fa.wikipedia.org/wiki/\%D8\%A8\%D8\%A7\%D8\%B4\%DA\%AF\%D8\%A7\%D9\%8

7 \%D8\%AE\%D8\%A8\%D8\%B1\%D9\%86\%DA\%AF\%D8\%A7\%D8\%B1\%D8\%A7\%D9 \%86_\%D8\%AC\%D9\%88\%D8\%A7\%D9\%86

Wikipedia, (2017), The Islamic Republic News Agency, Retrieved from:

https://en.wikipedia.org/wiki/Islamic_Republic_News_Agency

Wikipedia, (2017), Deutsche_Welle, Retrieved from:

https://en.wikipedia.org/wiki/Deutsche_Welle

Wikipedia, (2017), Islamic_Republic_of_Iran_Broadcasting, Retrieved from:

https://en.wikipedia.org/wiki/Islamic_Republic_of Iran_Broadcasting

Wikipedia, (2017), Radio Farda, Retrieved from:

https://en.wikipedia.org/wiki/Radio_Farda

Wimmer, A. (2007). How (not) to think about ethnicity in immigrant societies: A boundary making perspective (Working Paper No. 44). Oxford, UK: ESRC Centre on Migration, Policy and Society, University of Oxford.

World Bank (2015), Retrieved from:

https://data.worldbank.org/indicator/SP.DYN.TFRT.IN?locations=IR

Wu, Z., \& Balakrishnan, T. R. (1992). Attitudes towards cohabitation and marriage in Canada. Journal of Comparative Family Studies, 1-12.

Xie,Y., Raymo, M, Goyette, A. (2003) Economic Potential and Entry into Marriage and Cohabitation, Demography, 40(2) 351-367.

Xu, X., Hudspeth, C. D., \& Bartkowski, J. P. (2006). The role of cohabitation in remarriage. Journal of Marriage and Family, 68(2), 261-274.

Yeganeh, N. (1984). Women Movement in Iran, The other half, 2(3) 7-28. 
Yjcnews, (2014), Renaming illegitimate relationships to white marriage, retrieved from:

https://www.yjc.ir/fa/news/4977710/\%D8\%AA\%D8\%BA\%DB\%8C\%DB\%8C\%D8\%B1 \%D9\%86\%D8\%A7\%D9\%85-\%D8\%B1\%D8\%A7\%D8\%A8\%D8\%B7\%D9\%87\%D9\%86\%D8\%A7\%D9\%85\%D8\%B4\%D8\%B1\%D9\%88\%D8\%B9\%D8\%A8\%D9\%87-\%D8\%A7\%D8\%B2\%D8\%AF\%D9\%88\%D8\%A7\%D8\%AC\%D8\%B3\%D9\%81\%DB\%8C\%D8\%AF

Yjcnews, (2015), What is white marriage, Retrieved from:

https://www.yjc.ir/fa/news/4993668/\%D8\%A7\%D8\%B2\%D8\%AF\%D9\%88\%D8\%A7\% D8\%AC-\%D8\%B3\%D9\%81\%D9\%8A\%D8\%AF\%DA\%86\%D9\%8A\%D8\%B3\%D8\%AA

Yjcnews, (2016), White marriage that is blacker than black, Retrieved from:

https://www.yjc.ir/fa/news/5910542/\%D8\%A7\%D8\%B2\%D8\%AF\%D9\%88\%D8\%A7\% D8\%AC-\%D8\%B3\%D9\%81\%DB\%8C\%D8\%AF\%DB\%8C-\%DA\%A9\%D9\%87\%D9\%BE\%D8\%B1\%D8\%B1\%D9\%86\%DA\%AF\%E2\%80\%8C\%D8\%AA\%D8\%B1$\% \mathrm{D} 8 \% \mathrm{~A} 7 \% \mathrm{D} 8 \% \mathrm{~B} 2-\% \mathrm{D} 8 \% \mathrm{~B} 3 \% \mathrm{DB} \% 8 \mathrm{C} \% \mathrm{D} 8 \% \mathrm{~A} 7 \% \mathrm{D} 9 \% 87 \% \mathrm{DB} \% 8 \mathrm{C}-$ $\% \mathrm{D} 8 \% \mathrm{~A} 7 \% \mathrm{D} 8 \% \mathrm{~B} 3 \% \mathrm{D} 8 \% \mathrm{AA}$

Yu, J., \& Xie, Y. (2015). Cohabitation in China: Trends and determinants. Population and development review, 41(4), 607-628.

Ze'Evi, D. (2006). Producing desire: changing sexual discourse in the Ottoman Middle East, 1500-1900 (Vol. 52). University of California Press. 